\author{
$B|B|$ IOTECA \\ INSTITUTOO DE QUIMICA \\ Universidade de Sāo Paulo \\ Lio 4 i 4 \\ UNIVERSIDADE DE SÃO PAULO \\ INSTITUTO DE QUÍMICA
}

\title{
A INFLUÊNCIA DO EFEITO MATRIZ NA DETERMINAÇÃO DOS PESTICIDAS ORGANOCLORADOS E ORGANOFOSFORADOS EM AMOSTRAS DE MANGA
}

\author{
ELIANE VIEIRA
}

Dissertação de Mestrado

Orientador: Prof. Doutor Jaim Lichtig

SÃO PAULO

2003 


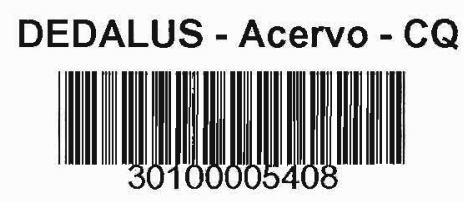

Ficha Catalográfica

Elaborada pela Divisão de Biblioteca e

Documentação do Conjunto das Químicas da USP.

\section{Vieira, Eliane}

V658i A influência do efeito matriz na determinação dos pesticidas organoclorados e organofosforados em amostras de manga : Eliane Vieira. -- São Paulo, 2003.

$102 p$.

Dissertação (mestrado) - Instituto de Química da Universidade de São Paulo. Departamento de Química Fundamental.

Orientador: Lichtig, Jaim

1. Cromatografia a gás: Química analítica I. T. Il. Lichtig, Jaim, orientador. 


\section{"A Influência do Efeito Matriz na Determinação dos Pesticidas \\ Organoclorados e Organofosforados em Amostras de Manga"}

\section{ELIANE VIEIRA}

Dissertação de Mestrado submetida ao Instituto de Química da Universidade de São Paulo como parte dos requisitos necessários à obtenção do grau de Mestre em Química - Área: Química Analítica.

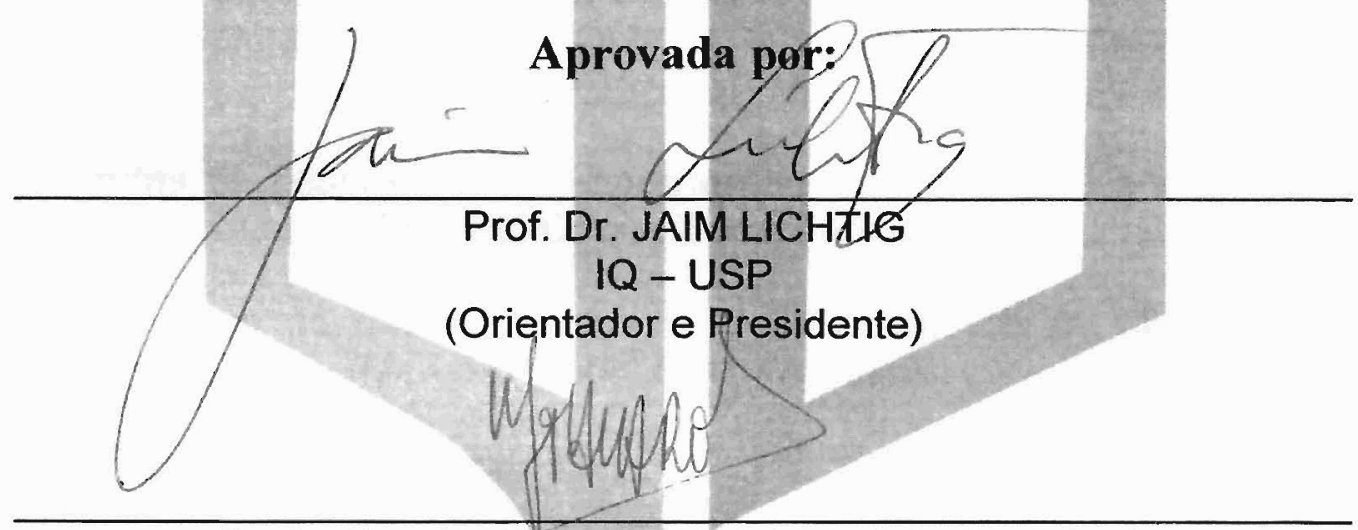

Profa. Dra. MARINA FRANCO MAGGI TAVARES

$I Q-U S P$

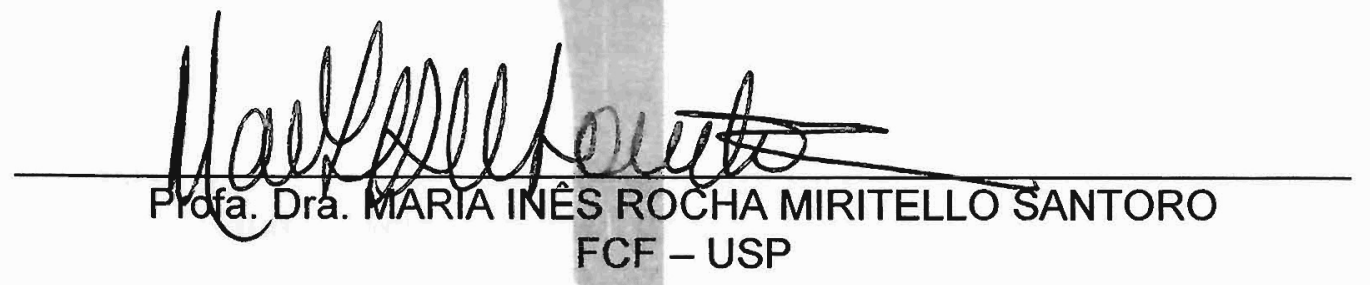

SÃO PAULO

11 DE MARÇO 2003. 


\section{AGRADECIMENTOS}

- A Deus, meu porto seguro.

- A meu anjo da guarda aqui na terra Odete N. K. Inomata, minha primeira orientadora, minha "mãe" de laboratório, minha amiga, o meu muito obrigada por tudo.

- Ao meu orientador Jaim Lichtig pelo apoio e incentivo.

- A meu grande amigo e também orientador Koichi Mizuta.

- Ao Instituto Adolfo Lutz e a chefe do Laboratório de Aditivos e Pesticidas Residuais Heloisa $H$. B. de Toledo que me possibilitaram iniciar meu interesse pela pesquisa a sete anos atrás e me tornaram possivel a conclusão desta dissertação hoje. O Instituto Adolfo Lutz foi minha grande e melhor faculdade.

- Aos pesquisadores do Instituto Adolfo Lutz: Teresa Atsuko Kussumi, Maria Anita Scorsafava, Vera Regina Rossi Lemos, Sonia Otero B. Rocha, Reinaldo Amauri Ribeiro e Nelson Aranha Dias.

- A minhas colegas de trabalho no Laboratório de Resíduos de Pesticidas: Elaine Cristina Loiola Damasceno e Luciana Maria Sbrana pela ajuda e amizade.

- As todas as pessoas que compraram as mangas para análise: Antônia, Cristiane, Cristina, Edilene, Odete, Sara, Tânia e Thays.

- Aos colegas do Laboratório na USP : Carlos, César, Chico, Cristiane, Gilberto, Luciana, Marcelo, Paulo César e Ulisses.

- Ao professor Jorge Masini

- A professora Lílian e suas alunas Andréia e Larisse que muito me auxiliaram no início desta tese quando precisei utilizar o HPLC.

- Aos funcionários e professores da Química Analítica da USP.

- Aquelas que secaram todas as minhas lágrimas e não me deixaram desistir: Claudia Motta Santos, Isabel Cristina da Silva e Sara Lucia de Freitas Osório, obrigada pela amizade.

- A minhas irmãs pelo apoio e estimulo: Edilene, Cristiane, Thays

- A minha irmãzinha Aline por ter lido toda tese pacientemente e me ajudado nos acertos finais 
A meus pais...

Álvaro e Maria Lúcia

Muito obrigada por todos os anos de luta, pelo amor e por acreditarem em mim... 
A minha avó

Maria José Ribeiro

(em memória) 
A alma é imortal, a bondade de Deus a destinou a felicidade.

Tomás Mozus

BIBLIOTECA InSTITUTO DE OUIMICA

Unversidase de Sá Paulo

"Um amigo fiel é uma poderosa proteção, quem o achou, descobriu um tesouro."

Eclo 6, 14 


\section{SUMÁRIO}

Resumo

Abstract

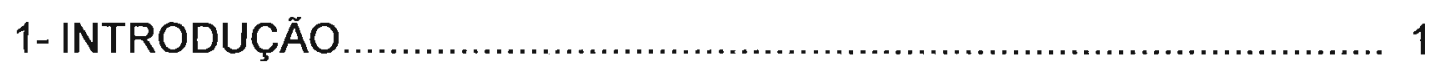

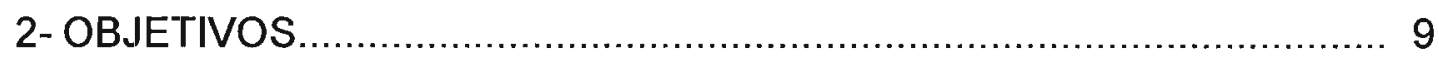

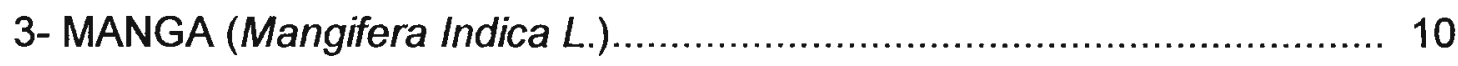

4- LEGISLAÇÃO DE DEFENSIVOS AGRÍCOLAS NO BRASIL................ 16

4.1 Definição de Agrotóxico.................................................... 16

4.2 Resíduo Estranho.......................................................... 17

4.3 Limite máximo de resíduo (LMR) ................................... 17

4.4 IDA (ingestão diária aceitável) ou Dose diária aceitável............. 17

4.5 Intervalo de segurança ou período de carência......................... 17

4.6 Boa prática agrícola no uso de agrotóxicos........................... 18

4.7 Classificação Toxicológica............................................... 18

4.8 Registro de Defensivos Agrícolas no Brasil........................... 21

5. PESTICIDAS ORGANOCLORADOS, PIRETRÓIDES E OUTROS........ 23

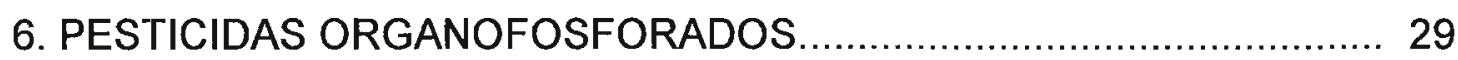

7. VALIDAÇÃO DE METODOLOGIA EMPREGADA NA ANÁLISE DE 33 RESÍDUOS DE PESTICIDAS

7.1 Linearidade ................................................................. 33

7.2 Especificidade............................................................. 34

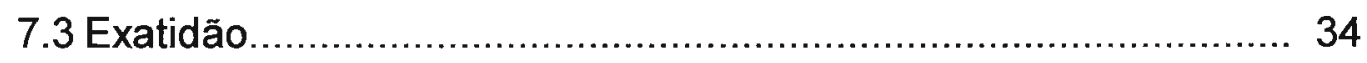

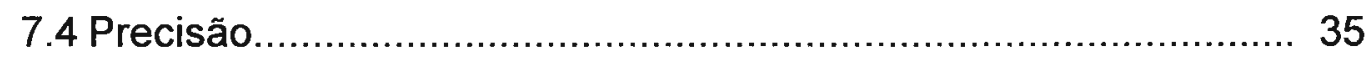

7.5 Limite de Detecção........................................................ 35

7.6 Limite de Quantificação.................................................... 36 
8. MÉTODO ANALÍTICO PARA DETERMINAÇÃO MULTIRESÍDUOS DE PESTICIDAS ORGANOCLORADOS E ORGANOFOSFORADOS EM MANGA

8.1 Considerações Gerais........................................................... 37

8.2 PARTE EXPERIMENTAL_................................................. 41

8.2.1 Aparelhos/Equipamentos.................................................... 41

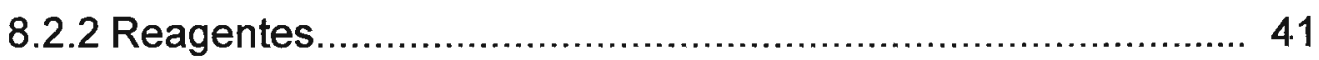

8.2.3 Padrão Analítico................................................................ 41

8.2.4 Vidrarias e outros Materiais............................................. 42

8.2.5 Preparação das soluções padrão para construção das curvas analíticas............................................................. 43

8.2.6 Parâmetros cromatográficos .............................................. 43

8.2.7 Procedimento Analítico......................................................... 45

8.3 Confirmação dos resultados..................................................... 45

8.4 Limpeza da vidraria........................................................ 45

8.5 Fluxograma: análise multiresíduos de pesticidas em amostras de

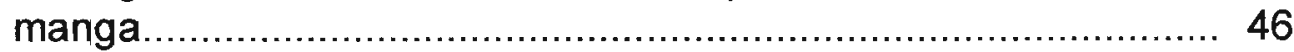

9.EFEITO MATRIZ

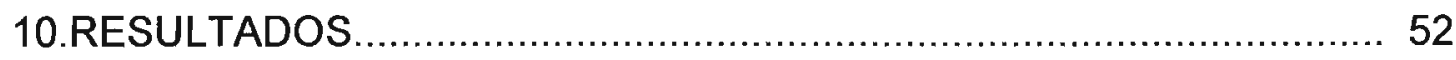

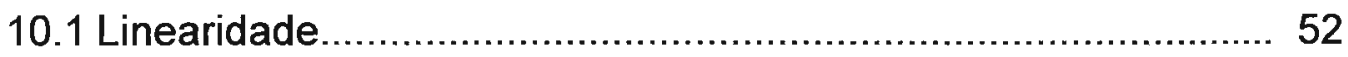

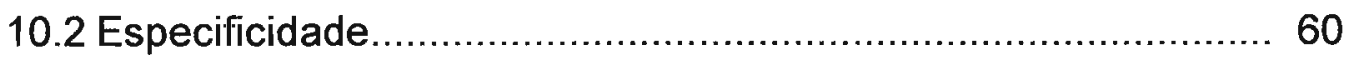

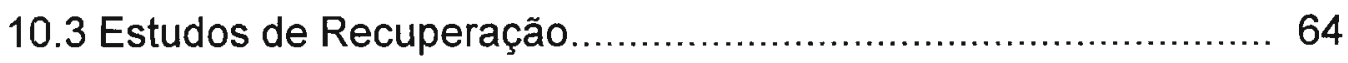

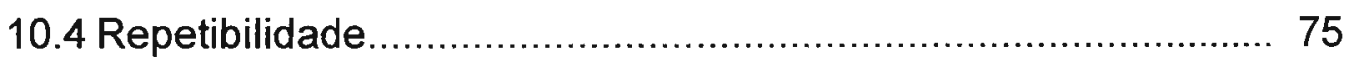

10.5 Limite de Deteç̧ão e Limite de Quantificação 88

10.6 Resultados das amostras de manga compradas no varejo de 90 São Paulo

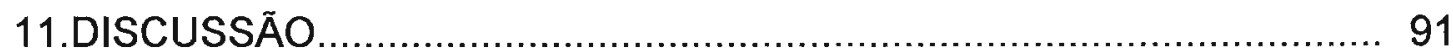

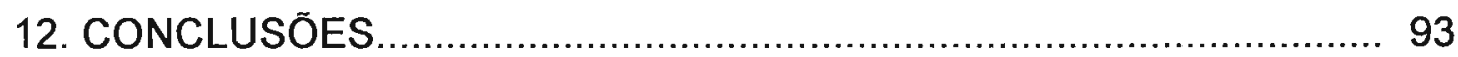

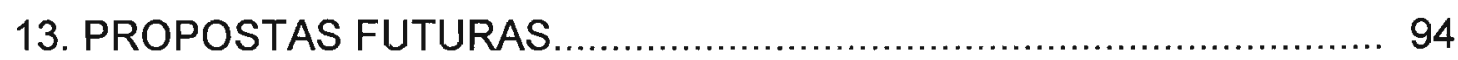

14. REFERÊNCIAS BIBLIOGRÁFICAS.................................................. 95 


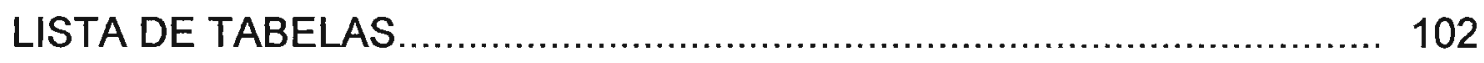

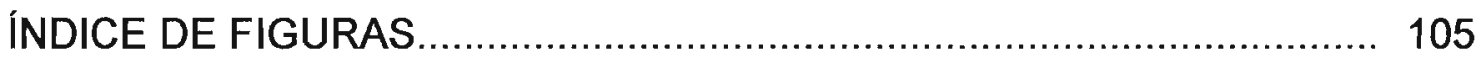

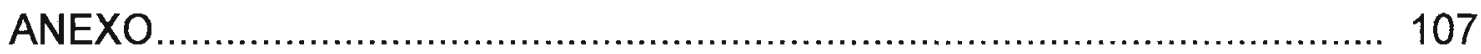

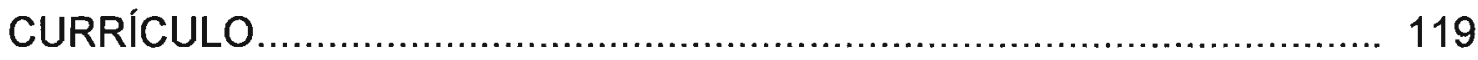




\section{RESUMO}

Devido à importância da agricultura para a econômia do Brasil e para a dieta da população brasileira, um esforço contínuo tem sido feito para preservar a qualidade dos alimentos. Um dos mais importantes critérios de qualidade é a concentração correta dos pesticidas ou a não detecção destes nos alimentos.

O objetivo deste trabalho é estudar o efeito matriz na analise de resíduos de pesticidas por cromatografia à gás em manga, a contaminação de mangas compradas na cidade de São Paulo por pesticidas e a otimização de um método multiresíduo neste tipo de matriz .

O método empregado foi o utilizado pelo Governo Holandês adaptado de Lucke (1975), e constou da extração com acetona e partição em uma mistura diclorometano:hexano 1:1 . O extrato foi concentrado e injetado em cromatógrafo à gás com detector de captura de elétrons e detector fotométrico de chama.

Foram analisados 23 princípios ativos diferentes entre herbicidas, inseticidas, fungicidas e acaricidas; a metodologia empregada permitiu um limite de quantificação que variou de $0,01 \mathrm{mg} / \mathrm{Kg}$ a $0,30 \mathrm{mg} / \mathrm{Kg}$. A recuperação de amostras fortificadas variou de 70 a $120 \%$.

Os resultados mostraram que a matriz apresenta uma grande influência na determinação dos princípios ativos Procloraz, Difenoconazol, Fosmete, Azoxistrobina e sulfato Endosulfam; o único princípio ativo encontrado nas amostras compradas no varejo foi o fungicida Procloraz com valores permitidos pela Legislação Brasileira.

Palavras Chave: Efeito Matriz, Pesticidas, Frutas 


\section{ABSTRACT}

Due to the importance of Agriculture for the economy of Brazil and for the diet of Brazilian population, a continuous effort is being made to preserve its high quality characteristics. One of the most important quality criteria is the right concentration or better not detectable pesticide residues.

This work had the objective to study the matrix enhancement effect in gas chromatographic analysis of pesticide residue in mango fruit; the contamination of mango fruit by pesticide bought in Sao Paulo city and the optimization of the multiresidue method in this matrix.

The employed method in the analysis was adapted from Lucke (1975), used by Netherlands Government; extraction with acetone and partition in a dichlorometane:hexane (1:1), and Gas Chromatographic determination with ECD and FPD.

We studied about 23 active substances among herbicides, fungicides, insecticides and acaricides, the developed method allowed a quantification limit ranging from $0,01 \mathrm{mg} / \mathrm{Kg}$ to $0,30 \mathrm{mg} / \mathrm{Kg}$. The recoveries of fortified samples ranged from 70 to $120 \%$.

The results showed that the matrix had a effect in the determination of the pesticides: prochoraz,difenoconazol, Fosmete, Azoxistrobina and Endosulfam Sulfate. It was found that the mango fruit were contaminated only by Procloraz; according to the Brazilian legislation, this pesticide can be present in mango.

Key words: Matrix effect, pesticides, fruits 


\section{1- INTRODUÇÃO}

Os pesticidas são aplicados ao redor do mundo nas mais variadas culturas e seu uso é inevitável para a produção de grandes safras para a alimentação da população. O cultivo de produtos agrícolas é de extrema importância para a economia brasileira, sendo que o Brasil encontra-se no nono lugar nas exportações destes produtos (Tabela 1). Entretanto os agroquímicos podem apresentar sérios riscos à saúde da população e controlar a qualidade e segurança dos alimentos consumidos na dieta é vital para o bem estar das pessoas.

As pestes destroem um terço de todo alimento cultivado ao redor do mundo, desde o crescimento até a armazenagem. Em países em desenvolvimento este número pode ser maior. Além disso, cinqüenta por cento da população mundial tem como meio de sobrevivência a agricultura e metade das pessoas ao redor do mundo não tem uma dieta adequada. Por todos estes motivos a FAO (Food and Agriculture Organization of the United Nations) reconhece que o uso de pesticidas é essencial na agricultura para que toda a população possa se alimentar adequadamente.

Em nosso País, a primeira fase de implantação do uso dos pesticidas, particularmente os inseticidas, é atribuída ao cultivo do algodão que, no Centro Sul, substituiu em parte a lavoura de café, após a crise de 1929 (Azevedo, 2001). O uso de produtos fitossaritários se intensificou em 1975, com a criação do PNDA (Plano Nacional de Defensivos Agrícolas) que financiou a compra de agrotóxicos pelos agricultores e levou a indústria a investir cerca de duzentos e cinqüenta milhões de dólares em 43 projetos de síntese de produtos técnicos e em unidades de formulações para cerca de 150 produtos. (Azevedo, 2001 ; Conceição, 2002 ). Em 2002, segundo dados do Sindicato Nacional da Indústria de Produtos para Defesa Agrícola, SINDAG, foram comercializados 714 formulações diferentes englobando os herbicidas, acaricidas, inseticidas, fungicidas entre outros. O Brasil é o $8^{\circ}$ consumidor mundial de pesticidas (Figura 1), ele consome $3,2 \mathrm{~kg}$ de pesticidas por hectare. 
O Brasil é um grande produtor de alimentos; aproximadamente $25 \%$ do seu PIB é gerado através das exportações de produtos agropecuários. A safra de 2000-2001 de grãos foi estimada em 94,3 milhões de toneladas. O setor de fruticultura é reconhecido como um dos segmentos mais importantes na alavancagem das exportações do país; as exportações de frutas frescas no ano de 1999 totalizaram 170 milhões de dólares. O nivel de rentabilidade de determinadas espécies frutíferas chega aos cinqüenta e sete mil dólares por hectare e a capacidade de ocupação de mão de obra registra até seis trabalhadores por hectare (Ministério da Agricultura e Abastecimento).

Tabela I - Principais paises exportadores de produtos agricolas

\begin{tabular}{l|c|c|c|c|c|c|c|c|c|c}
\hline \multicolumn{1}{c|}{ PAÍSES } & $\mathbf{1 9 9 1}$ & $\mathbf{1 9 9 2}$ & $\mathbf{1 9 9 3}$ & $\mathbf{1 9 9 4}$ & $\mathbf{1 9 9 5}$ & $\mathbf{1 9 9 6}$ & $\mathbf{1 9 9 7}$ & $\mathbf{1 9 9 8}$ & $\mathbf{1 9 9 9}$ & $\mathbf{2 0 0 0}$ \\
\hline $\mathbf{1}^{\circ}$ EUA & 44,6 & $\mathbf{4 8 , 2}$ & $\mathbf{4 7 , 8}$ & 52,3 & 62,3 & 66,3 & 62,5 & 57,4 & 52,7 & 56,5 \\
$\mathbf{2}^{\circ}$ FRANÇA & 32,8 & 36,3 & 33,3 & 34,9 & 40,7 & 40,4 & 38,5 & 38,3 & 36,8 & 33,1 \\
$\mathbf{3}^{\circ}$ HOLANDA & 30,9 & 33,8 & 29,4 & 35,1 & 36,9 & 37,3 & 32,1 & 30,2 & 34,4 & 27,8 \\
$\mathbf{4}^{\circ}$ ALEMANHA & 21,9 & 24,2 & 21,3 & 23,5 & 24,7 & 26,5 & 24,6 & 25,3 & 23,6 & 24,1 \\
$\mathbf{5}^{\circ}$ ITALIA & 12,0 & 13,0 & 11,9 & 13,3 & 14,6 & 16,9 & 15,7 & 16,1 & 15,9 & 15,6 \\
$\mathbf{6}^{\circ}$ CHINA & 11,6 & 12,0 & 12,2 & 14,6 & 14,4 & 14,3 & 13,4 & 16,9 & 15,5 & 17,1 \\
$\mathbf{7}^{\circ}$ R.UNIDO & 13,5 & 15,1 & 13,1 & 14,0 & 14,6 & 15,4 & 17,4 & 16,6 & 15,7 & 16,6 \\
$\mathbf{8}^{\circ}$ ESPANHA & 8,9 & $\mathbf{9 , 5}$ & 9,8 & 11,0 & 13,2 & 15,0 & 15,1 & 14,9 & 14,0 & 14,0 \\
\hline $9^{\circ}$ BRASIL & 8,0 & 9,1 & 9,7 & 12,6 & 13,4 & 14,3 & 16,0 & 15,2 & 13,8 & 12,8 \\
\hline
\end{tabular}

FONTE: FAO - Food and Agriculture Organization. (www.fao.org)

Atualizado em 21/03/2002.

www.agricultura.gov.br 


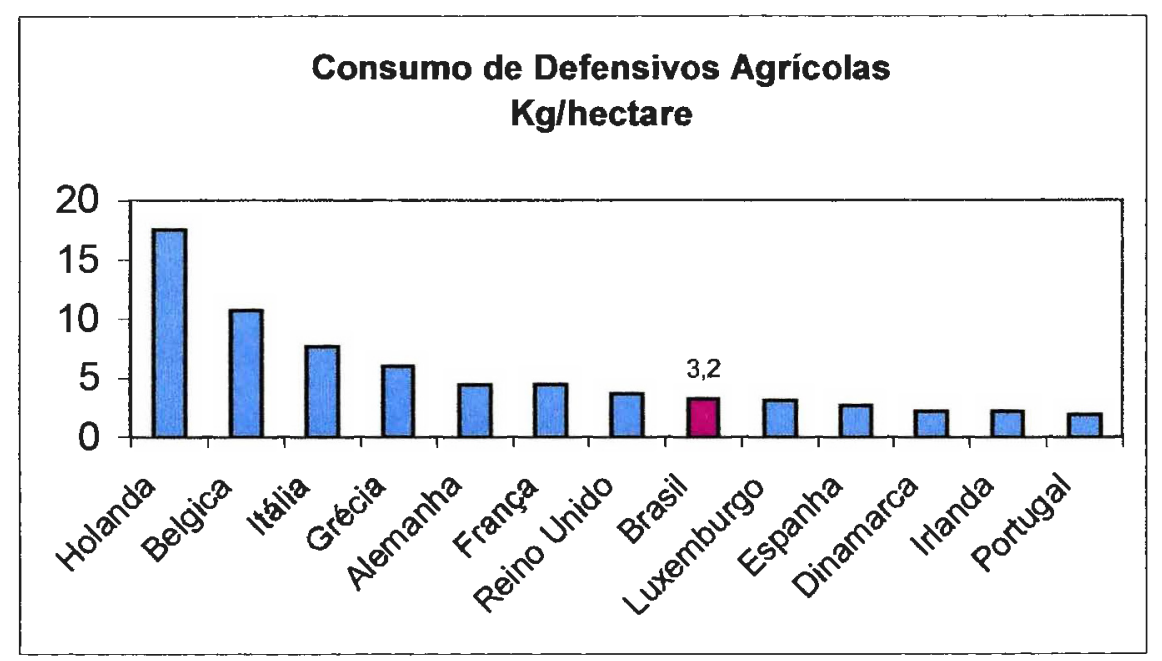

Figura 1 - Principais países Consumidores de Defensivos Agrícolas

O Brasil é um dos maiores produtores de frutas tradicionais tropicais: abacaxi, banana, manga, melão, papaia e uva (Amaral et al., 1999). O Brasil aparece como o maior produtor mundial de papaia em 1997, o terceiro maior de banana e o segundo de abacaxi. O Brasil produziu em 1997, 456 mil toneladas de manga e é o nono maior produtor desta fruta. Esta quantidade equivale a aproximadamente $2 \%$ da produção mundial. O Brasil exportou 20 milhões de dólares em 1997, ocupando o quarto lugar a nível mundial entre os exportadores. Além de ser um grande exportador de frutas tropicais, o Brasil possui um grande mercado consumidor de frutas e absorve a quase totalidade do que produz (Amaral et al., 1999).

Até 2003 o Brasil pretende comercializar para o mercado internacional um bilhão de dólares em frutas frescas. O Brasil, em 1998 teve um déficit de US\$ 113 milhões de dólares nas exportações de frutas e em 2000 saltou para um superávit de US\$55 milhões. A manga lidera o ranking das frutas que mais trazem lucros ao Brasil. Em 2001 esta fruta trouxe ao País US\$ 36 milhões através da venda de 94 mil toneladas. Em segundo lugar no ranking está a maçã, seguida pelo melão, papaia, laranja e uva (www.terrarural.com.br). 
A indústria de produtos fitossanitários vem investindo no Brasil, por ano, cerca de 25 milhões de dólares em pesquisa, desenvolvimento de produtos e suas aplicações, fornecendo diferentes formulações, disponibilizando cerca de 200 ingredientes ativos diferentes (Azevedo, 1999; Ciscato,2000).

Os pesticidas, quando usados corretamente, podem evitar que $40 \%$ das safras de diferentes culturas sejam perdidas (Richardson,1998) porém, o mal uso deles pode gerar sérios riscos para o meio ambiente e para a saúde dos seres vivos em geral. O crescente aumento da população mundial nos leva à necessidade de aumentarmos cada vez mais a quantidade de alimentos produzidos e o uso de produtos fitossanitários é inevitável.

É necessário controlarmos os resíduos que permanecem das aplicações nas mais diversas culturas. Os resíduos remanescentes nas culturas dependem de muitos fatores de variada importância como grau de adsorção nas camadas superficiais, degradação química ou metabolismo, desaparecimento aparente devido à diluição pelo crescimento da planta e volatilidade do depósito (Lemes et al., 1993).

Os pesticidas podem ser classificados de várias formas. Quanto à sua ação eles podem ser divididos em: fungicidas, herbicidas, inseticidas, acaricidas, nematicidas, etc. Quanto à função química eles podem ser divididos em organofosforados, organoclorados, piretróides, carbamatos, ditiocarbamatos, benzimidazóles e outros.

A classificação quanto à função química nos leva ao sistema de detecção utilizado: os pesticidas organofosforados são analisados por cromatografia a gás com detector fotométrico de chama (FPD) que analisa compostos de enxofre e fósforo ou o com o detector de nitrogênio fósforo (NPD) que analisa compostos de nitrogênio e fósforo. Os pesticidas organoclorados são geralmente analisados através da cromatografia a gás com detector de captura de elétrons (ECD); os carbamatos e benzimidazóles são analisados por 
cromatografia líquida com detecção UV ou fluorescência; os ditiocarbamatos podem ser analisados por espectofotometria ou cromatografia gasosa com detector fotométrico de chama no modo enxofre. Além destes sistemas de detecção ainda podemos utilizar o cromatógrafo a gás ou líquido com detecção de massa, com os quais podem ser determinados todos os pesticidas. Estas são as formas mais usuais da determinação dos pesticidas. No entanto, outros métodos analíticos estão sendo utilizados atualmente, como a eletroforese capilar (Wu et al., 2001).

Encontrar um único método com o qual se possa avaliar os pesticidas é uma tarefa praticamente impossível, devido às diferenças físico-químicas encontradas em cada princípio ativo. No entanto, existem classes de pesticidas que podem ser analisados conjuntamente. A extração pode ser igual para diferentes classes, porém a detecção nem sempre é a mesma, sendo necessário mais de uma técnica para determiná-los.

Os métodos podem ser multiresíduos ou métodos individuais; os métodos multiresíduos são os os preferidos na hora da escolha de um método, pois eles analisam vários pesticidas em uma única extração, porém nem todos os pesticidas podem ser analisados desta forma levando a necessidade de um método específico (Torres et al.,1996).

A literatura apresenta diversos métodos de determinação de pesticidas: Niessner e colaboradores (1996) estudaram a determinação de 23 principios ativos diferentes em diversas ervas através do uso de SPE (extração em fase sólida) para purificação da amostra e encontraram melhores resultados de recuperação com o uso de colunas preenchidas com poliestileno divinil benzeno. Soliman (2001), estudando a presença de pesticidas em amostras de batata crua e preparada na região do Cairo (Egito), observou a presença de pp'DDT, lindano, hexaclorobenzeno e malationa. Simplício e colaboradores (1999), analisando pesticidas organofosforados utilizando SPME (micro extração em fase sólida) em amostras de frutas e suco de frutas encontraram valores aceitáveis de recuperação para 6 dos 7 princípios ativos estudados. 
Oliveira e colaboradores (2001), estudando a degradação do tiabendazol e imazalil em laranja pêra, constataram que as amostras apresentam-se em condições de consumo. Costa e colaborador (2002), estudando os níveis de procloraz em maçãs observaram que os resíduos permanecem predominantemente na casca, e quando a fruta é analisada totalmente (polpa + casca) os resíduos remanescentes não ultrapassaram o limite máximo de resíduos permitidos.

Os pesticidas organoclorados foram os primeiros pesticidas orgânicos eficazes largamente utilizados ao redor do mundo. Os primeiros pesticidas organoclorados sintetizados, incluindo o DDT, aldrin, hexaclorobenzeno entre outros, hoje estão banidos devido à persistência destes e de seus metabólitos tanto no meio ambiente, como nos seres vivos em geral, incluindo-se aqui o ser humano. Atualmente são considerados contaminantes ambientais e não propriamente pesticidas. No Brasil está proibido o uso, tanto para agricultura, quanto para fins de campanha de saúde pública. Entretanto novos compostos foram criados que não persistem no ambiente como os anteriores e são largamente utilizados.

Os piretróides foram introduzidos no mercado nos últimos 50 anos para controlar seres nocivos em produtos armazenados e como protetores de grãos. O piretro e as piretrinas são extraídos das flores do crisânteno e são usados como inseticidas há centenas de anos. O termo piretro refere-se à planta, à flor ou ao extrato concentrado cru ou refinado e o termo piretroide é reservado ao ingrediente ativo. Os piretros são eficientes para matar uma série de insetos. O único inconveniente dos piretros é serem instáveis sob a ação da luz, sendo que esta propriedade restringiu seu uso na agricultura. Em 1953 o primeiro piretróide sintético foi sintetisado: a aletrina, este ingrediente ativo mostrou-se eficiente contra moscas, porém ainda é fotodegradável. Em 1976 o primeiro piretróide sintético estável à luz foi criado: o fenvalerato . Depois disso a permetrina, cipermetrina, e deltametrina foram comercializados com sucesso. Uma segunda geração de piretróides foi criada a partir de 1980, 
porém estes apresentam-se mais tóxicos para os peixes: ciflutrina, flumetralina, fenpropatrina, bifentrina e fluvalinato. Os piretróides são largamente utilizados, pois são muito ativos em pequenas quantidades (10 gramas de ingrediente ativo por hectare). Apresentam excelente eficácia, baixa toxicidade para os aplicadorese baixo impacto ambiental (Chen et al., 1996).

Os inseticidas organofosforados são, provavelmente, a maior classe de substâncias usadas como inseticidas nos dias de hoje, sendo derivados do ácido fosfórico e tiofosfórico. Existem mais ou menos cem componentes usados em todo o mundo. Eles são usados para a agricultura e hoje substituem os organoclorados em campanhas de Saúde Pública (Conceição, 2002). Apresentam algumas desvantagens em relação a outras classes de pesticidas incluindo a alta toxicidade para muitos organismos, porém, não persistem no meio ambiente como os organoclorados e geralmente se decompõem em produtos não tóxicos. A elevada toxicidade pode afetar a vida animal incluindo a do próprio homem (Barceló et al.,1992).

Os carbamatos possuem baixa persistência no ambiente e baixa toxicidade para os mamíferos. A introdução do uso se deu no final da década de 50 . São utilizados como inseticidas de contato em culturas agrícolas (Hassal,1993; Nunes, 1999). Os carbamatos são derivados do ácido carbâmico. A síntese e comercialização destes compostos acentuou-se na segunda metade do século com a busca de substituintes dos pesticidas organoclorados. Em 1957 o carbaril, o primeiro carbamato a ser sintetizado, mostrou-se como um produto de grande atividade inseticida de amplo espectro de ação e relativamente estável. Outros compostos foram e estão sendo sintetizados (Nunes, 1999).

Os pesticidas são também classificados quanto à ação contra os seres nocivos. Os acaricidas são utilizados para matar os ácaros. Este tipo de praga pode gerar grandes perdas para a agricultura. Os ácaros são diferentes dos insetos e por isso nem sempre os inseticidas são eficientes para elimina-los. Um grande número de acaricidas não tem efeitos sobre os insetos. Alguns 
pesticidas organofosforados e carbamatos têm ação contra os insetos e contra os ácaros. Os organoclorados, por outro lado, quando são utilizados como acaricidas não tem ação contra os insetos e vice-versa. O uso de inseticidas pode causar um grande aumento na infecção por ácaros, pois estas substâncias eliminam muitos predadores naturais destes parasitas. (Matolcsy et al., 1988).

Os fungicidas são substâncias químicas ou biológicas que atacam os fungos sem atacar as culturas. Protegem as plantas contra a evasão de patógenos ou são usados para erradicar infecções já estabelecidas. O início da aplicação de fungicidas em grande escala para o controle de doenças se deu com a descoberta da calda bolonhesa (mistura de sulfato de cobre e cal hidratada) em 1882. Por mais de 50 anos foi um dos fungicidas mais utilizados (Azevedo,2001). De acordo com a FAO (Food and Agricultural Organization) os fungicidas são insumos importantes para a produção mundial de alimentos. Os fungicidas além de terem função na manutenção do potencial produtivo das culturas, contribuem também para a manutenção da germinação e vigor das sementes, e no pronlogamento da vida útil dos frutos na pós-colheita (Azevedo, 2001).

Os herbicidas são utilizados para controlar as ervas daninhas. As ervas daninhas competem com a cultura por nutrientes, água, luz e espaço e por isso são prejudiciais. Os herbicidas são diferentes na maneira de agir, podendo ser seletivos e não seletivos. Os seletivos atacam espécies específicas de plantas enquanto os não seletivos atacam qualquer planta. Os herbicidas são os pesticidas mais utilizados ao redor do mundo, sendo que o primeiro mais utilizado é o glifosato e o segundo é o alacloro (Barceló e Hennion, 1997).

A Comunidade Econômica Européia e os Estados Unidos têm se mostrado cada vez mais exigentes quanto à qualidade de produtos comestíveis importados de outros países. É essencial que o Brasil melhore a qualidade de seus produtos para tornar-se competitivo no mercado externo, além de proteger e melhorar a saúde da sua população. 


\section{2- OBJETIVOS}

O objetivo fundamental do presente trabalho é otimizar uma metodologia multiresíduo para análise de manga. Como objetivos específicos pretende-se:

a) otimizar uma metodologia que diminua a quantidade de solventes utilizados durante a análise, para assim diminuir os custos da análise e diminuir a geração de resíduos tóxicos;

b) verificar a existência do chamado "efeito matriz" na análise multiresíduo;

c) avaliar a qualidade das mangas consumidas na região da cidade de São Paulo. 


\section{3-MANGA ( Mangifera indica L.)}

A manga tem sua origem na Ásia. Foi introduzida pelos portugueses no Brasil, difundiu-se por todo o território, que é hoje um dos principais produtores mundiais. A mangueira adapta-se bem ao clima quente e úmido. Com estação seca marcante, prefere solos profundos e férteis, mas se desenvolve bem em quase todos os solos. É uma fruta que para o cultivo não exige muitos cuidados, adaptando-se melhor em regióes tropicais. A mangueira é uma planta perene, de grande porte e sistema radicular vigoroso, muito sensível a geadas e, de produção alternada. O período ideal para plantio é na estação chuvosa. A propagação é por sementes ou mudas enxertadas (Fonseca, 1998).

Pode-se favorecer a indução artificial da floração pulverizando-se a planta com etefom (pesticida utilizado para estimular o crescimento) ou nitratos (de potássio ou amônio). Um mês após o tratamento ocorre a floração antecipando assim a frutificação (Fonseca, 1998).

Atualmente uma das preocupações do governo Brasileiro é que toda a manga seja produzida através da produção integrada, que é uma proposta de agricultura sustentável sob os pontos de vista ecológico, social e econômico e permite a rastreabilidade do produto. No Nordeste várias empresas exportadoras já aderiram ao programa devido às exigências internacionais.

A demanda mundial de manga tem aumentado significativamente. A manga talvez seja a fruta brasileira com maior potencial de crescimento de suas exportações a curto prazo (www.cati.sp.gov.br). O maior comprador de manga brasileira é a Holanda, para redistribuir pela Europa através do porto de Roterdã (mww.coresesaborestropicais.com.br).

O Nordeste é responsável por $44,7 \%$ da produção nacional, sendo o maior exportador de manga. No Estado de São Paulo, a manga teve uma expansão na década de 90 de aproximadamente $50 \%$ da área cultivada e do número de produtores rurais envolvidos. Em 1989, as mangueiras ocupavam 16.514 
hectares, em 2002 já ocupavam 25.617 hectares distribuidos em 7.007 propriedades rurais. A maior parte da produção destina-se ao consumo do próprio Estado de São Paulo (www.cati.sp.gov.br).

A manga e a mangueira estão sujeitas ao ataque das mais variadas pragas e doenças e, devido a isso, o controle químico através de pesticidas ainda é a melhor forma para se evitar danos econômicos. As Tabelas II e III contém informações retiradas do Agrofit (Sistema interativo de informações sobre agrotóxicos, identificação de pragas, doenças e plantas infestantes com ocorrência no Brasil, fornecida pelo Ministério da Agricultura) citando as principais pragas e doenças da planta e dos frutos. 


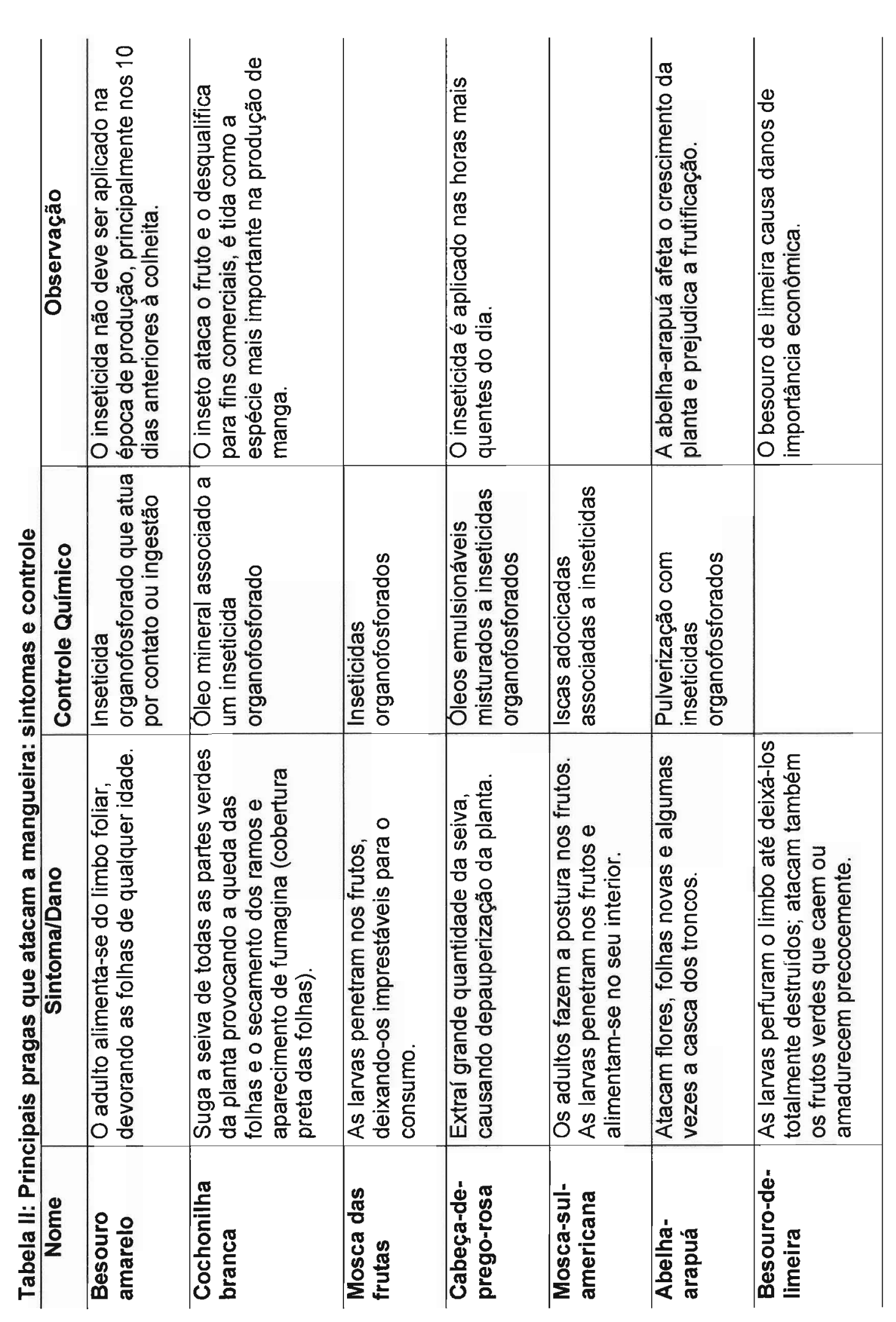




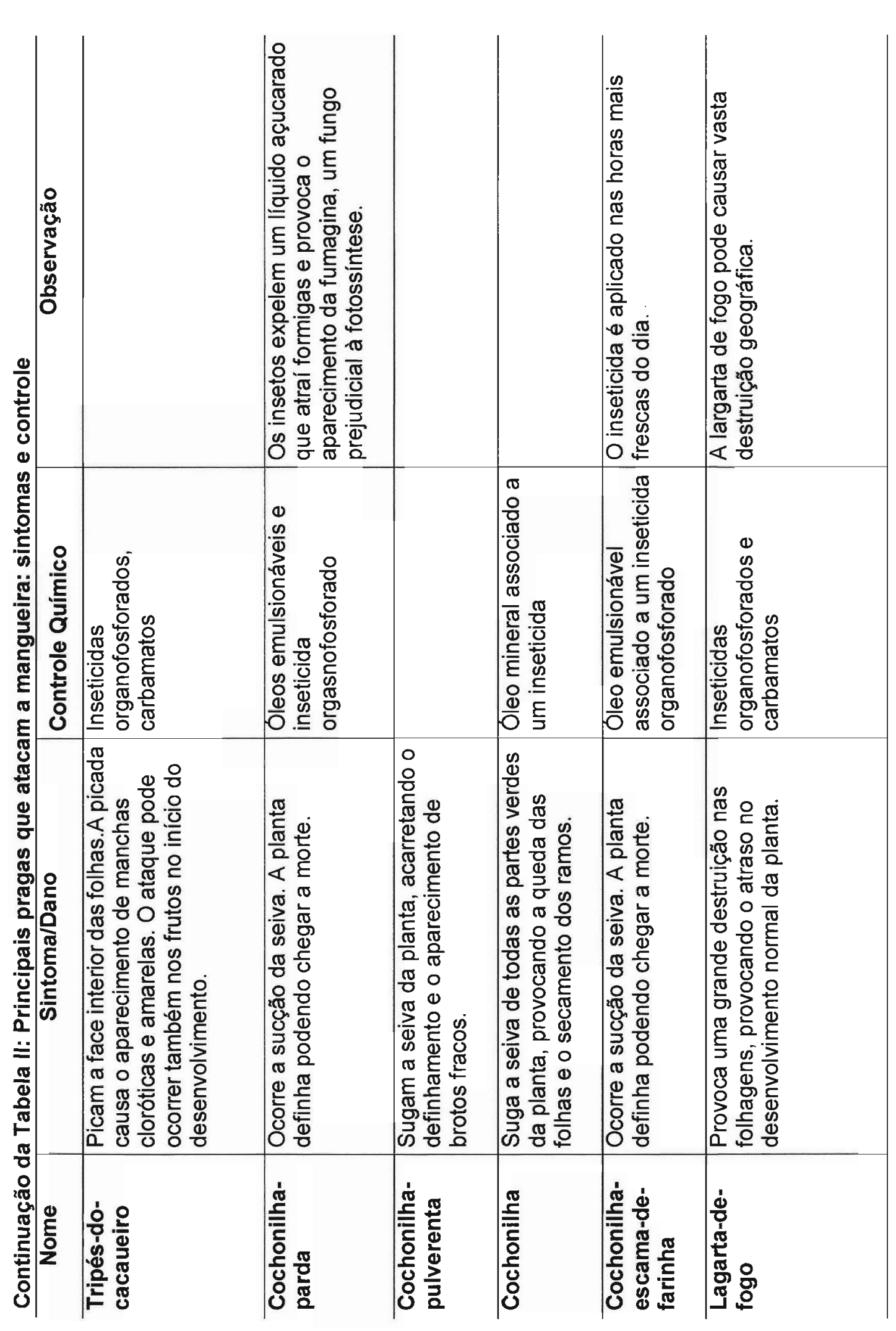




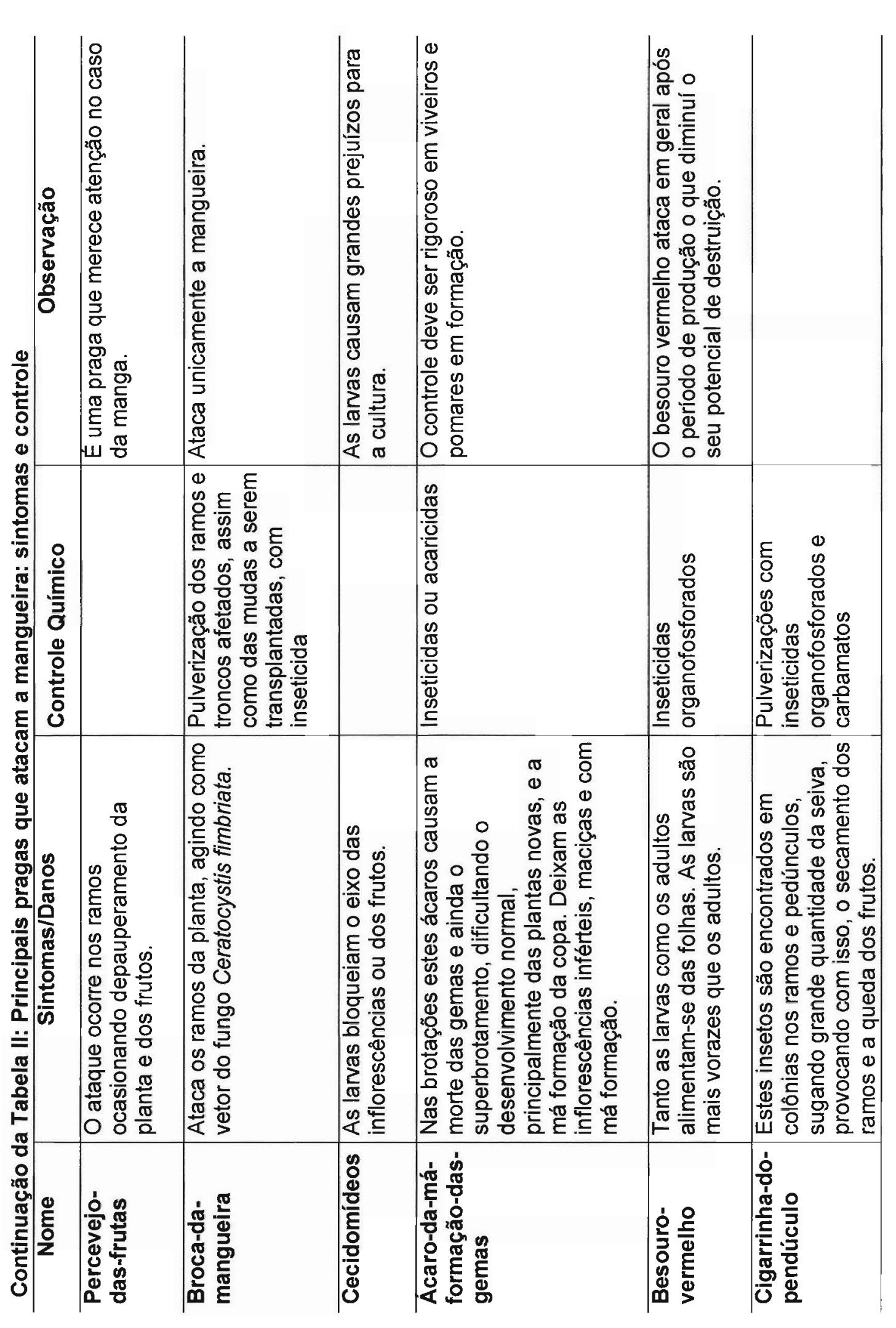

B I BLI O TECA INSTITUTO DE QUIMICA 


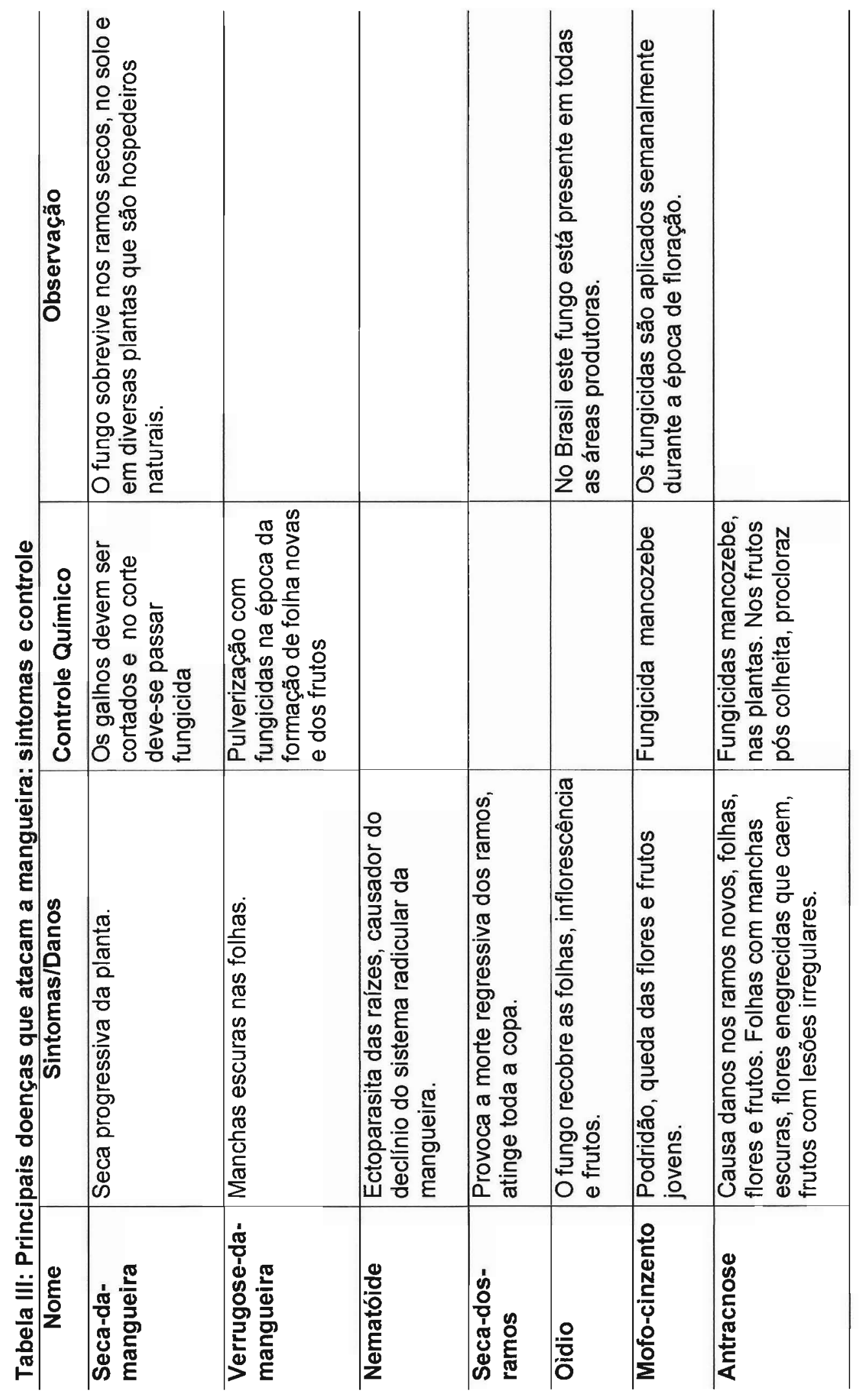




\section{4-LEGISLAÇÃO DE DEFENSIVOS AGRÍCOLAS NO BRASIL}

Através da Lei 7.802 de 11 de julho de 1989 e da Portaria $n^{\circ} 03$ de 16 de janeiro de 1992, tem-se as diretrizes para a utilização de pesticidas no Brasil. Os Ministérios da Saúde, Agricultura e o IBAMA, cada um na sua área de atuação ficam como os responsáveis pela autorização ou não da utilização dos pesticidas no Brasil. Compete aos Estados e ao Distrito Federal, legislar bem como fiscalizar sobre o uso, a produção, o consumo, o comércio e o armazenamento dos agrotóxicos, seus componentes e afins.

A Legislação garante que o registro para novo produto agrotóxico será concedido se a sua ação tóxica sobre o ser humano e o meio ambiente for comprovadamente igual ou menor do que a daqueles já registrados para o mesmo fim. O Brasil proibiu o registro de agrotóxicos, que revelem características teratogênicas, carcinogênicas ou mutagênicas. (BRASIL Leis e Decretos Portaria $\mathrm{n}^{\circ} 3$ de 16 de janeiro de 1992)

Algumas definições retiradas desta Legislação são expostas abaixo.

\subsection{Definição de agrotóxico}

\section{São considerados agrotóxicos e afins:}

a) Os produtos e os agentes de processos físicos, químicos ou biológicos, destinados ao uso nos setores de produção, no armazenamento e beneficiamento de produtos agrícolas, nas pastagens, na proteção de florestas, nativas ou implantadas, e de outros ecossistemas e também de ambientes urbanos, hídricos e industriais, cuja finalidade seja alterar a composição da flora ou da fauna, a fim de preservá-las da ação danosa de seres vivos considerados nocivos;

b) Substâncias e produtos empregados como desfolhantes, dessecantes, estimuladores e inibidores de crescimento; 


\subsection{Resíduo Estranho}

Resíduo de agrotóxico e de seus produtos de transformação presentes nos alimentos mas não provenientes de sua aplicação direta. O resíduo estranho é freqüentemente devido à contaminação ambiental ou da cadeia alimentar.

\subsection{Limite máximo de resíduo (LMR)}

Quantidade máxima de resíduo de agrotóxico legalmente aceita no alimento, em decorrência da aplicação adequada numa fase específica, desde sua produção até o consumo, expressa em partes (em peso) do agrotóxico ou seus derivados por um milhão de partes de alimento (em peso) (ppm ou $\mathrm{mg} / \mathrm{kg}$ ). Os Limites Máximos de Residuos referem-se aos valores provenientes dos experimentos de campo, efetuados no Brasil, para cada cultura alimentar.

Até 1985 o Brasil adotava os Limites Máximos de Resíduos recomendados pelo CODEX. O governo brasileiro começou a partir desta data a exigir dados gerados no Brasil.

\subsection{IDA (ingestão diária aceitável) ou Dose diária aceitável}

A Portaria 3 nos diz que IDA é a quantidade máxima que, ingerida diariamente durante toda a vida, parece não oferecer risco apreciável à saúde, à luz dos conhecimentos atuais. É expressa em $\mathrm{mg}$ do agrotóxico por $\mathrm{kg}$ de peso corpóreo ( $\mathrm{mg} / \mathrm{kg}$ ). No Brasil utilizam-se dados do IBGE (Instituto Brasileiro de Geografia e Estatística) para verificação do consumo dos alimentos e assim estima-se a ingestão alimentar dos resíduos de pesticidas.

\subsection{Intervalo de segurança ou período de carência}

Intervalo de segurança ou período de carência vem a ser o intervalo de tempo entre a última aplicação do agrotóxico e a colheita ou comercialização. Para os 
casos de tratamento de pós-colheita será o intervalo de tempo entre a última aplicação e a comercialização.Para as pastagens, será o intervalo de tempo entre a última aplicação e a reentrada dos animais no pasto.

\subsection{Boa prática agrícola no uso de agrotóxicos}

Boa prática agrícola no uso de agrotóxicos vem a ser o emprego correto e eficaz de um agrotóxico, considerados os riscos toxicológicos envolvidos em sua aplicação, de modo que os resíduos sejam os menores possíveis e toxicologicamente aceitáveis.

\subsection{Classificação Toxicológica}

Classe I - Produtos Extremamente Tóxicos;

Classe II - Produtos Altamente Tóxicos;

Classe III - Produtos Medianamente Tóxicos;

Classe IV - Produtos Pouco Tóxicos.

A classificação toxicológica é dada para a formulação e para o principio ativo. Assim um mesmo princípio ativo pode ter diferentes classificações toxicológicas dependendo da formulação em que esteja, como podemos ver na Tabela IV referente ao herbicida alacloro. A classificação toxicológica do princípio ativo alacloro na ANVISA (Agência Nacional de Vigilância Sanitária) mostra que ele se encontra na classe III - medianamente tóxico. Na Tabela V estão apresentados os defensivos agrícolas comercializados no Brasil por classe toxicológica. 
Tabela IV: Formulações de Alacloro comercializadas no Brasil com classificação toxicológica e classificação ambiental

\begin{tabular}{|c|c|c|c|c|}
\hline $\begin{array}{c}\text { Marca } \\
\text { Comercial }\end{array}$ & $\begin{array}{c}\text { Ingrediente } \\
\text { Ativo }\end{array}$ & $\begin{array}{c}\text { Concentração } \\
\text { do i.a. }\end{array}$ & $\begin{array}{l}\text { Classificação } \\
\text { Toxicológica } \\
\end{array}$ & $\begin{array}{c}\text { Classificação } \\
\text { Ambiental }\end{array}$ \\
\hline Alaclor Nortox ${ }^{\circledR}$ & Alacloro & $480 \mathrm{~g} / \mathrm{L}$ & $\begin{array}{l}\text { altamente } \\
\text { tóxico }\end{array}$ & $\begin{array}{l}\text { muito } \\
\text { perigoso }\end{array}$ \\
\hline Alanex $480 \mathrm{CE}^{\circledR}$ & Alacloro & $480 \mathrm{~g} / \mathrm{L}$ & $\begin{array}{l}\text { medianamente } \\
\text { tóxico }\end{array}$ & $\begin{array}{l}\text { muito } \\
\text { perigoso }\end{array}$ \\
\hline Laço CE ${ }^{\circledR}$ & Alacloro & $480 \mathrm{~g} / \mathrm{L}$ & $\begin{array}{l}\text { extremamente } \\
\text { tóxico }\end{array}$ & perigoso \\
\hline Agimix ${ }^{\circledR}$ & $\begin{array}{l}\text { Alacloro + } \\
\text { atrazina }\end{array}$ & $260+260 \mathrm{~g} / \mathrm{L}$ & $\begin{array}{l}\text { altamente } \\
\text { tóxico }\end{array}$ & ** \\
\hline $\begin{array}{l}\text { Alaclor + } \\
\text { Atrazina SC } \\
\text { Nortox }^{\circledR}\end{array}$ & $\begin{array}{l}\text { Alacloro + } \\
\text { atrazina }\end{array}$ & $240+250 \mathrm{~g} / \mathrm{L}$ & $\begin{array}{l}\text { extremamente } \\
\text { tóxico }\end{array}$ & $\begin{array}{l}\text { muito } \\
\text { perigoso }\end{array}$ \\
\hline Alazine $500 \mathrm{SC}^{\circledR}$ & $\begin{array}{l}\text { Alacloro + } \\
\text { atrazina }\end{array}$ & $250+250 \mathrm{~g} / \mathrm{L}$ & $\begin{array}{l}\text { medianamente } \\
\text { tóxico }\end{array}$ & $\begin{array}{l}\text { muito } \\
\text { perigoso }\end{array}$ \\
\hline Boxer ${ }^{\circledR}$ & $\begin{array}{l}\text { Alacloro + } \\
\text { atrazina }\end{array}$ & $300+180 \mathrm{~g} / \mathrm{L}$ & $\begin{array}{l}\text { extremamente } \\
\text { tóxico }\end{array}$ & $\begin{array}{l}\text { muito } \\
\text { perigoso }\end{array}$ \\
\hline Lance $^{\circledR}$ & $\begin{array}{l}\text { Alacloro + } \\
\text { trifluralina }\end{array}$ & $400+300 \mathrm{~g} / \mathrm{L}$ & $\begin{array}{l}\text { extremamente } \\
\text { tóxico }\end{array}$ & ** \\
\hline
\end{tabular}

* i.a = ingrediente ativo

Fonte:Agrofit disponivel em URL : wwwministerioagricultura.gov.br pesquisa feita em dezembro de 2001

** Dados não fornecidos no Agrofit 


\begin{tabular}{|c|c|c|c|c|c|c|}
\hline \multirow{4}{*}{ 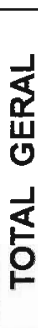 } & 今ิ & $\grave{ָ}$ & $\stackrel{\mathscr{S}}{\stackrel{2}{\sigma}}$ & $\frac{\Delta}{N}$ & $\stackrel{\mathscr{\infty}}{\mathscr{0}}$ & $\frac{N}{N}$ \\
\hline & ఫ్ & $\stackrel{m}{\leftarrow}$ & $\stackrel{\sim}{\sim}$ & $\Phi_{\sigma}^{\infty}$ & 哭 & శ్రి \\
\hline & $\hat{\partial}$ & : & $\stackrel{2}{\infty}$ & $\mathscr{\mathscr { C }}$ & 욤 & 莒 \\
\hline & 点 & 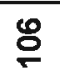 & 哭 & $\stackrel{\circ}{\circ}$ & $\stackrel{\oplus}{\rightleftharpoons}$ & గ్రై \\
\hline & $\widetilde{\widetilde{\jmath}}$ & $\nabla$ & 우 & $\sim$ & 的 & ก้ \\
\hline$\underset{x}{\mathscr{c}}$ & 犬্̀ิ & $\forall$ & 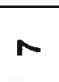 & $\omega$ & $\mathscr{N}$ & $\mathscr{q}$ \\
\hline క & פ & + & in & $\nabla$ & $\hat{N}$ & 웅 \\
\hline & Бे & N & (n) & $\theta$ & $\stackrel{2}{\sim}$ & $\mathscr{e}$ \\
\hline \multirow{4}{*}{ 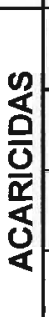 } & స్요 & on & $F$ & 우 & $\boldsymbol{\omega}$ & Nै \\
\hline & స్ & م & $\stackrel{\sim}{\sim}$ & 우 & م & $\mathcal{N}$ \\
\hline & बे & wo & $m$ & $F$ & $\nabla$ & $m$ \\
\hline & $\overline{\mathrm{g}}$ & $\forall$ & \pm & 움 & $\boldsymbol{\omega}$ & mे \\
\hline \multirow{4}{*}{ 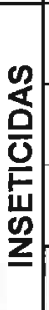 } & 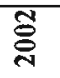 & $\stackrel{\mathscr{0}}{\circ}$ & $\stackrel{\Re}{\Re}$ & 5 & 芯 & 导 \\
\hline & ఫ్ & 脶 & $\mathscr{8}$ & 乌 & $F$ & $\stackrel{\sim}{\mathbf{N}}$ \\
\hline & $\hat{\sigma}$ & $\overline{\text { in }}$ & 曲 & 邑 & స్ & $\stackrel{\mathscr{R}}{\mathscr{2}}$ \\
\hline & & : & 嵒 & $\sigma$ & N & $\underset{\Xi}{ \pm}$ \\
\hline \multirow{4}{*}{ 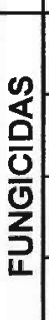 } & 气ิ & $\stackrel{\infty}{\sim}$ & लn & 8 & f & $\stackrel{\mathscr{E}}{\varrho}$ \\
\hline & ఫે & $F$ & జ్ & นึ & $\mathscr{m}$ & 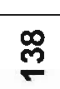 \\
\hline & बे & $\stackrel{m}{\sim}$ & $\ddot{m}$ & 요 & స్ & 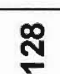 \\
\hline & פ & $\stackrel{ \pm}{ \pm}$ & 요 & 5 & 요 & $\stackrel{2}{N}$ \\
\hline \multirow{4}{*}{ 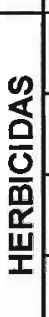 } & 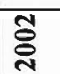 & 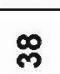 & ֻீ & N & 年 & $\stackrel{\mathscr{N}}{\mathcal{N}}$ \\
\hline & ठ্ণે & ๙ั & 曲 & $\tilde{\sigma}$ & 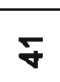 & $\stackrel{\mathscr{2}}{\stackrel{2}{2}}$ \\
\hline & gू & 胥 & 怘 & ஜ & m & $\stackrel{R}{R}$ \\
\hline & $\sqrt{\overline{2}}$ & : & 员 & $\mathscr{0}$ & $\mathscr{N}$ & $\underset{N}{\mathbb{N}}$ \\
\hline \multicolumn{2}{|c|}{ 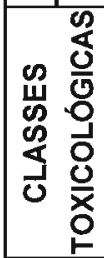 } & $\begin{array}{l}\bar{w} \\
\ddot{s} \\
\dot{S} \\
\end{array}$ & 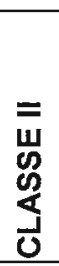 & 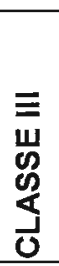 & 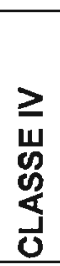 & $\begin{array}{l}\stackrel{\ddot{\alpha}}{5} \\
\text { o }\end{array}$ \\
\hline
\end{tabular}




\subsection{Registro de Defensivos Agrícolas no Brasil}

Os ensaios destinados a pesquisa de resíduos de pesticidas devem, no mínimo, ser conduzidos em 2 (dois) locais representativos das áreas de cultivo ou em 2 (duas) safras consecutivas, seguindo as boas práticas agrícolas. A formulação aplicada deverá ser a mesma que a comercializada. Pelo menos duas doses deverão ser testadas: máxima a ser recomendada e o dobro. Todas as amostras deverão ser acompanhadas de testemunhas. Entende-se por testemunha a amostra não tratada, coletada no mesmo local e no mesmo intervalo que a amostra tratada. Após o estudo de campo dados laboratoriais são gerados e enviados ao Ministério da Saúde; caso o pesticida seja aprovado para aquela cultura o Ministério da Saúde edita uma Monografia, publicada no Diário Oficial da União, divulgando os limites máximos de resíduos para todas as culturas estudadas.

Os ensaios de campo servem para estimar o LMR (limite máximo de resíduos) para a cultura, já que os dados de campo são utilizados como dados para o estabelecimento dos limites máximos permitidos. A dose dupla aplicada não pode fornecer resultados superiores ao limite máximo permitido, pois neste caso a formulação não será registrada.

A Portaria $n^{\circ} 160$ de 31 de dezembro de 1996 Art. $1^{\circ}$, item a, diz que para efeito de obtenção de registro e reavaliação técnica o requerente deverá fornecer o método analítico com a respectiva validação, para determinação de resíduos do ingrediente ativo (i.a.) e seus derivados nas culturas indicadas na solicitação de registro.

A resolução-RDC $n^{\circ} 44$, de 10 de maio de 2000 (Anexo 1) item 5.2 Relátório Analítico determina os dados que deverão constar no relatório de estudos de resíduos. No Método de análise deverão constar:

- Identificação,

- Quantificação,

- Curva de Calibração, 
- Recuperação em dois níveis de fortificação com pelo menos três repetições cada um, sendo que o intervalo aceito para as recuperaçãoes será de 70 a $120 \%$

- Limite de Quantificação

- Resultados

- Bibliografia 


\section{5- PESTICIDAS ORGANOCLORADOS, PIRETRÓIDES E OUTROS}

Dentre os organoclorados estudados encontramos fungicidas, inseticidas e herbicidas. Com algumas poucas exceções os organoclorados têm baixa toxicidade para os mamíferos e alta toxicidade para os insetos (New Zealand Total Diet Survey Part 1: Pesticide Residues). Eles são componentes estáveis, solúveis em gorduras; os componentes mais novos como o dicofol e o endosulfam são degradáveis no meio ambiente. Os piretróides são inseticidas e a azoxistrobina é um fungicida que são analisados conjuntamente com os organoclorados através do detector de captura de eletrons.

A tabela VI mostra os pesticidas organoclorados, piretróides e azoxistrobina com a classificação toxicológica.

Tabela VI: Pesticidas organoclorados, e classificação toxicológica

\begin{tabular}{l|c}
\hline $\begin{array}{l}\text { Ingrediente } \\
\text { Ativo }\end{array}$ & $\begin{array}{c}\text { Classificação } \\
\text { toxicológica }\end{array}$ \\
\hline Propanil & III \\
Alacloro & III \\
Dicofol & II \\
Aletrina & III \\
Procimidona & IV \\
Endosulfam & I \\
Bifentrina & II \\
Fenpropatrina & II \\
Tetradifona & IV \\
Procloraz & I \\
Difenoconazol & III \\
Azoxistrobina & III \\
\hline
\end{tabular}




\section{Propanil}

Herbicida, solúvel na maioria dos solventes orgânicos, é muito utilizado na cultura de arroz (Hassal, 1983). Produto considerado perigoso ao meio ambiente é altamente tóxico para algas.

\section{Alacloro}

O alacloro é um herbicida seletivo de ação não sistêmica, recomendado para o controle em pré-emergência das plantas daninhas. Sob o ponto de vista ambiental o alacloro é altamente móvel, apresentando alto potencial de deslocamento no solo e é altamente persistente no meio ambiente, podendo atingir principalmente águas subterrâneas ou o lençol freático. É altamente tóxico para algas (Agrofit, 2002).

\section{Dicofol}

O dicofol é um importante acaricida organoclorado de contato e ingestão que age em estágios mais desenvolvidos da vida do ácaro. Possuí efeito residual prolongado (Hassal, 1983).

\section{Aletrina}

Foi o primeiro piretróide a ser descoberto. Inseticida piretróide, instável à luz. Por esta razão só é utilizado como inseticida doméstico (Chen et al., 1996).

\section{Procimidona}

Fungicida sistêmico de amplo espectro de ação. É altamente persistente no meio ambiente, e extremamente tóxico para algas (Agrofit, 2001).

\section{Endosulfam}

O endosulfam é um inseticida e acaricida não sistêmico de contato e ingestão constituido pela mistura de 2 isômeros ( $\alpha$ e $\beta$ Endosulfam) e pertence ao grupo dos ciclodienos. Ao contrário dos outros ciclodienos conhecidos (aldrin, clordane, heptacloro, mirex, etc), o endosulfam é considerado pouco persistente no ambiente e apresenta baixa toxicidade para a maioria dos organismos superiores, com exceção de algumas espécies aquáticas, particularmente peixes 
(Nishiguchi,1999). O sulfato de endosulfam é o principal produto de degradação do endosulfam, sendo considerado tão tóxico quanto os isômeros $\alpha$ e $\beta$. É considerado tóxico para organismos aquáticos, abelhas.

\section{Bifentrina}

Inseticida piretróide de contato e ingestão largamente utilizado no tratamento de grãos armazenados. É um sólido branco, de baixa polaridade, pouco volátil e apresenta baixa solubilidade em água (Hassal, 1983). É altamente persistente no meio ambiente e extremamente tóxico para microcrustáceos (Agrofit, 2002).

\section{Fempropatrina}

Inseticida piretróide, é um sólido branco de baixa polaridade, pouco volátil e apresenta baixa solubilidade em água (Hassal, 1983).

\section{Tetradifona}

Acaricida, largamente utilizado no Brasil

\section{Procloraz}

O procloraz é um fungicida que é utilizado na manga em aplicação pós colheita para evitar a podridão dos frutos (Manley, 1989). O procloraz pertence ao grupo dos imidazóis. Foram primeiramente estudados pela indústria farmacêutica e estes estudos formaram a base da aplicação destes compostos como protetores de plantas (Hassal, 1983).

\section{Difenoconazol}

É um fungicida sistêmico que surgiu no início da década de 90 . É utilizado em doenças que causam manchas foliares em hortaliças, em doenças no final de ciclo na cultura de soja e em tratamento de sementes (Azevedo, 2001) . É altamente persistente no meio ambiente e altamente tóxico para os microcrustáceos (Agrofit, 2002). 


\section{Azoxistrobina}

Fungicida sistêmico com atividade preventiva, curativa e anti-esporulante que surgiu no final da década de 90 . É amplamente empregado no controle de manchas foliares e oídio (fungo largamente distribuído no território brasileiro) das hortaliças. É um dos fungicidas mais vendidos no mundo e no Brasil (Azevedo, 2001) É altamente tóxico para organismos aquáticos.

A fórmula estrutural dos pesticidas analisados pelo detector de captura de elétrons se encontra na tabela VII. 
Tabela VII: Pesticidas organoclorados, piretróides e estrobirulina : função, classe e fórmula estrutural

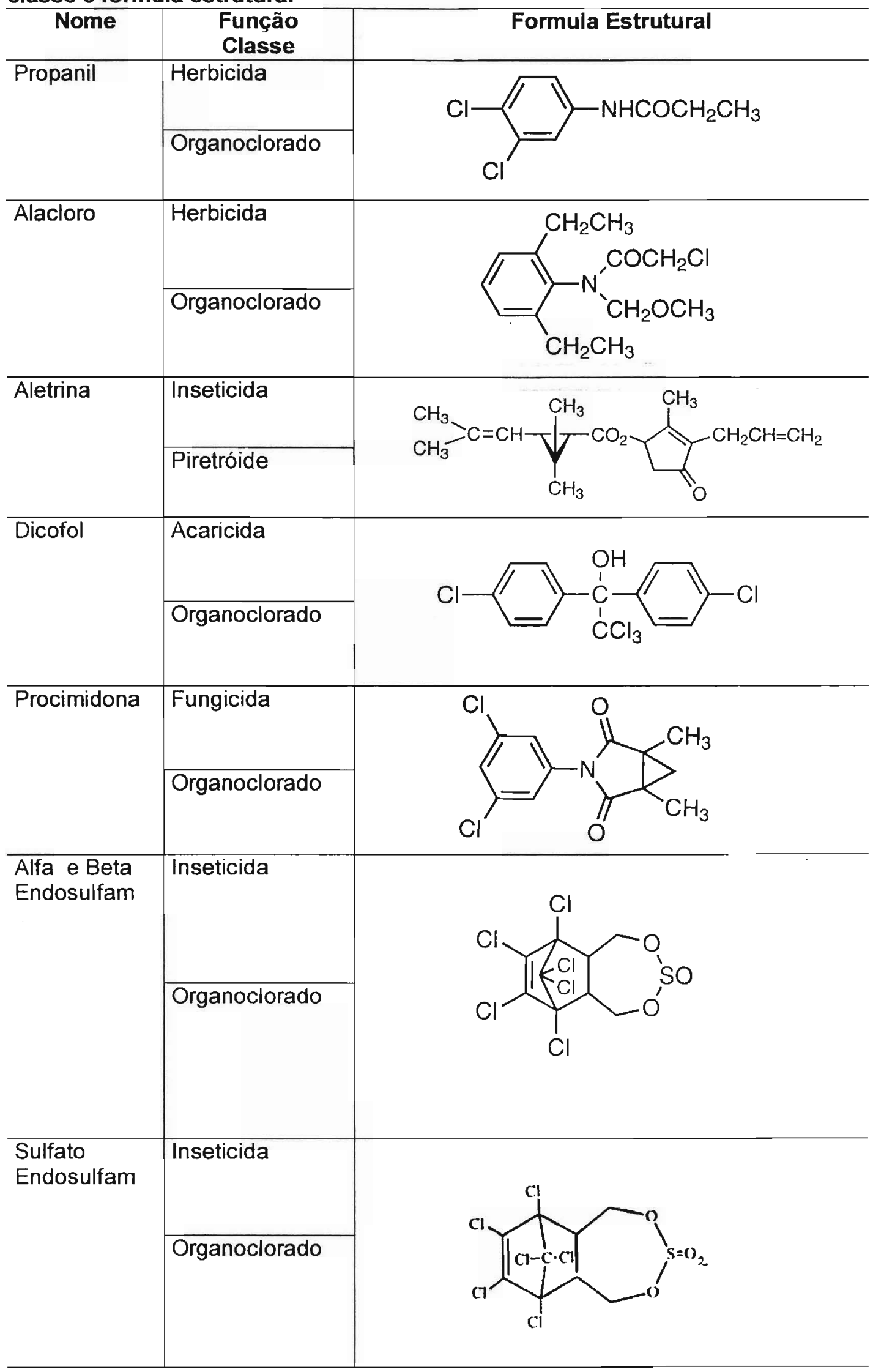


Continuação da Tabela VII: Pesticidas organoclorados, piretróides e estrobirulina: função, classe e fórmula estrutural

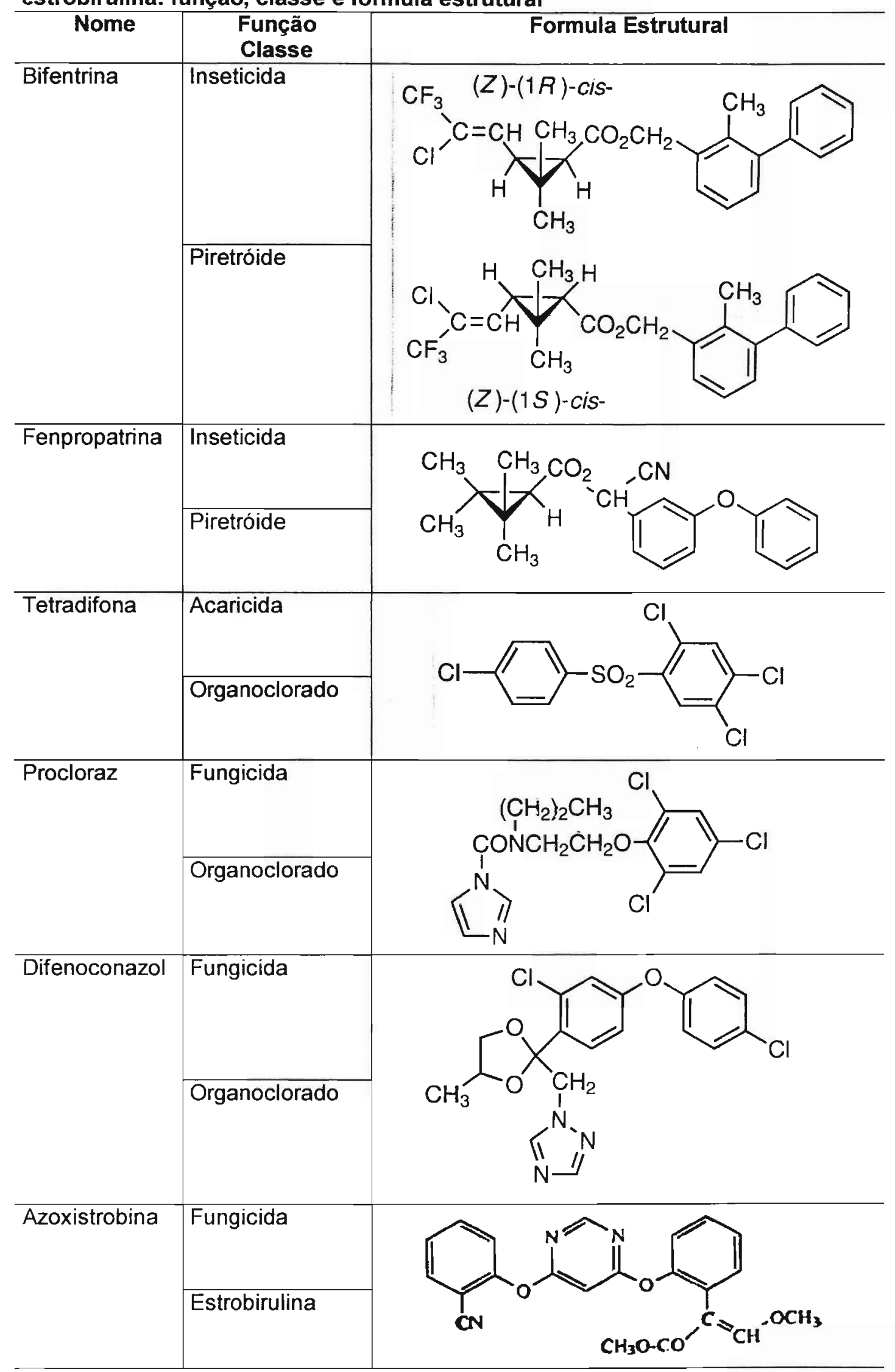




\section{PESTICIDAS ORGANOFOSFORADOS}

A maioria dos pesticidas organofosforados são empregados como inseticidas; entretanto sua aplicação não se estende somente nesta área, pois são também utilizados como acaricidas, nematicidas, rodenticidas entre outros. Recentemente foram sintetizados alguns organofosforados que têm ação fungicida e herbicida. Alguns componentes são usados também como medicamento; por exemplo, 0 paraoxon é utilizado contra o glaucoma e o endosan é utilizado contra tumores malignos (Eto, 1974). Os pesticidas organofosforados foram analisados através da cromatografia à gás com detector fotométrico de chama. A tabela VIII mostra os pesticidas organofosforados estudados, com a classificação toxicológica.

\section{Tabela VIII: Pesticidas organofosforados, e classificação toxicológica}

\begin{tabular}{l|c}
\hline $\begin{array}{l}\text { Ingrediente } \\
\text { Ativo }\end{array}$ & $\begin{array}{c}\text { Classificação } \\
\text { Toxicológica }\end{array}$ \\
\hline diclorvós & II \\
forato & $\mathrm{I}$ \\
diazinom & $\mathrm{II}$ \\
clorpirifós & $\mathrm{I}$ \\
malationa & $\mathrm{II}$ \\
fentiona & $\mathrm{II}$ \\
fentoato & $\mathrm{II}$ \\
etiona & $\mathrm{II}$ \\
fosmete & $\mathrm{II}$ \\
\hline
\end{tabular}

\section{Diclórvos, DDVP ou Vapona}

O diclorvós é um inseticida que foi descoberto em 1955 como uma impureza do inseticida triclorfon (Eto,1974). O triclorfon é rapidamente convertido a diclorvós. O diclorvós é um líquido amarelo, miscível com muitos solventes orgânicos. $A$ meia vida em água a $\mathrm{pH} 7,0$ é de aproximadamente de 8 horas. O diclórvos é um inseticida de contato com ação fumigante e de baixa atividade residual. 


\section{Fentiona}

Foi desenvolvido em 1958 como inseticida (Eto,1974). É um líquido solúvel em muitos solventes orgânicos exceto em hidrocarbonetos alifáticos. O fentiona é estável à hidrólise ácida e básica e ao aquecimento, conseqüentemente é um inseticida persistente. Altamente tóxico para organismos aquáticos, abelhas e aves.

\section{Diazinom}

Foi descoberto em 1952. É um inseticida que age matando os insetos pelo contato e/ou pela ingestão. É utilizado na fumigação de grãos armazenados (Eto,1974). O diazinom puro é um líquido incolor, é altamente solúvel em solventes orgânicos. Ele demonstra ter uma ação residual longa, porém sua toxicidade é relativamente baixa.

\section{Malationa}

Foi introduzido em 1950 e é conhecido como o primeiro inseticida organofosforado com toxicidade seletiva (Eto,1974). É um inseticida que mata os insetos por contato e ou através da ingestão. O malationa é um líquido amarelo, altamente solúvel em muitos solventes orgânicos exceto os alcanos. O malationa é rapidamente hidrolisado em soluções aquosas, acima de $\mathrm{pH} 7,0$ e abaixo de $\mathrm{pH}$ 5,0 . Devido à baixa toxicidade e ação inseticida elevada é muito utilizado. É extremamente tóxico para microcrustáceos.

\section{Clorpirifós}

Foi descoberto em 1965. É solúvel em muitos solventes orgânicos. É moderadamente persistente e relativamente estável, exceto sob soluções fortemente alcalinas ou ácidas. É solúvel nos solventes orgânicos (Eto,1974).

\section{Forato}

É extremamente tóxico para os mamíferos. Tem grande persistência por isso protege as plantas durante um longo periodo (Eto, 1974). 


\section{Fentoato}

Foi introduzido em 1964, é um inseticida que mata por contato e ou pela ingestão. O produto puro é líquido, solúvel em hidrocarbonetos aromáticos,cetonas, álcoois entre outros. É relativamente instável sob aquecimento. Tem ação inseticida e acaricida. Sua toxicidade depende da pureza. O produto puro apresenta $\mathrm{DL}_{50}$ para ratos $=4700 \mathrm{mg} / \mathrm{kg}$ enquanto o produto técnico (pureza $78,7 \%$ ) é 40 vezes mais tóxico.

\section{Etiona}

Foi desenvolvido em 1956 como inseticida de contato e ingestão. É um líquido amarelo, praticamente insolúvel em água e altamente solúvel em hidrocarbonetos aromáticos, é levemente oxidado no ar. É um inseticida com baixa toxicidade para os mamíferos.

\section{Fosmete}

Foi introduzido em 1966 como inseticida e acaricida de contato e ingestão. È um sólido cristalino branco, solúvel em muitos solventes orgânicos exceto hidorocarbonetos alifáticos. É um inseticida não sistêmico.

A fórmula estrutural dos pesticidas organofosforados estudados se encontra na Tabela VIX. 
Tabela XIX: Pesticidas organofosforados: função, classe e fórmula estrutural

\begin{tabular}{|c|c|c|}
\hline Nome & $\begin{array}{c}\text { Função } \\
\text { Classe }\end{array}$ & Formula Estrutural \\
\hline \multirow[t]{2}{*}{ Diclorvós } & $\begin{array}{l}\text { Inseticida } \\
\text { Acaricida }\end{array}$ & \multirow{2}{*}{ 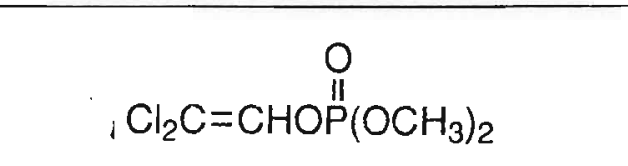 } \\
\hline & Organofosforado & \\
\hline \multirow[t]{2}{*}{ Forato } & $\begin{array}{l}\text { Inseticida } \\
\text { Acaricida }\end{array}$ & \multirow{2}{*}{$\mathrm{CH}_{3} \mathrm{CH}_{2} \mathrm{SCH}_{2} \mathrm{SP}\left(\mathrm{OCH}_{2} \mathrm{CH}_{3}\right)_{2}$} \\
\hline & Organofosforado & \\
\hline \multirow[t]{2}{*}{ Diazinom } & $\begin{array}{l}\text { Inseticida } \\
\text { Acaricida }\end{array}$ & \multirow[t]{2}{*}{$\mathrm{CH}_{3}$} \\
\hline & Organofosforado & \\
\hline \multirow[t]{2}{*}{ Clorpirifós } & $\begin{array}{l}\text { Inseticida } \\
\text { Acaricida }\end{array}$ & \multirow{2}{*}{$\mathrm{Cl} \sim \mathrm{N} \rightleftharpoons \mathrm{S} \stackrel{\mathrm{S}}{\mathrm{OP}}\left(\mathrm{OCH}_{3}\right)_{2}$} \\
\hline & Organofosforado & \\
\hline \multirow[t]{2}{*}{ Malationa } & $\begin{array}{l}\text { Inseticida } \\
\text { Acaricida }\end{array}$ & \multirow{2}{*}{ 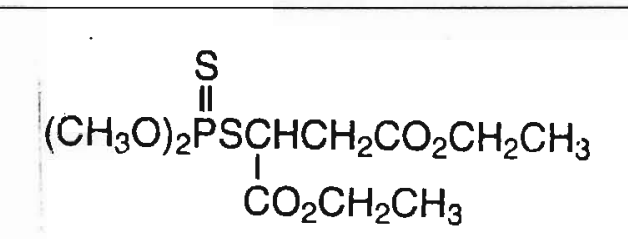 } \\
\hline & Organofosforado & \\
\hline \multirow[t]{2}{*}{ Fentiona } & Inseticida & \multirow[t]{2}{*}{$\mathrm{CH}_{3}$} \\
\hline & Organofosforado & \\
\hline \multirow[t]{2}{*}{ Fentoato } & $\begin{array}{l}\text { Inseticida } \\
\text { Acaricida }\end{array}$ & \multirow{2}{*}{ 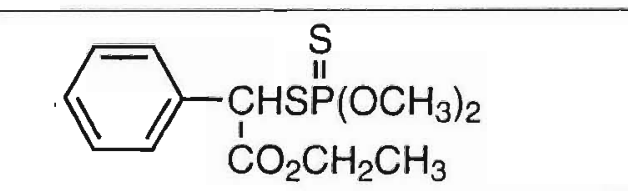 } \\
\hline & Organofosforado & \\
\hline \multirow[t]{2}{*}{ Etiona } & $\begin{array}{l}\text { Inseticida } \\
\text { Acaricida }\end{array}$ & \multirow{2}{*}{$\stackrel{\mathrm{S}}{\mathrm{I}} \stackrel{\mathrm{S}}{\|}\left(\mathrm{CH}_{3} \mathrm{CH}_{2} \mathrm{O}\right)_{2} \mathrm{PSCH} \mathrm{PSP}_{2} \mathrm{SP}\left(\mathrm{OCH}_{2} \mathrm{CH}_{3}\right)_{2}$} \\
\hline & Organofosforado & \\
\hline \multirow[t]{2}{*}{ Fosmete } & $\begin{array}{l}\text { Inseticida } \\
\text { Acaricida }\end{array}$ & \\
\hline & Organofosforado & \\
\hline
\end{tabular}




\section{VALIDAÇÃO DA METODOLOGIA EMPREGADA NA ANÁLISE DE RESÍDUOS DE PESTICIDAS}

A avaliação da metodologia analítica na área de resíduos de pesticidas é realizada para garantir que o método seja exato, específico e reprodutível. A avaliação envolve a interação princípio ativo - matriz dentro de uma marcha analítica que resulta na quantificação por métodos instrumentais. A conformidade da metodologia deve ter alguns parâmetros obrigatórios:

Linearidade

Especificidade

Exatidão

Precisão

Limite de Detecção

Limite de Quantificação

\subsection{Linearidade}

A linearidade é geralmente o primeiro passo a ser verificado em análise de resíduos de pesticidas. Antes da escolha do método de análise, avalia-se a linearidade da determinação do princípio ativo para o sistema de detecção escolhido. A linearidade é obtida através da Curva Analítica do princípio ativo, geralmente com medidas de um mínimo de cinco níveis de concentração, procurando-se injetar no mínimo 3 vezes cada concentração correspondente a um determinado ponto da curva . A linearidade corresponde à capacidade do método em fornecer resultados diretamente proporcionais à concentração da substância dentro de uma determinada faixa. Através da linearidade verifica-se a variação da inclinação da linha de regressão que deve apresentar um coeficiente de determinação quadrado maior ou igual a 0,99 para garantir que o princípio ativo seja linear naquelas condições. A curva analítica deve conter o ponto correspondente ao limite de quantificação do método.

Para obter-se a curva analítica são necessárias soluções padrão de concentrações definidas obtidas através de padrão de referência. Qualquer método cromatográfico depende fortemente da existência de padrões de 
referência para o fornecimento de dados exatos; assim, a pureza dos padrões de referência é um item especialmente importante na avaliação de resíduos de pesticidas. Alguns cuidados devem ser observados quanto ao padrão de referência: devem ser armazenados nos frascos originais, as tampas não devem ser de borracha, pois podem contaminar o padrão. Os padrões devem ser armazenados de acordo com as instruções do produtor para evitar a degradação. Geralmente o armazenamento em temperatura baixa (freezer) e no escuro é satisfatório (Guidelines for Residues Monitoring in the European Union Document SANCO $7826 / \mathrm{VI} / 97$ )

\subsection{Especificidade}

O método analítico empregado deve ser capaz de determinar o analito quantitativamente mesmo na presença de outras substâncias. Corresponde ao grau de interferência de espécies, como outro princípio ativo, reagentes, impurezas e produtos de degradação, garantindo que o pico de resposta cromatográfico seja exclusivamente de um componente simples, isto é, que não existam interferentes naquele tempo de retenção.

Para verificar a especificidade de um método deve-se primeiramente verificar se os reagentes empregados na análise e a vidraria não apresentam interferentes que apresentem o mesmo tempo de retenção do analito, ou seja há necessidade de injetar um branco do método. Análise do branco é aquela na qual faz-se uma análise completa com todos os passos da marcha analítica sem o uso da amostra. É necessário também analisar uma amostra testemunha para verificar a presença de interferentes da própria matriz. Amostra testemunha é a amostra que não contém o analito em estudo.

\subsection{Exatidão}

Segundo o EPA (Environmental Protection Agency, 1996) a exatidão representa o grau de concordância entre os resultados individuais encontrados em relação a um valor aceito como referência. A exatidão assegura o desempenho do método 
analítico. É expressa como o percentual de resposta obtida através do ensaio de uma quantidade conhecida do analito adicionado á matriz. A recuperação de pesticidas de amostras fortificadas é usada como medida de eficiência de um método analítico.

A exatidão dentro da avaliação de metodologia é conferida através do estudo de recuperação do princípio ativo; para isto fortifica-se uma amostra testemunha. $A$ fortificação consiste na adição de uma solução do pesticida em concentrações conhecidas na amostra testemunha. Através da análise desta amostra, pode-se verificar se a marcha analítica determina o princípio ativo quantitativamente. Através da fortificação da amostra obtém-se os resultados de recuperação. $O$ intervalo aceito para os valores de recuperação varia de 70 a $120 \%$ segundo o EPA (Environmental Protection Agency, 1996) e o desvio padrão relativo deve estar abaixo de $20 \%$ segundo o próprio EPA (1996) e o CODEX ALIMENTARIUS (Programa das Nações Unidas sobre Harmonização de Normas Alimentares, gerenciado pela FAOMHO-Food and Agriculture Organization e World Health Organization, 2000) .O EPA aceita valores inferiores a $70 \%$ de recuperação para casos especiais, porém o pesticida não pode ser extremamente tóxico.

\subsection{Precisão}

A precisão expressa o grau de repetibilidade entre os resultados de análises individuais quando o procedimento é aplicado mais de uma vez em uma mesma amostra homogênea, em idênticas condições de análise. Normalmente é expressa através do desvio padrão relativo em um número estatisticamente significativo de amostras.

\subsection{Limite de Detecção}

O Limite de detecção (LD) representa a mais baixa concentração da substância em exame que pode ser detectada com um certo limite de confiabilidade utilizando um determinado procedimento experimental. 


\subsection{Limite de Quantificação}

O limite de quantificação (LQ) é definido como a mais baixa concentração do analito que pode ser quantificado com uma certa confiabilidade, utilizando uma marcha analítica específica (The American Chemical Society-Commitee on Environmental Improvement). O LQ engloba uma relação entre a concentração, precisão e exatidão. 


\section{8- MÉTOdo ANALítico PARA DETERMinAÇÃo MULTIRESíduOS DE PESTICIDAS ORGANOCLORADOS E ORGANOFOSFORADOS EM MANGA}

\subsection{Considerações Gerais}

Existem diversas metodologias direcionadas à determinação de multiresíduos publicadas na literatura (Schenck et al., 2000). Encontrar uma que extraia todos os pesticidas e estabeleça limites de quantificação que atendam à legislação é tarefa praticamente impossível.

Em muitos casos a extração é feita com acetona ou acetato de etila. Lucke propôs um dos primeiros métodos para determinação de multiresiduos de pesticidas em alimentos (Lucke, 1975).

O FDA (Food and Drug Administration) utiliza a extração com acetona, partição com diclorometano:éter de petróleo e posterior filtração em cloreto de sódio. Em 1993 o FDA adicionou a purificação da amostra com SPE (extração em fase sólida) ao seu método original, que é conhecido como Método de Luke II . Este fato deve-se a interferentes na matriz e ao maior uso do cromatógrafo gasoso com detetor de massa "íon-trap".

O PMRA (Canadian Pest Management Regulatory Agency), órgão que controla o uso de Pesticidas no Canadá, indica a extração dos pesticidas com acetonitrila saturada de cloreto de sódio.

O Netherlands General Inspectory for Health Protection, orgão de fiscalização da Holanda utiliza o método original de Lucke seguido de identificação através do CG-ITMS (cromatografia gososa com detecção de massa "íon trap"). A tabela $X$ apresenta alguns métodos propostos para a extração multiresíduos. No presente trabalho as determinações foram realizadas empregando-se o método de Lucke seguido pelo governo Holandês, com algumas modificações.

Um método analítico deve ter alguns requisitos mínimos. As recomendações da Agência de Proteção Ambiental Americana são as seguintes: 
1) A execução do método deve ser relativamente rápida, geralmente não deve durar mais que um dia a não ser para alguns princípios ativos especiais. Para as substâncias extremamente tóxicas a análise não deve demorar mais do que 24 horas entre o início da análise e o resultado final, devido a necessidade da utilização de medidas de proteção.

2) O método deve ser específico na identificação e quantificação levando -se em conta que mais de um pesticida pode estar presente na mesma amostra.

3) O método deve ser sensível o suficiente para atender a Legislação em vigor.

4) Durante todo o procedimento não se devem usar substâncias ou reagentes extremamente tóxicos.

5) O EPA não tem uma lista de instrumentos adequados para cada análise, porém métodos empregando a Cromatógrafo a gás ou a Líquido com os vários sistemas de detecção existentes são aceitos. Métodos empregando a cromatografia em papel ou em camada delgada podem ser utilizados para confirmação ou identificação, porém não são precisos o suficiente para quantificação.

6) A confirmação dos resultados é necessária. Em geral a confirmação é realizada idealmente com o detector de massa, porém na ausência deste detector o uso de uma coluna de polaridade diferente, ou uma outra forma de detecção ou ainda o uso de uma fase móvel de seletividade diferente podem ser utilizados. Além disto a especificidade do método pode ser obtida através de purificação mais específica ou de derivatização. O EPA não determina que seja feito um estudo para verificar a possibilidade de que outros pesticidas permitidos para a cultura sejam considerados como interferentes. O documento SANCO $825 / 00$ da European Comission diz que 
não é necessário um método confirmatório quando o método utiliza o CG/MS com a utilização de ao menos três fragmentos para identificação/quantificação. 


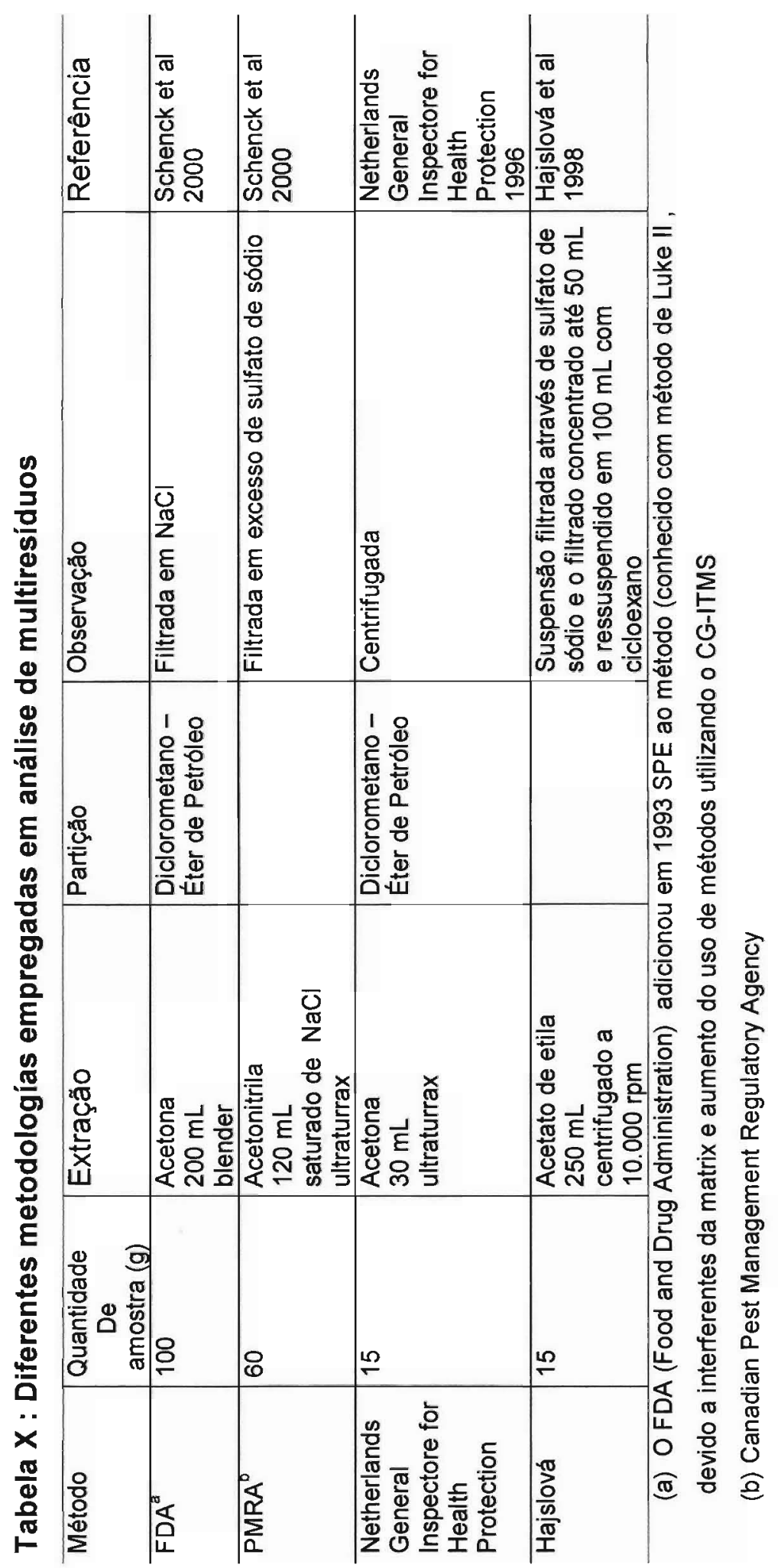




\subsection{PARTE EXPERIMENTAL}

\subsubsection{Aparelhos/equipamentos}

a) Ultraturrax Heidolph modelo DIAX 900

b) Centrífuga Inábras modelo Spin VI

c) Balança Analítica Mettler Toledo, modelo AB 204

d) Balança semi-analítica Micronal, modelo B 4000

e) Evaporador Rotatório Bücher modeloR-114

f) Banho com aquecimento Bücher modelo B-480

g) Cromatógrafo em fase gasosa HP 6890, com detector de captura de elétrons, com amostrador automático e microcomputador com Chemstation

h) Cromatógrafo em fase gasosa HP 5890, com detector de fotométrico de chama, com amostrador automático e integrador

\subsubsection{Reagentes}

- Acetona grau resíduo

- Diclorometano grau resíduo

- Hexano grau resíduo

- Tolueno grau resíduo

- Isooctano grau resíduo

\subsubsection{Padrão analítico}

Os padrões analíticos foram obtidos da SUPELCO com pureza igual ou superior a $99,8 \%$

- Diclorvós

- Forato

- Diazinom

- Clorpirifós

- Malationa

- Fentiona

- Fentoato

- Etiona

- Fosmete 
- Alacloro

- Tetradifona

- Alfa Endosulfam

- Beta Endosulfam

- Sulfato Endosulfam

- Procimidona

- Propanil

- Dicofol

- Fenpropatrina

- Aletrina

- Bifentrina

- Difenoconazol

- Procloraz

- Azoxistrobina

\subsubsection{Vidrarias e outros Materiais}

Provetas graduadas de $100 \mathrm{~mL}$ Frasco de teflon de $250 \mathrm{~mL}$

Balões Volumétricos de 10,0 e $100,0 \mathrm{~mL}$

Pipetas volumétricas de várias capacidades

Béqueres de $10 \mathrm{~mL}$

Bastão de vidro

Frascos de vidro de $2,0 \mathrm{~mL}$ próprios para uso no injetor automático dos cromatógrafos com tampa e septo descartável de teflon

Espátulas

Frasco de vidro de $100 \mathrm{~mL}$ com tampa de teflon

Balões de fundo chato com boca esmerilhada de $125 \mathrm{~mL}$ 
8.2.5 Preparação das soluções padrão para construção das curvas analíticas

a) Solução mãe

Pesar $10 \mathrm{mg}$ do padrão analítico certificado em balão volumétrico de $100 \mathrm{~mL}$, completar até a marca com isooctano. Transferir para frasco de vidro de $100 \mathrm{~mL}$ com tampa revestida de teflon.

\section{b) Soluções intermediárias}

\section{b.1) Soluções Intermediárias para uso no CG-ECD}

As soluções intermediárias foram preparadas de duas formas: em hexano e no extrato da amostra testemunha ressuspendido em hexano.

\section{b.2) Soluções intermediárias para uso no CG-FPD}

As soluções intermediárias foram preparadas de duas formas em isooctanotolueno 9:1 e no extrato da amostra testemunha ressuspendido em isooctano:tolueno 9:1.

\section{b.3) Soluções de fortificação}

Todas as soluções de fortificação foram preparadas em hexano

\subsubsection{Parâmetros cromatográficos}

$\begin{array}{ll}\text { a) Cromatógrafo a Gás com Detetor de Captura de Eletrons } \\ \text { Cromatógrafo à gás: } \mathrm{HP}, \text { modelo } 6890 \text { series com microcomputador com } \\ & \text { Chemstation } \AA \\ \text { Coluna cromatográfica: } & \text { Coluna capilar HP-5 } 30 \text { metros de comprimento, diâmetro interno de } \\ & 0,32 \mathrm{~mm}, 0,25 \mu \mathrm{m} \text { de espessura de filme } \\ \text { Gás de arraste: } & \text { Nitrogênio } \\ \text { Injetor: } & \text { Modo: Splitless, } \\ & \text { Temperatura } 250^{\circ} \mathrm{C} \\ & \text { Vazão Total: } 23,2 \mathrm{~mL} / \mathrm{min} . \\ & \text { Gás: nitrogênio } \\ & \text { Pressão: } 5,1 \mathrm{psi}\end{array}$

Volume de injeção: $\quad 2 \mu \mathrm{L}$ 
Temperatura do forno: $\quad$ Temperatura Inicial $60^{\circ} \mathrm{C}$ por $1 \mathrm{~min}$.

$\begin{array}{lcc}\text { Rampa } & \text { Temperatura Final } & \text { Tempo Final } \\ 10^{\circ} \mathrm{C} / \mathrm{min} . & 220 & 6 \mathrm{~min} . \\ 3^{\circ} \mathrm{C} / \mathrm{min} . & 280 & 17 \mathrm{~min} .\end{array}$

Tempo Total $60 \mathrm{~min}$

Detector: Detector de captura de elétrons (ECD), gás make-up gás: nitrogênio 60 $\mathrm{mL}, 320^{\circ} \mathrm{C}$

\section{b) Cromatógrafo a Gás com Detetor Fotométrico de Chama (FPD)}

Cromatógrafo à gás: $\quad$ HP, modelo 5890 series com integrador

Coluna cromatográfica: Coluna capilar HP-5 30 metros de comprimento, diâmetro interno de 0,53 $\mathrm{mm}, 2,65 \mu \mathrm{m}$ de espessura de filme

Gás de arraste: Nitrogênio

Fluxo do Gás de Arraste: $18 \mathrm{~mL} / \mathrm{min}$.

Fluxo do Hidrogênio: $\quad 75 \mathrm{~mL} / \mathrm{min}$.

Fluxo do Ar Sintético: $\quad 100 \mathrm{~mL} / \mathrm{min}$.

Volume de injeção: $\quad 2 \mu \mathrm{L}$

Temperatura do forno: Temperatura Inicial $90^{\circ} \mathrm{C}$

$\begin{array}{lcc}\text { Rampa } & \text { Temperatura Final } & \text { Tempo } \\ 30^{\circ} \mathrm{C} / \mathrm{min} . & 190 & 5 \mathrm{~min} . \\ 5^{\circ} \mathrm{C} / \text { minuto } & 280 & 5 \mathrm{~min} .\end{array}$

Tempo Total 32 minutos

Detector: $\quad$ Detector Fotométrico de Chama (FPD) $300^{\circ} \mathrm{C}$ 


\subsubsection{Procedimento analítico}

\section{a) Amostragem}

Triturar as amostras em blender. Foram utilizadas a casca e a polpa da manga no processo de amostragem. O caroço foi desprezado.

\section{b)Extração}

- Homogeneizar a amostra e pesar uma alíquota de $15 \mathrm{~g}$ em um frasco de polietileno. Adicionar $30 \mathrm{~mL}$ de acetona e agitar em ultraturrax por 30 segundos.

- Adicionar $60 \mathrm{~mL}$ de uma mistura diclorometano:hexano (1:1) e agitar por mais 30 segundos em ultraturrax.

- Centrifugar a amostra a 5.000 rpm por 10 minutos.

- Medir o extrato em proveta graduada.

- Transferir 0,40 mL do extrato para frasco próprio do injetor automático, Deixar evaporar todo solvente e ressuspender em $1,0 \mathrm{~mL}$ de hexano para injeção no CG-ECD (detetor de captura de elétrons).

- Transferir $25,0 \mathrm{~mL}$ para balão de fundo chato de $125 \mathrm{~mL}$ com boca esmerilhada. Concentrar até secura em evaporador rotatório e ressuspender em $2,5 \mathrm{~mL}$ de uma mistura isooctano:tolueno (9:1). Injetar no CG-FPD (detetor fotométrico de chama).

\subsection{Confirmação dos resultados}

A confirmação dos resultados foi feita através do uso da uma coluna HP 1701 .

\subsection{Limpeza da vidraria}

Todo material de vidro foi imerso em uma solução de Extran ${ }^{\circledR}$ alcalino a $10 \%$ por 12 horas, seguido de lavagem com água com enxágüe final com água Milli $Q^{\circledR}$. $A$ secagem foi feita em estufa e a eliminação de possiveis interferentes efetuada com hexano grau resíduo. Os balões volumétricos e pipetas utilizados para o preparo de padrões foram primeiramente descontaminados com solventes antes da lavagem. 


\subsection{FLUXOGRAMA: ANÁLISE MULTIRESÍDUOS DE PESTICIDAS EM AMOSTRAS DE MANGA}
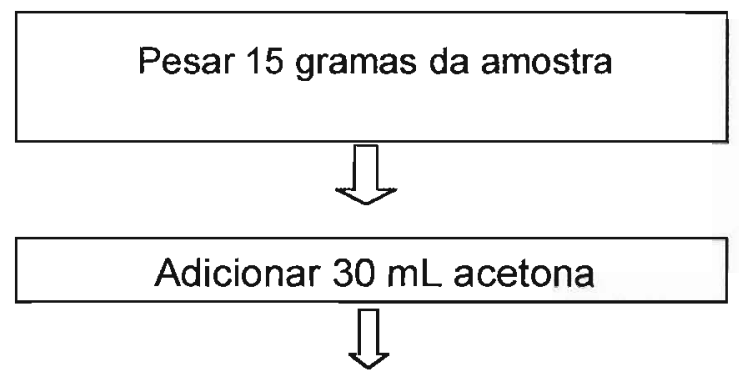

Agitar em ultraturrax por 60 segundos
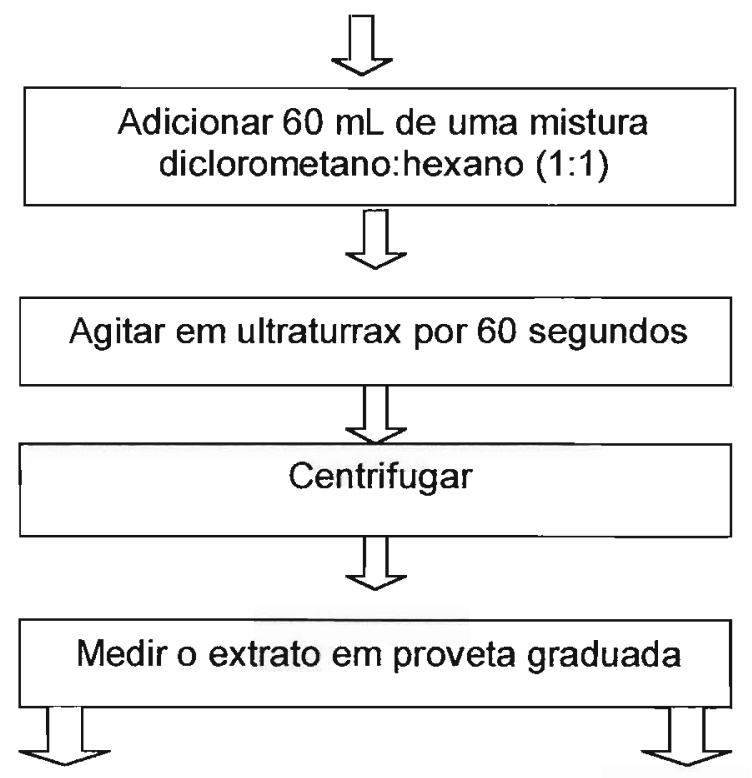

Transferir $0,40 \mathrm{~mL}$ do extrato para frasco próprio para injetor automático e deixar evaporar todo solvente

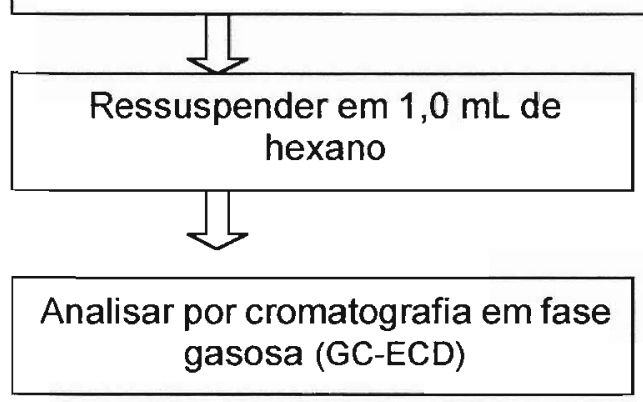

Transferir $25 \mathrm{~mL}$ do extrato para balão de fundo chato com boca esmerilhada de $125 \mathrm{~mL}$ e concentrar no evaporador rotatório

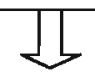

Ressuspender em 2,5 $\mathrm{mL}$ de uma mistura Isooctano:Tolueno 9:1

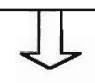

Analisar por cromatografia em fase gasosa (GC-FPD) 


\section{9- EFEITO MATRIZ}

O efeito matriz é uma característica conhecida em análise de residuos de pesticidas; caracteriza-se por resultados acima dos esperados nos estudos de recuperação, ou seja, adicionando-se uma quantidade conhecida de pesticida na amostra os resultados de recuperação apresentam-se superiores ao adicionado.

A teoria recentemente proposta é que os sitios ativos do sistema cromatográfico principalmente do liner do injetor são bloqueados por componentes da matriz, o que leva a resultados de recuperação superiores aos esperados (Schenck et al.,2000; Hajslová et al., 1998).

No preparo de uma solução padrão, os pesticidas são diluídos em solvente e, durante a injeção estes sofrem uma interação com o bloco de injeção adsorvendose nos sítios ativos; já quando injeta-se uma amostra que contenha os pesticidas componentes da matriz, bloqueiam os sítios ativos do sistema fazendo com que o pesticida passe diretamente para coluna e detector, levando a resultados superiores aos esperados.

Johnson e colaboradores estudando 26 pesticidas diferentes encontraram resultados de recuperação elevados em amostras de vegetais, para o demeton, parationa metílico, parationa etílico e cianazina ; eles corrigiram este problema através do uso de solução padrão feita no extrato da matriz.

O efeito matriz está relacionado a quatro fatores distintos : natureza do pesticida, natureza da matriz, interação pesticida-matriz e sistema cromatográfico. A literatura (Schenck et al.,2000; Johnson et al.,1997; Cabras et al.,1997) mostra alguns caminhos para minimizar este efeito:

- uso de padrão preparado no extrato da amostra testemunha,

- uso da adição de padrão,

- purificação da amostra,

- uso de padrão radiomarcado,

- injeção on-colon,

- preenchimento dos sítios ativos do sistema,

- compensação do cálculo através de um fator que corrija o efeito matriz. 
O uso de solução padrão feita no extrato da amostra testemunha parece ser o método mais comumente aceito (Johnson et al.,1997; Cabras et al.,1997; Rizos et al.,2001; Jimenez et al., 1998).

A purificação da amostra também é um dos procedimentos utilizados (Schenck et al., 2000); porém, Jimenez e colaboradores analisando mel após purificação em coluna de florisil observaram o efeito matriz e relataram que este ocorre mais significativamente em concentrações inferiores. Eles fortificaram amostras em niveis variando de 0,025 a $2,5 \mathrm{mg} / \mathrm{kg}$ e chegaram em recuperações perto de $100 \%$ no nível mais alto e em alguns casos acima de $1000 \%$ no nível de 0,025 $\mathrm{mg} / \mathrm{kg}$. Eles tentaram corrigir o problema de duas formas: fazendo a solução padrão no solvente:extrato da amostra 1:1 e no extrato puro da amostra; o fosalona, parationa, malationa e forato só obtiveram resultados aceitáveis de recuperação quando a solução padrão foi preparada no extrato puro da matriz.

A utilização de métodos de purificação torna a análise mais cara, leva a um consumo maior de solventes, gera uma maior quantidade de resíduos tóxicos e aumenta os passos da análise.

Estudar o efeito matriz é uma tarefa difícil já que muitos fatores estão envolvidos, a análise cromatográfica não é estática já que matrizes diferentes são injetadas no cromatógrafo. O sistema cromatográfico muda conforme componentes da matriz são depositados no liner do injetor e na entrada da coluna. A constituição do liner pode não ser exatamente a mesma dependendo do fabricante e até do lote; os pesticidas também são diferentes e a cada dia novos compostos são sintetizados.

Schenck e colaboradores (2000) ao estudarem o efeito matriz em compostos organofosforados relataram que os pesticidas com ligação $P=O$ tem uma maior tendência a apresentar o efeito matriz do que aqueles que não possuem. Os compostos com 2 ligações $\mathrm{C}=\mathrm{O}$ também apresentaram uma certa tendência $\mathrm{a}$ apresentarem o efeito matriz.

Em nosso trabalho das 5 compostos que apresentaram o efeito matriz 2 delas: 0 sulfato endosulfan e azoxistrobina apresentaram o efeito matriz no menor nível de concentração do pesticida e não apresentaram quando a quantidade adicionada foi maior. 
Tabela XI : Recuperação do sulfato endosulfam e azoxistrobina em 6 amostras de manga comparando-se com o padrão preparado em hexano

\begin{tabular}{|c|c|c|c|c|c|c|c|}
\hline Pesticida & $\begin{array}{c}\text { Quantidade } \\
\text { Adicionada } \\
\text { (mg } / \mathrm{kg})\end{array}$ & $\begin{array}{c}\text { A } \\
\text { \%Recuperada }\end{array}$ & $\begin{array}{c}\text { B } \\
\text { \%Recuperada }\end{array}$ & $\begin{array}{c}\text { C } \\
\text { \%Recuperada }\end{array}$ & $\begin{array}{c}\text { D } \\
\text { \%Recuperada }\end{array}$ & $\begin{array}{c}\text { E } \\
\text { \%Recuperada }\end{array}$ & $\begin{array}{c}\text { F } \\
\text { \%Recuperada }\end{array}$ \\
\hline $\begin{array}{l}\text { Sulfato } \\
\text { endosulfam }\end{array}$ & 0,05 & 100 & 140 & 120 & 100 & 120 & 120 \\
\hline azoxistrobina & 0,40 & 120 & $14 \overline{3}$ & $14 \overline{0}$ & 133 & 140 & * \\
\hline
\end{tabular}

$A, B, C, D, E, F:$ amostras fortificadas com a solução padrão

* amostra não analisada

Tabela XII : Recuperação do sulfato endosulfam e azoxistrobina em 6 amostras de manga comparando-se com o padrão preparado no extrato da amostra testemunha

\begin{tabular}{l|c|c|c|c|c|c|c}
\hline Pesticida & $\begin{array}{c}\text { Quantidade } \\
\text { Adicionada } \\
(\mathrm{mg} / \mathrm{kg})\end{array}$ & $\begin{array}{c}\mathrm{A} \\
\text { \%Recuperada }\end{array}$ & $\begin{array}{c}\mathrm{B} \\
\text { \%Recuperada }\end{array}$ & $\begin{array}{c}\mathrm{C} \\
\text { \%Recuperada }\end{array}$ & $\begin{array}{c}\mathrm{D} \\
\text { \%Recuperada }\end{array}$ & $\begin{array}{c}\mathrm{E} \\
\text { \%Recuperada }\end{array}$ & $\begin{array}{c}\text { \%Recuperada } \\
\text { sulfato } \\
\text { endosulfam }\end{array}$ \\
\hline \%,05 & 80 & 100 & 100 & 80 & 100 & 100 \\
\hline $\begin{array}{l}\text { sulfato } \\
\text { endosulfam }\end{array}$ & 0,50 & 90 & 82 & 88 & 82 & 82 & 92 \\
\hline axoxistrobina & 0,40 & 93 & 110 & 110 & 103 & 108 & $*$ \\
\hline azoxoxistrobina & 4,00 & 87 & 76 & 88 & 77 & 75 & 89 \\
\hline
\end{tabular}

$A, B, C, D, E, F$ : amostras fortificadas com a solução padrão

* amostra não analisada

Os outros 3 compostos: difenoconazol, procloraz e fosmete apresentaram problemas devido ao efeito matriz nos dois níveis de fortificação.

A tabela XIII mostra os resultados de recuperação quando a solução padrão de Difenoconazol e Procloraz foram preparadas em hexano. 
Tabela XIII : Recuperação do difenoconazol, procloraz e fosmete em 6 amostras de manga comparando-se com o padrão preparado em hexano

\begin{tabular}{l|c|c|c|c|c|c|c}
\hline Pesticida & $\begin{array}{c}\text { Quantidade } \\
\text { Adicionada } \\
(\mathrm{mg} / \mathrm{kg})\end{array}$ & $\begin{array}{c}\mathrm{A} \\
\text { \%Recuperada }\end{array}$ & $\begin{array}{c}\mathrm{B} \\
\text { \%Recuperada }\end{array}$ & $\begin{array}{c}\mathrm{C} \\
\text { \%Recuperada }\end{array}$ & $\begin{array}{c}\mathrm{D} \\
\text { \%Recuperada }\end{array}$ & $\begin{array}{c}\mathrm{E} \\
\text { \%Recuperada }\end{array}$ & $\begin{array}{c}\mathrm{F} \\
\text { \%Recuperada }\end{array}$ \\
\hline difenoconazol & 0,20 & 150 & 146 & 162 & 162 & 138 & 160 \\
\hline difenoconazol & 2,00 & 140 & 145 & 152 & 140 & 149 & 155 \\
\hline procloraz & 0,20 & 131 & 123 & 138 & 146 & 123 & 155 \\
\hline procloraz & 2,00 & 150 & 142 & 144 & 140 & 140 & 142 \\
\hline fosmete & 0,05 & 149 & 157 & 127 & 149 & 133 & 152 \\
\hline fosmete & 0,50 & 122 & 129 & 136 & 106 & 149 & 157 \\
\hline
\end{tabular}

A,B,C,D,E,F: amostras fortificadas com a solução padrão

A tabela XIV mostra os resultados de recuperação quando o padrão foi preparado no extrato da amostra testemunha resuspendido em hexano em dois níveis diferentes

Tabela XIV: Recuperação do difenoconazol , procloraz e fosmete em 6 amostras de manga comparando-se com o padrão preparado no extrato da amostra testemunha

\begin{tabular}{l|c|c|c|c|c|c|c}
\hline Pesticida & $\begin{array}{c}\text { Quantidade } \\
\text { Adicionada } \\
(\mathrm{mg} / \mathrm{kg})\end{array}$ & $\begin{array}{c}\mathrm{A} \\
\text { \%Recuperada }\end{array}$ & $\begin{array}{c}\mathrm{B} \\
\text { \%Recuperada }\end{array}$ & $\begin{array}{c}\mathrm{C} \\
\text { \%Recuperada }\end{array}$ & $\begin{array}{c}\mathrm{D} \\
\text { \%Recuperada }\end{array}$ & $\begin{array}{c}\mathrm{E} \\
\text { \%Recuperada }\end{array}$ & $\begin{array}{c}\mathrm{F} \\
\text { \%Recuperada }\end{array}$ \\
\hline difenoconazol & 0,20 & 90 & 85 & 95 & 97 & 107 & 92 \\
\hline difenoconazol & 2,0 & 81 & 94 & 95 & 92 & 95 & 96 \\
\hline procloraz & 0,20 & 87 & 84 & 77 & 83 & 92 & 79 \\
\hline procloraz & 2,0 & 96 & 103 & 108 & 94 & 99 & 109 \\
\hline fosmete & 0,05 & 108 & 91 & 93 & 101 & 92 & 102 \\
\hline fosmete & 0,50 & 85 & 90 & 95 & 74 & 77 & 79 \\
\hline
\end{tabular}

A,B,C,D,E,F: amostras fortificadas com a solução padrão

A figura 2 mostra o padrão de procloraz e difenoconazol preparado em hexano, a figura 3 mostra o padrão de procloraz e difenoconazol preparado no extrato da amostra testemunha e a figura 4 mostra a recuperação do procloraz a $1,0 \mathrm{mg} / \mathrm{kg}$ e Difenoconazol $2,0 \mathrm{mg} / \mathrm{kg}$. 


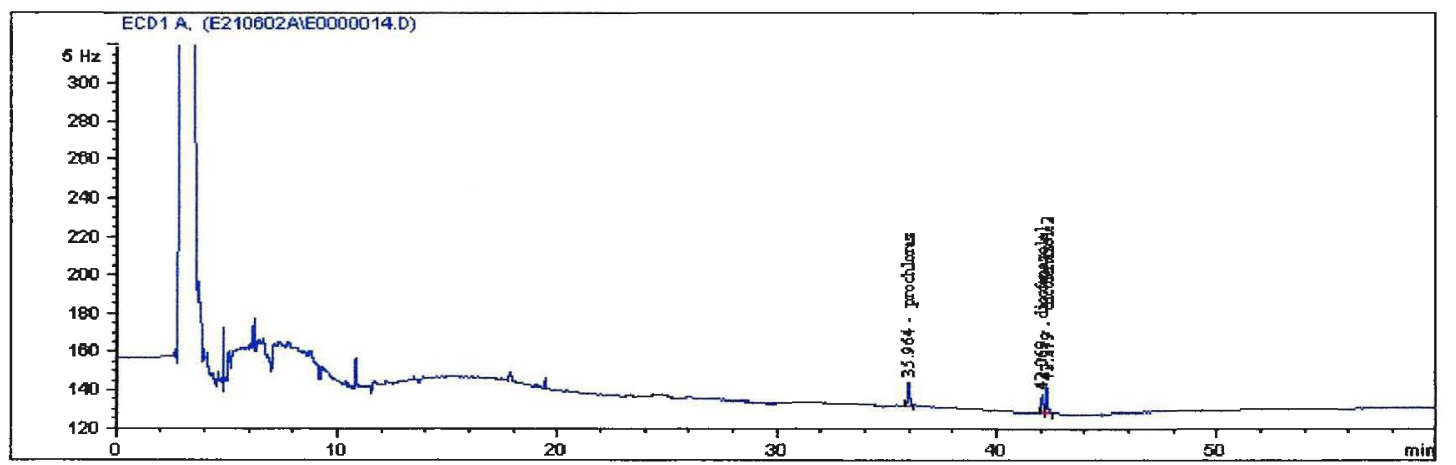

Figura 2:Padrão procloraz (Área $=87,24$ ) e difenoconazol (Área $=152,94) 75 \mathrm{pg} / \mathrm{uL}$ em hexano

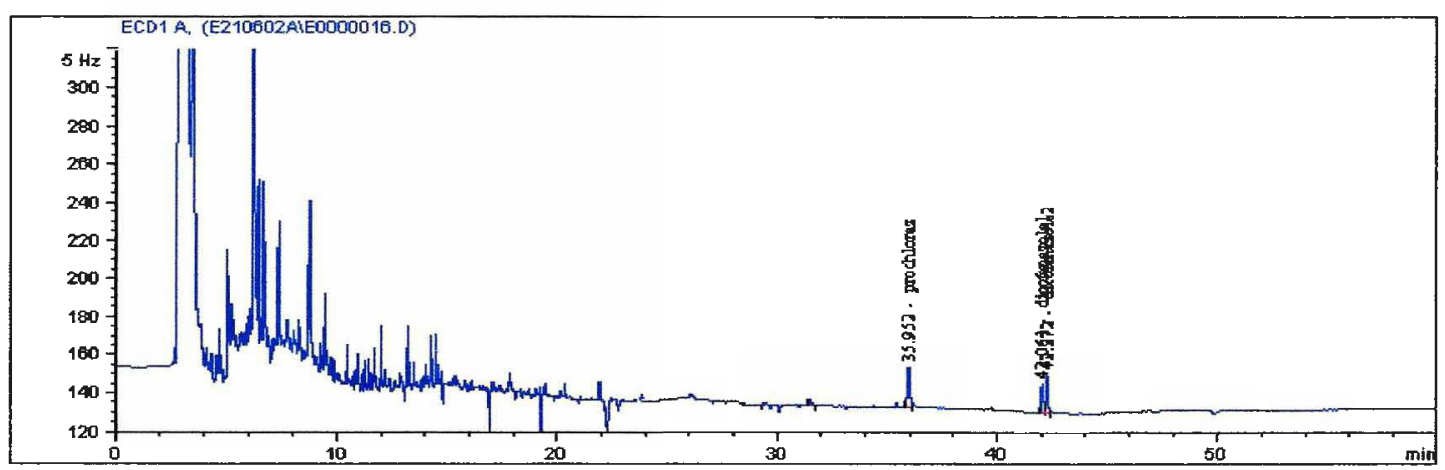

Figura 3: Padrão procloraz (Área $=147,24)$ e difenoconazol (Área $=221,49) 75 \mathrm{pg} / \mathrm{uL}$ pg/uL no extrato da matriz

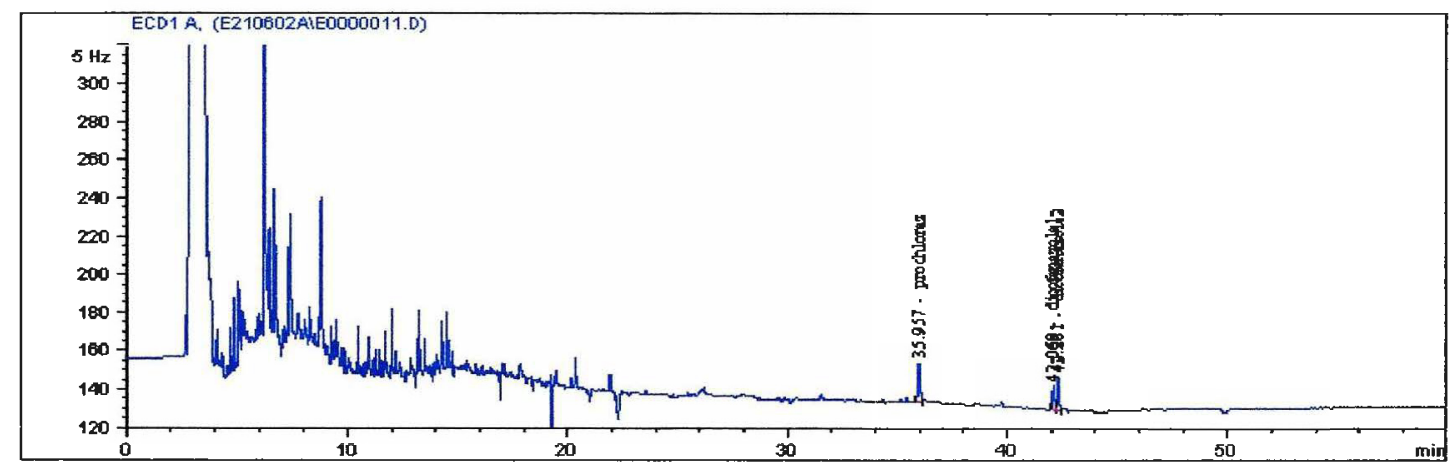

Figura 4: Recuperação: Amostra fortificada com procloraz $1,0 \mathrm{mg} / \mathrm{kg}$ e difenoconazol 2,0 mg/kg que corresponde ao padrão de procloraz e difenoconazol $75 \mathrm{pg} / \mathrm{uL}$

Como vemos nas figuras 2,3 e 4, o procloraz e o difenoconazol apresentam uma área maior quando o padrão é feito no extrato da amostra testemunha; utilizando-se o padrão preparado em hexano encontra-se recuperações acima dos níveis aceitáveis. 


\section{0-RESULTADOS}

\subsection{Linearidade}

A linearidade de todos os pesticidas estudados foi obtida através das curvas analíticas onde o coeficiente de correlação quadrado foi igual ou superior a 0,99 estando de acordo com as especificações do EPA (1996).

As curvas analíticas foram preparadas em 6 concentrações com a injetando-se 5 vezes cada ponto. A faixa variou de 0,5 até 10 vezes o menor valor adicionado na fortificação.

Curva Analítica dos Pesticidas Estudados

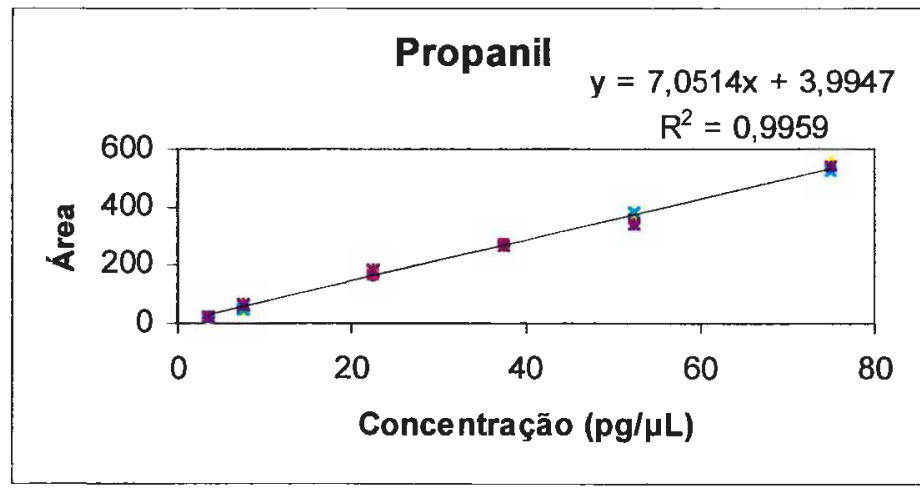

Figura 5-Curva Analítica Propanil

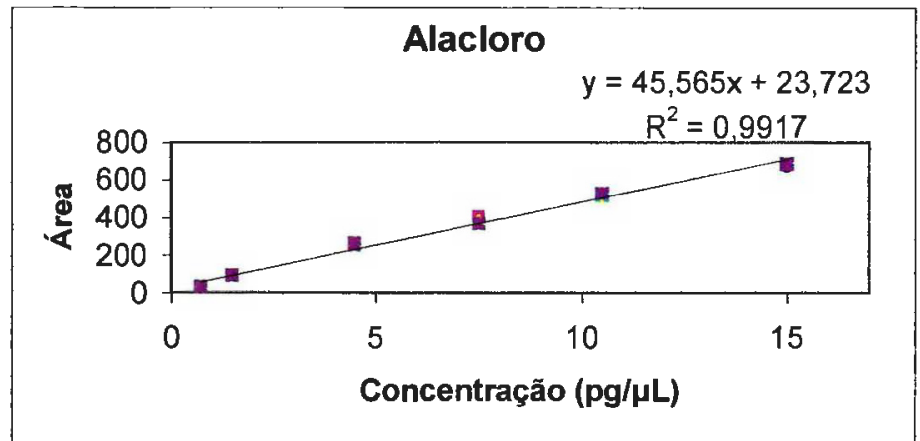

Figura 6 - Curva Analítica Alacloro 


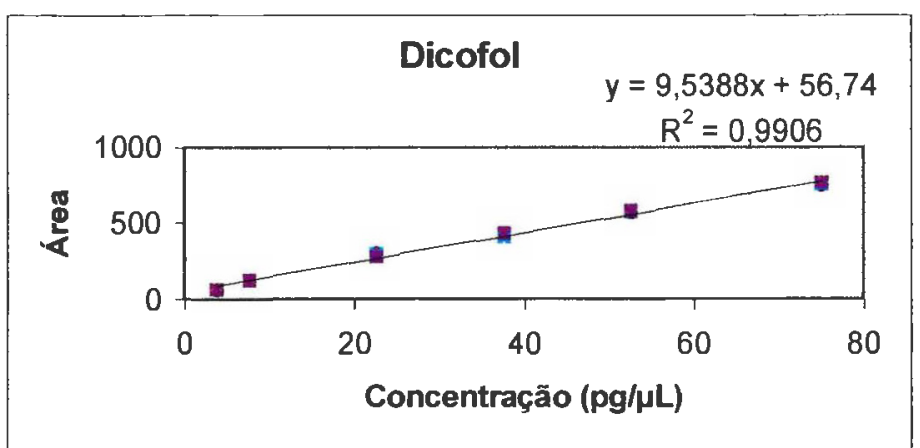

Figura 7 - Curva Analítica Dicofol

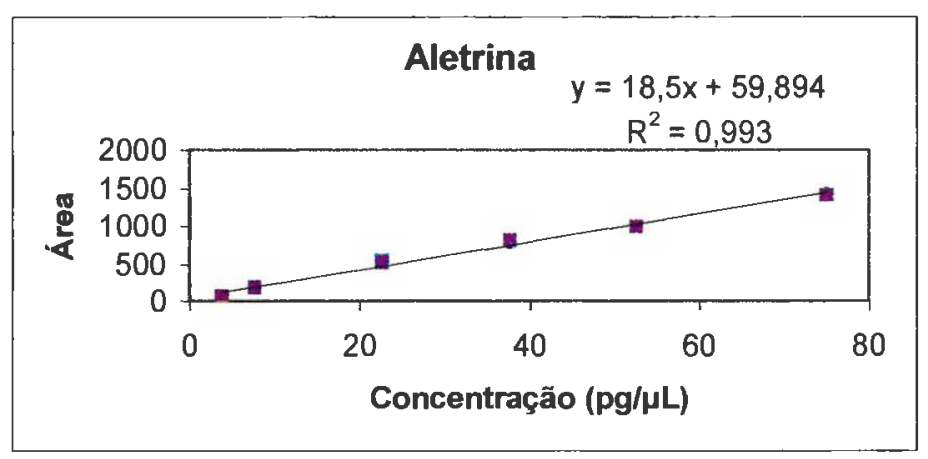

Figura 8 - Curva Analítica Aletrina

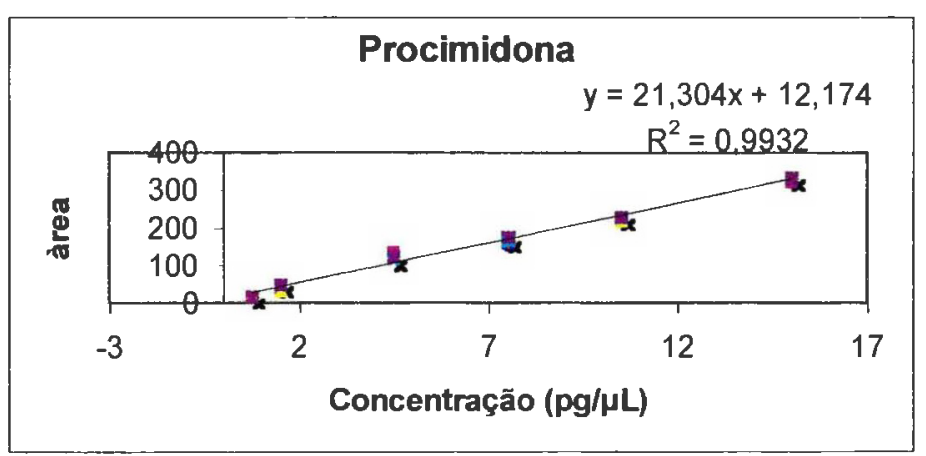

Figura 9 - Curva Analítica Procimidona

B | B L IOTECA INSTITUTO DE QUIMICA Universidade de São Paulo 


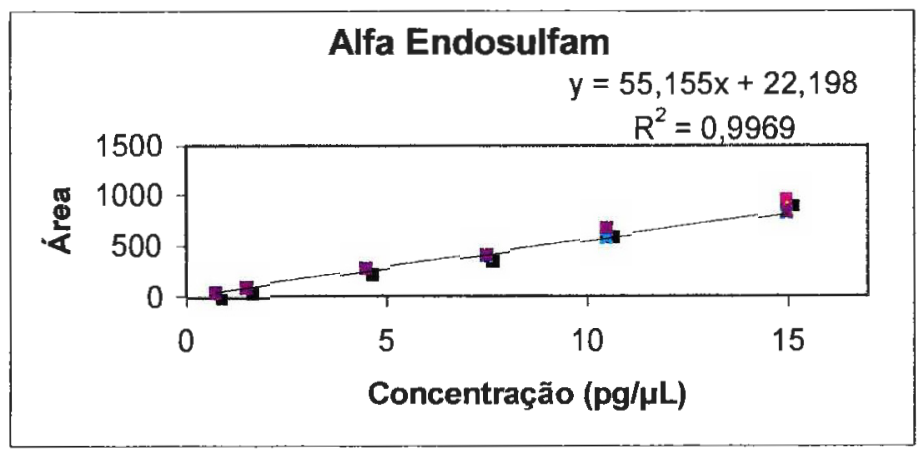

Figura 10 - Curva Analítica Alfa Endosulfam

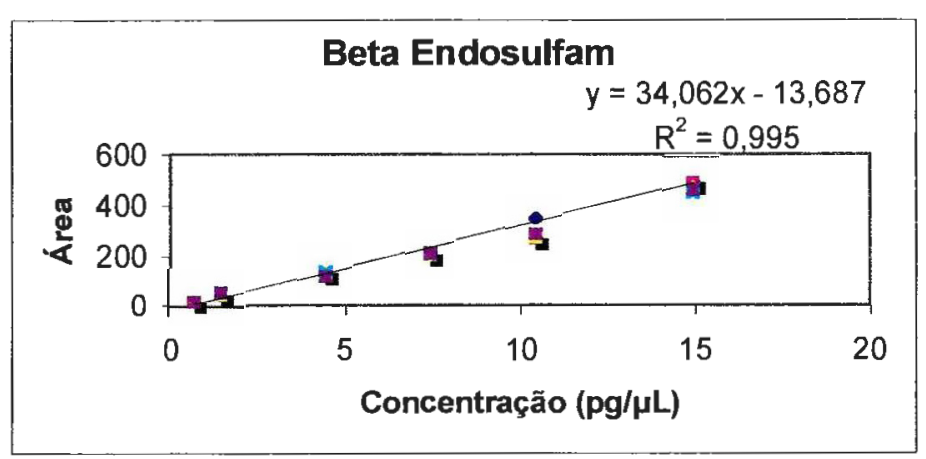

Figura 11 - Curva Analítica Beta Endosulfam

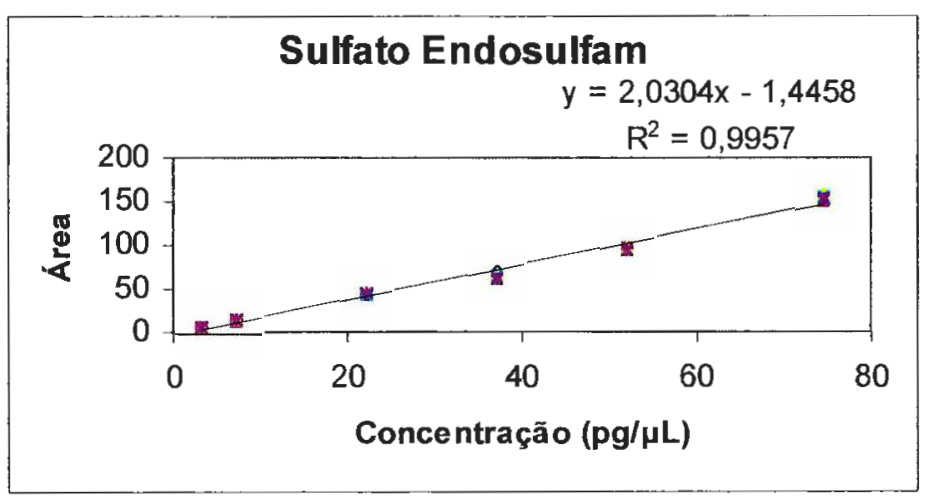

Figura 12 - Curva Analítica Sulfato Endosulfam 


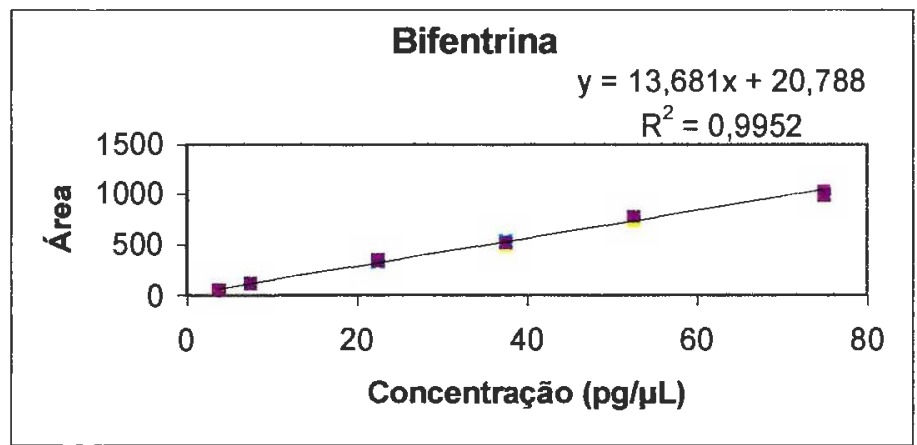

Figura 13 - Curva Analítica Bifentrina

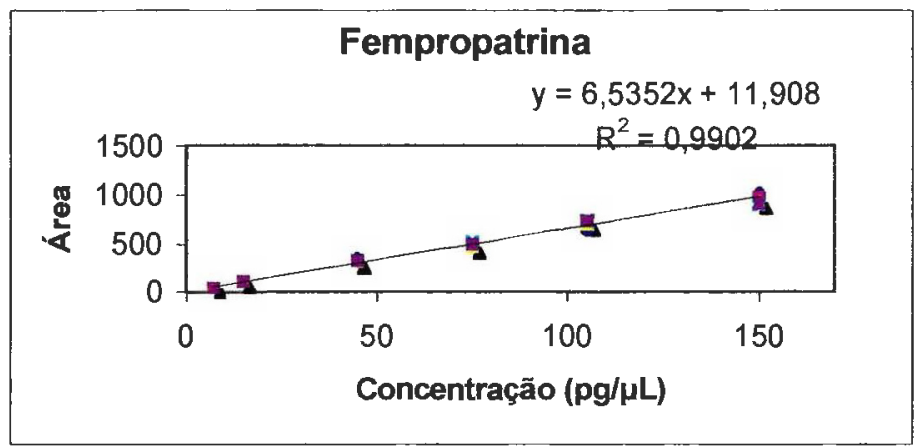

Figura 14 - Curva Analítica Fempropatrina

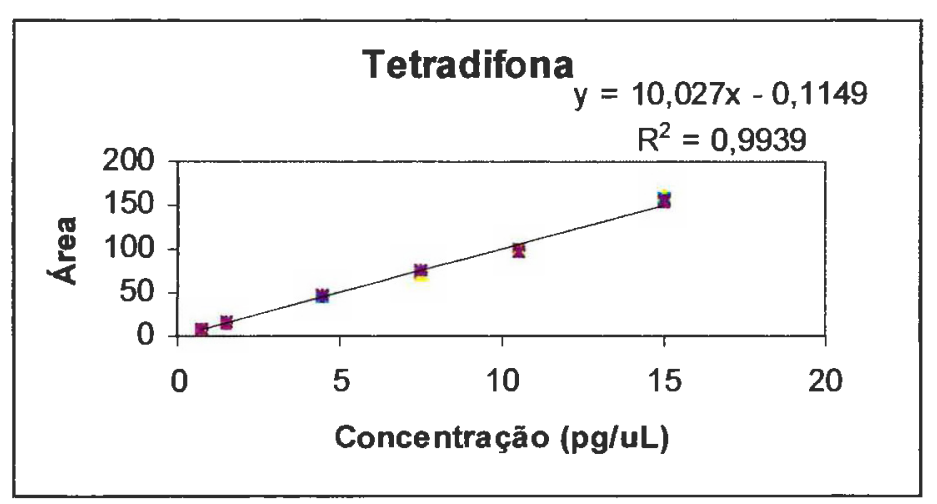

Figura 15 - Curva Analítica Tetradifona 


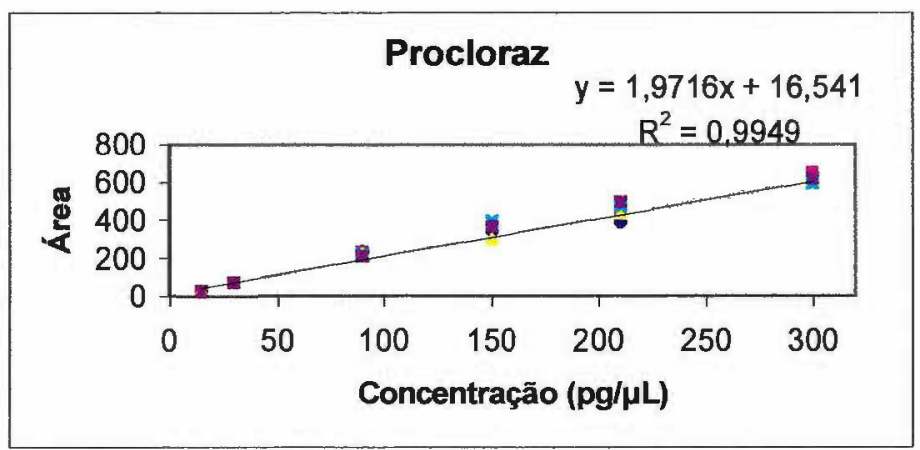

Figura 16 - Curva Analítica Procloraz

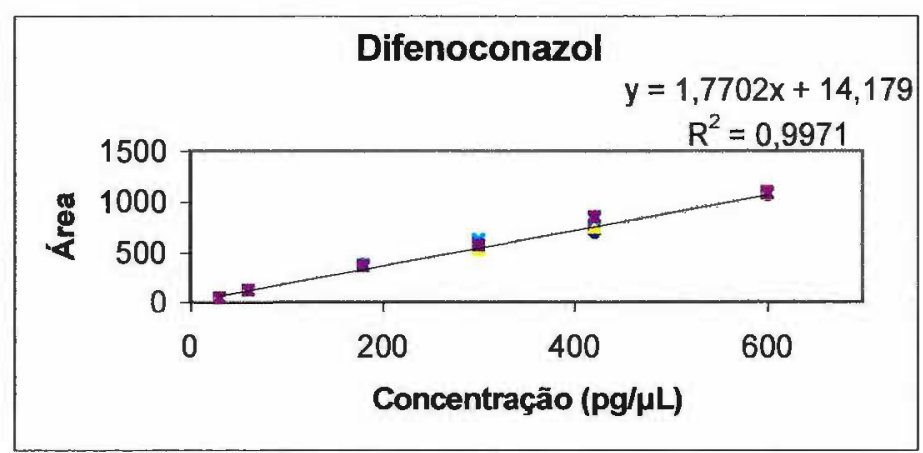

Figura 17 - Curva Analítica Difenoconazol

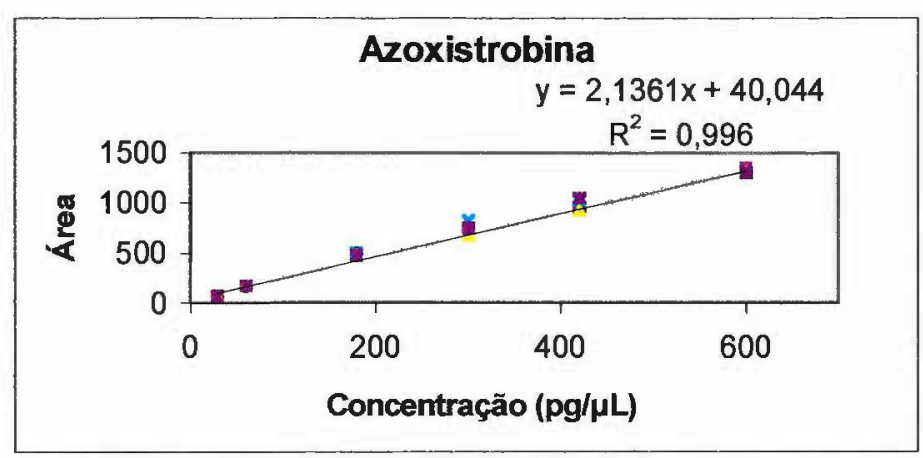

Figura 18 - Curva Analítica Azoxistrobina 


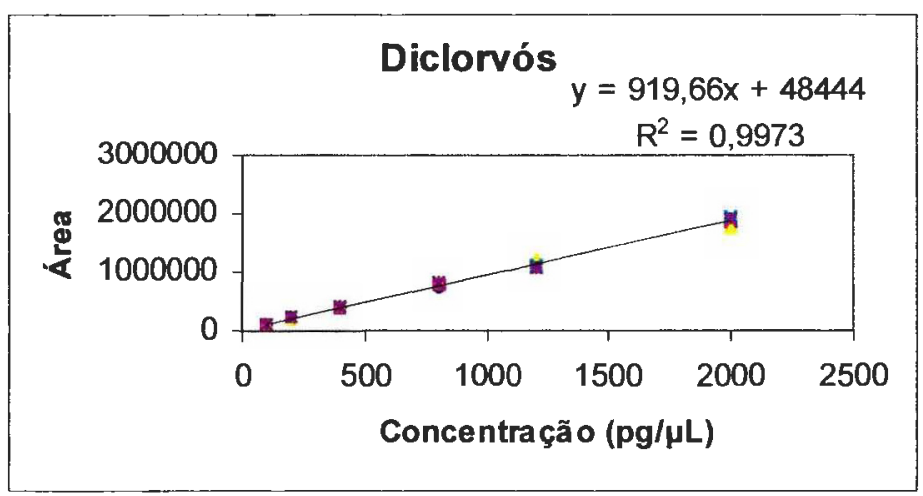

Figura 19 - Curva Analítica Diclorvós

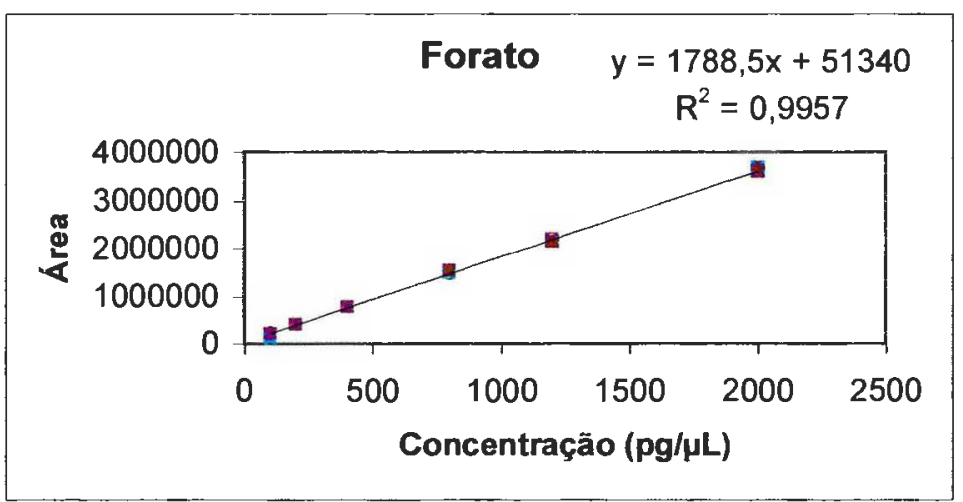

Figura 20 - Curva Analítica Forato

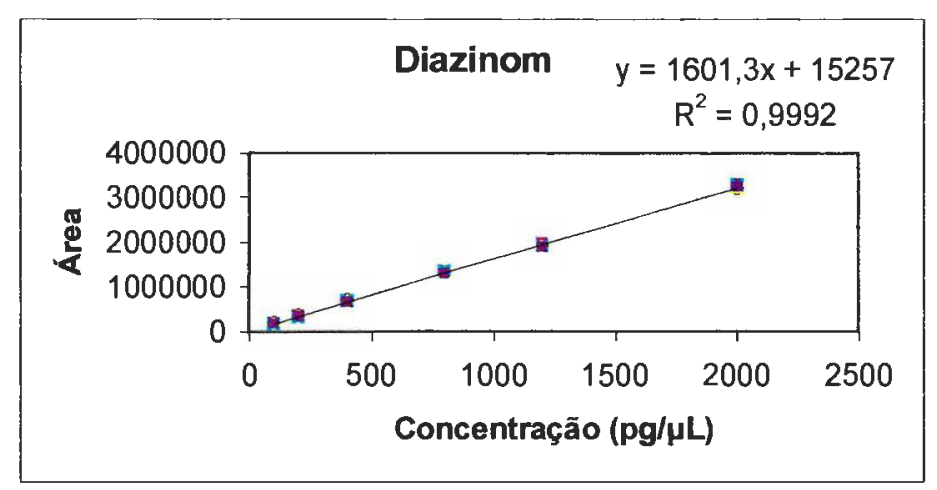

Figura 21 -Curva Analítica Diazinom 


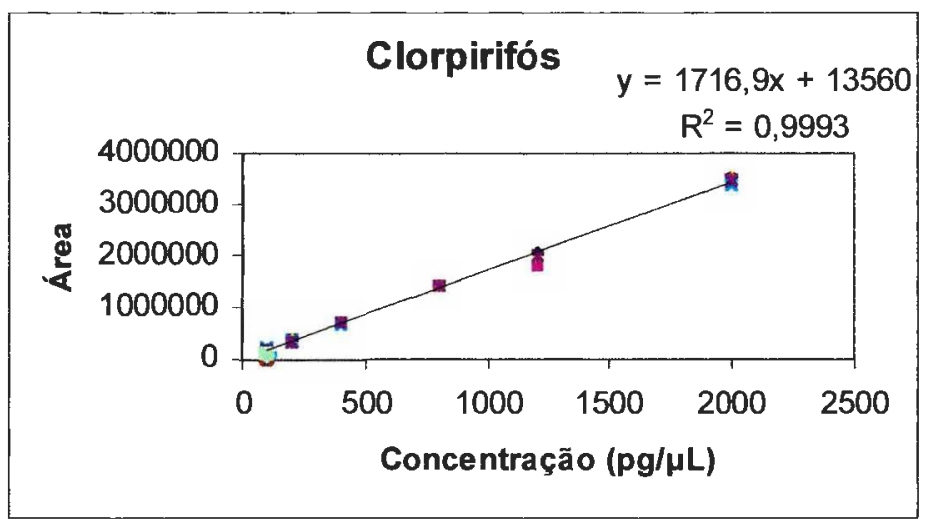

Figura 22 - Curva Analítica Clórpirifos

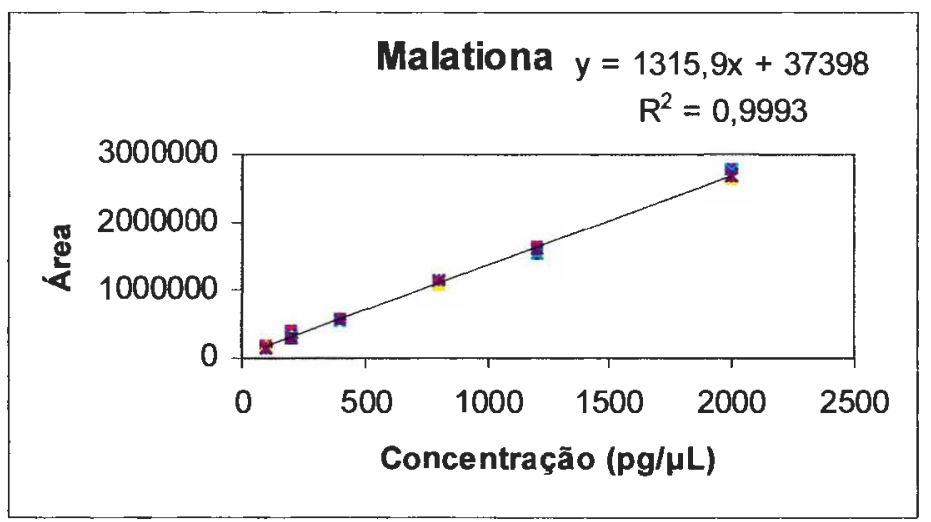

Figura 23 - Curva Analítica Malationa

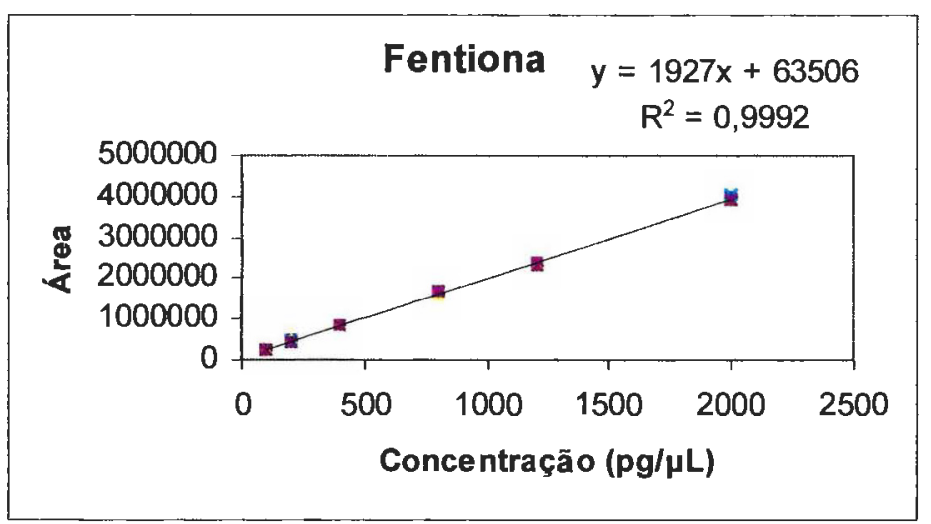

Figura 24 - Curva Analítica Fentiona 


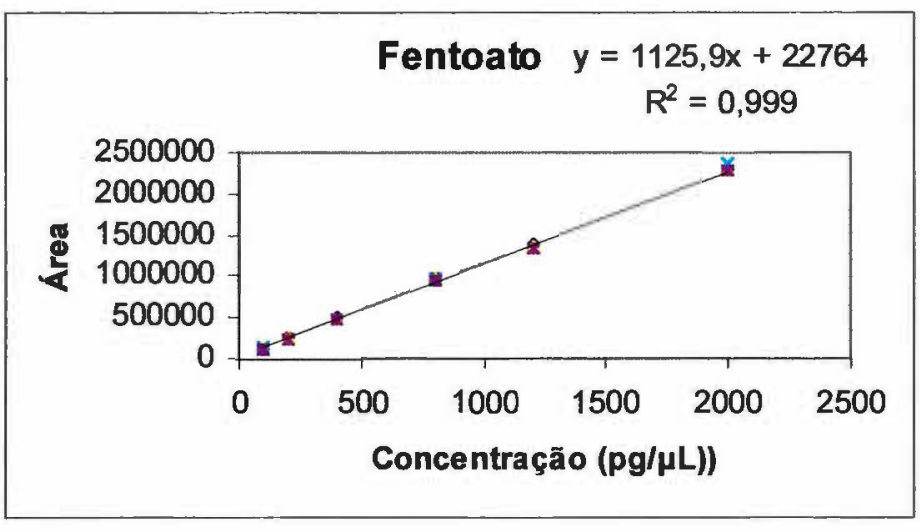

Figura 25 - Curva Analítica Fentoato

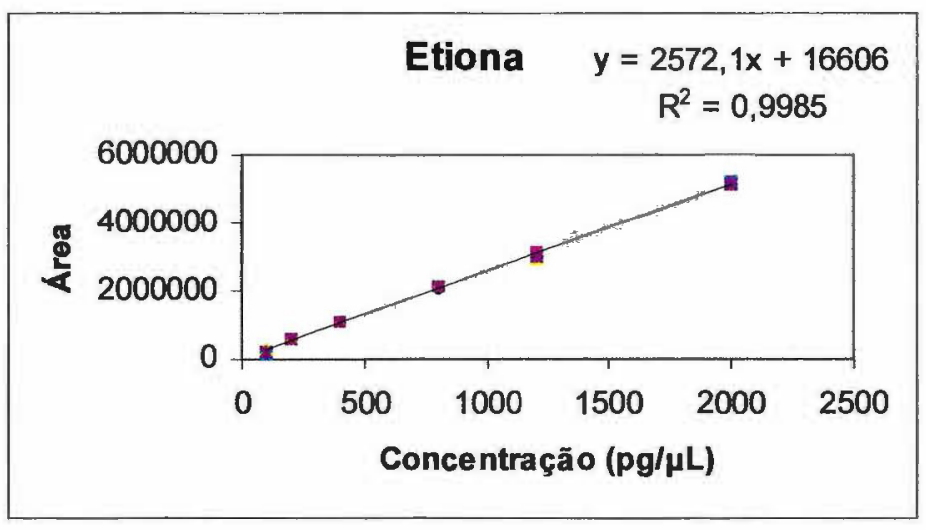

Figura 26-Curva Analítica Etiona

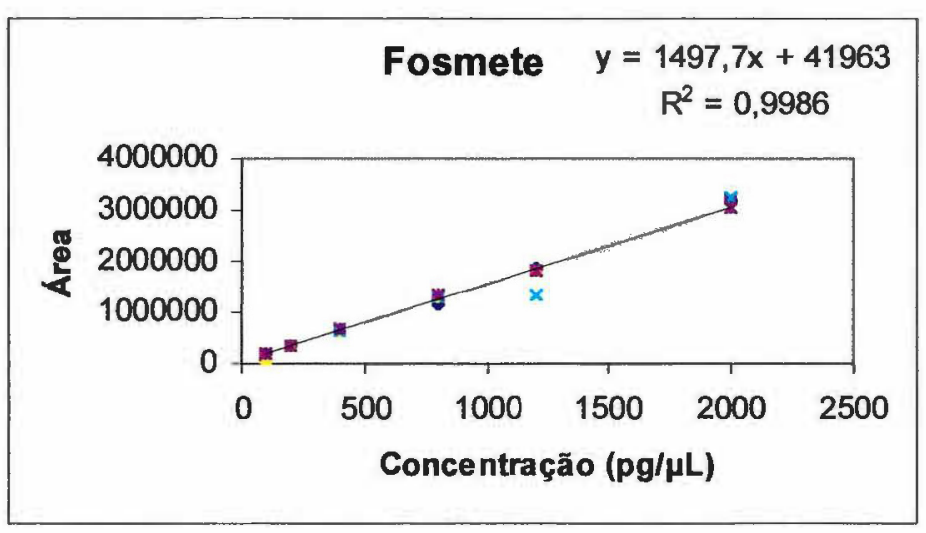

Figura 27-Curva Analítica Fosmete 


\subsection{Especificidade}

A especificidade do método foi obtida através da análise do branco dos reagentes e da amostra testemunha para verificar se possiveis interferentes não estariam presentes na amostra. As figuras 28,29 e 30 mostram os cromatogramas do branco dos reagentes, da amostra testemunha e dos padrões analisados no ECD, respectivamente. As figuras 31, 32 e 33 mostram os cromatogramas do branco dos reagentes, da amostra testemunha e dos padrões analisados no FPD, respectivamente.

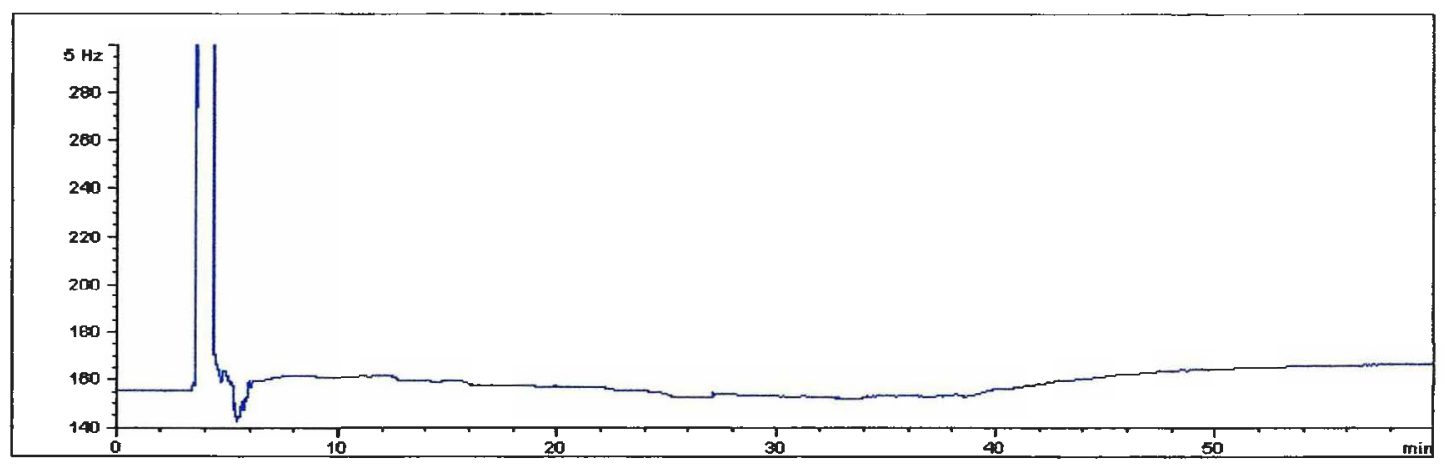

Figura 28: Cromatograma do branco dos reagentes analisado por cromatografia a gás com detector de captura de elétrons

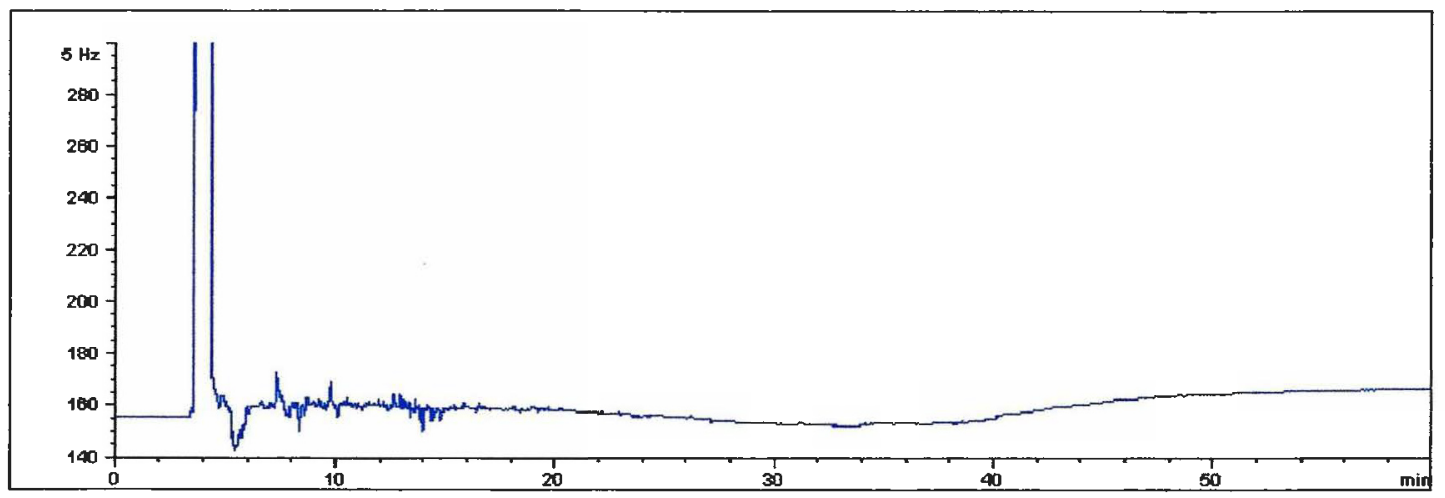

Figura 29: Cromatograma da amostra testemunha analisada por cromatografia a gás com detector de captura de elétrons 


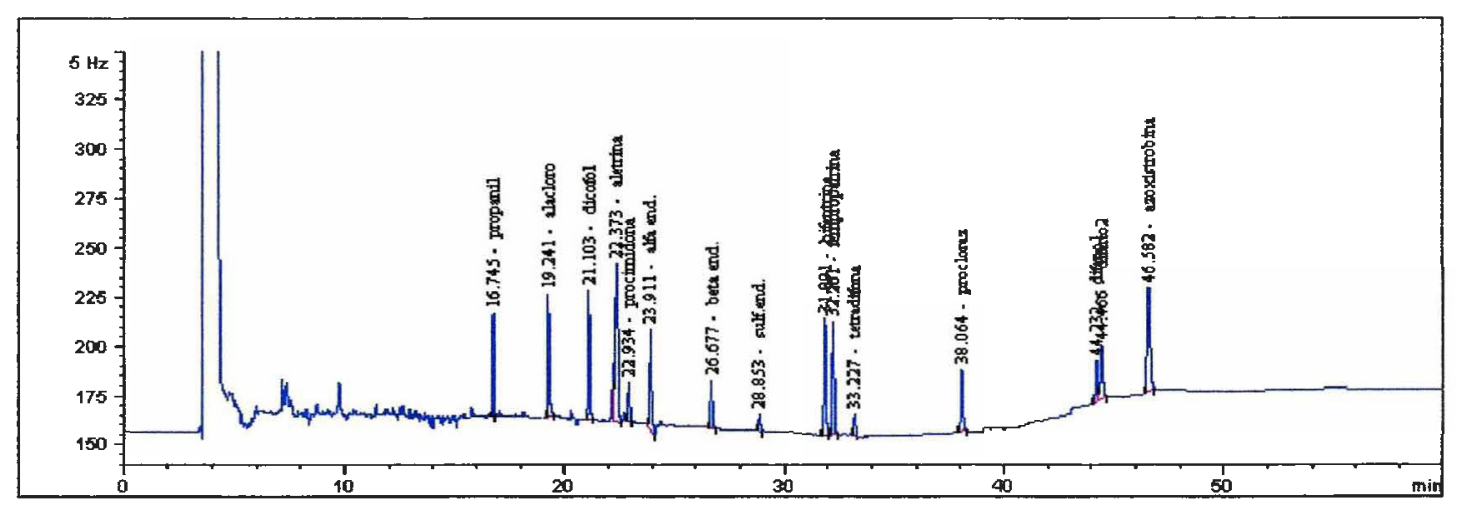

Figura 30: Cromatograma ds pesticidas organoclorados, piretróides e azoxistrobina analisados por cromatografia a gás com detector de captura de elétrons

Condiçōes Cromatográficas:

Injetor: $250^{\circ} \mathrm{C}$ modo de injeçăo splitless volume de injeção $2 \mu \mathrm{L}$

Detector: $320^{\circ} \mathrm{C}$

Forno: $60^{\circ} \mathrm{C}$ por 1 minuto, $10^{\circ} \mathrm{C}$ por minuto até $220^{\circ} \mathrm{C}$ (mantém por 6 minutos), $3^{\circ} \mathrm{C}$ por minuto até $280^{\circ} \mathrm{C}$ (manteém por 17 minutos).

Coluna: HP 530 metros de comprimento,, diâmetro interno de $0,32 \mathrm{~mm}, 0,25 \mu \mathrm{m}$ de espessura de filme

Gás de arraste: nitrogênio 


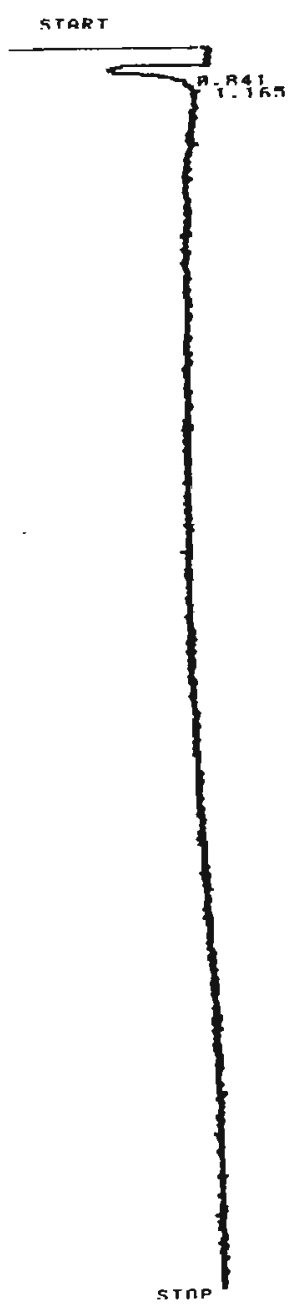

Figura 31

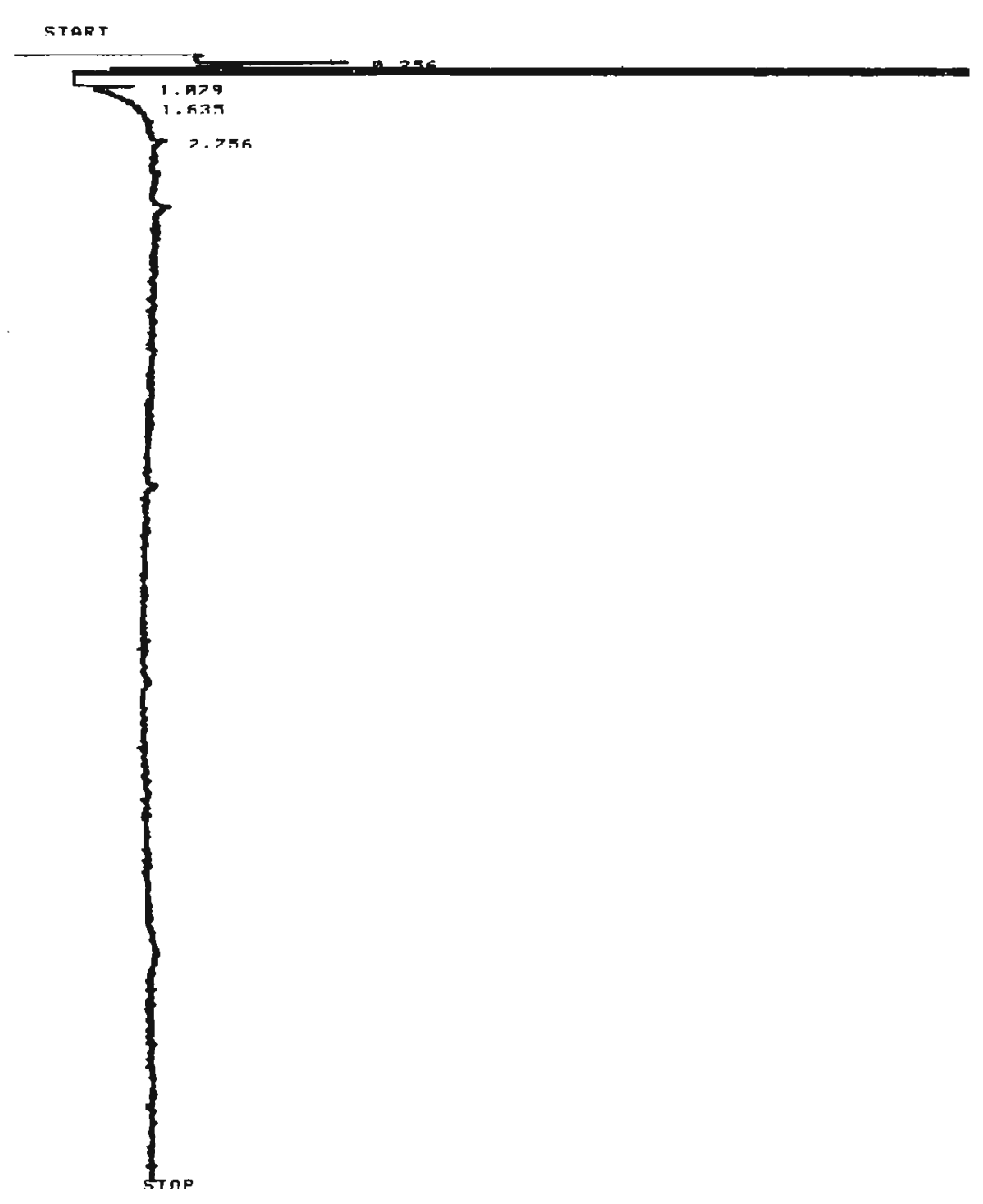

Figura 32

Figura 31 : Cromatograma do branco dos reagentes analisado por cromatografia a gás com detector fotométrico de chama.

Figura 32 : Cromatograma da amostra testemunha analisada por cromatografia a gás com detector fotométrico de chama. 


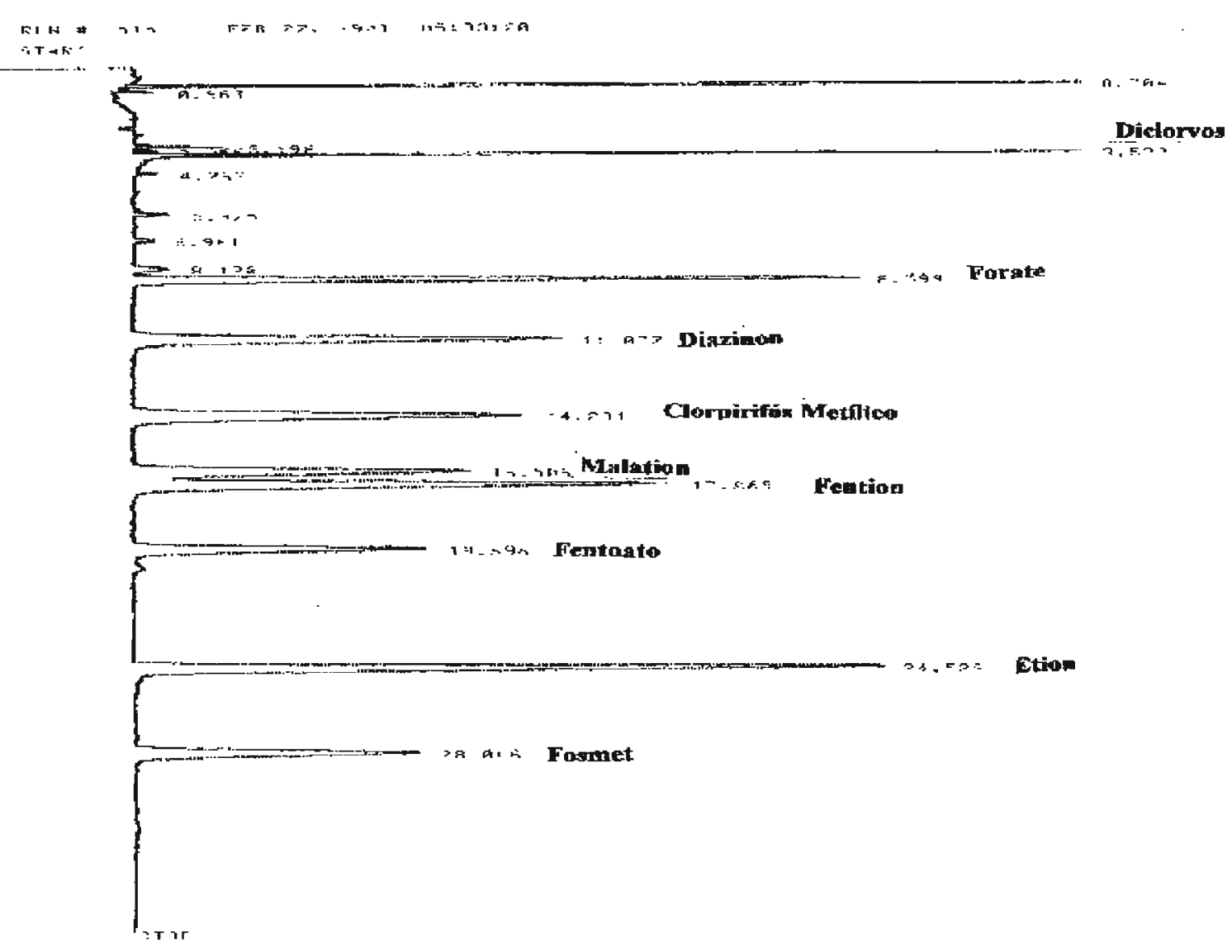

Figura 33: Cromatograma dos pesticidas organofosforados analisados por cromatografia a gás com detector fotométrico de chama.

Condições Cromatográficas:

Injetor: $240^{\circ} \mathrm{C}$ modo de injeção splitless, volume de injeção $2 \mu \mathrm{L}$

Detector: $300^{\circ} \mathrm{C}$

Forno: $90^{\circ} \mathrm{C}, 30^{\circ} \mathrm{C}$ por minuto até $190^{\circ} \mathrm{C}$ (mantém por 5 minutos), $5^{\circ} \mathrm{C}$ por minuto até $300^{\circ} \mathrm{C}$ (mantém por 10 minutos).

Coluna: HP 530 metros de comprimento, diâmetro interno de $0,53 \mathrm{~mm}, 2,65 \mu \mathrm{m}$ de espessura de filme

Gás de arraste: nitrogênio

Fluxo do gás de arraste: $18 \mathrm{~mL} /$ minuto

Fluxo do hidrogênio: $75 \mathrm{~mL} /$ minuto

Fluxo do ar sintético: $100 \mathrm{~mL} /$ minuto 


\subsection{Estudos de Recuperação}

A exatidão do método foi testada através da fortificação de 6 amostras testemunha em dois niveis diferentes totalizando 10 análises de recuperação para cada princípio ativo. As recuperações variaram de $70-120 \%$ e o coeficiente de variação não ultrapassou os $20 \%$, o que satisfaz as exigências do EPA (1996) para análise de resíduos de pesticidas.

Tabela XV: Recuperação Média das fortificações com propanil, desvio padrão e coeficiente de variação.

\begin{tabular}{|c|c|c|c|c|c|}
\hline $\begin{array}{c}\text { Nivel de } \\
\text { Fortificação } \\
\mathrm{mg} / \mathrm{kg}\end{array}$ & $\begin{array}{c}\text { Valor } \\
\text { encontrado } \\
\text { mg/kg }\end{array}$ & $\begin{array}{c}\text { Recuperação } \\
\%\end{array}$ & $\begin{array}{c}\text { Recuperação } \\
\text { Média } \\
\%\end{array}$ & \begin{tabular}{|l|} 
Desvio \\
Padrão
\end{tabular} & CV \\
\hline 0,050 & 0,060 & 120 & \multirow{6}{*}{118} & \multirow{6}{*}{2} & \multirow{6}{*}{2} \\
\hline 0,050 & 0,059 & 118 & & & \\
\hline 0,050 & 0,060 & 120 & & & \\
\hline 0,050 & 0,058 & 116 & & & \\
\hline 0,050 & 0,058 & 116 & & & \\
\hline 0,050 & 0,060 & 120 & & & \\
\hline 0,10 & 0,11 & 110 & \multirow{6}{*}{117} & \multirow{6}{*}{5} & \multirow{6}{*}{4} \\
\hline 0,10 & 0,11 & 110 & & & \\
\hline 0,10 & 0,12 & 120 & & & \\
\hline 0,10 & 0,12 & 120 & & & \\
\hline 0,10 & 0,12 & 120 & & & \\
\hline 0,10 & 0,12 & 120 & & & \\
\hline
\end{tabular}

Tabela XVI: Recuperação Média das fortificações com Alacloro, desvio padrão e coeficiente de variação

\begin{tabular}{|c|c|c|c|c|c|}
\hline $\begin{array}{c}\text { Nível de } \\
\text { Fortificação } \\
\mathrm{mg} / \mathrm{kg}\end{array}$ & $\begin{array}{c}\text { Valor } \\
\text { encontrado } \\
\mathrm{mg} / \mathrm{kg}\end{array}$ & \begin{tabular}{|c|} 
Recuperação \\
$\%$
\end{tabular} & $\begin{array}{c}\text { Recuperação } \\
\text { Média } \\
\%\end{array}$ & $\begin{array}{l}\text { Desvio } \\
\text { Padrão }\end{array}$ & $\mathrm{CV}$ \\
\hline 0,010 & 0,0084 & 84 & \multirow{6}{*}{104} & \multirow{6}{*}{13} & \multirow{6}{*}{13} \\
\hline 0,010 & 0,010 & 100 & & & \\
\hline 0,010 & 0,0097 & 97 & & & \\
\hline 0,010 & 0,011 & 110 & & & \\
\hline 0,010 & 0,011 & 110 & & & \\
\hline 0,010 & 0,012 & 120 & & & \\
\hline 0,10 & 0,095 & 95 & \multirow{6}{*}{95} & \multirow{6}{*}{3} & \multirow{6}{*}{3} \\
\hline 0,10 & 0,095 & 95 & & & \\
\hline 0,10 & 0,094 & 94 & & & \\
\hline 0,10 & 0,097 & 97 & & & \\
\hline 0,10 & 0,090 & 90 & & & \\
\hline 0,10 & 0,098 & 98 & & & \\
\hline
\end{tabular}


Tabela XVII: Recuperação Média das fortificações com dicofol, desvio padrão e coeficiente de variação.

\begin{tabular}{|c|c|c|c|c|c|}
\hline $\begin{array}{c}\text { Nível de } \\
\text { Fortificação } \\
\mathrm{mg} / \mathrm{kg}\end{array}$ & $\begin{array}{c}\text { Valor } \\
\text { encontrado } \\
\mathrm{mg} / \mathrm{kg}\end{array}$ & $\begin{array}{c}\text { Recuperação } \\
\%\end{array}$ & $\begin{array}{c}\text { Recuperação } \\
\text { Média } \\
\%\end{array}$ & \begin{tabular}{|l|} 
Desvio \\
Padrão
\end{tabular} & $\mathrm{CV}$ \\
\hline 0,050 & 0,042 & 84 & \multirow{6}{*}{82} & \multirow{6}{*}{9} & \multirow{6}{*}{11} \\
\hline 0,050 & 0,039 & 78 & & & \\
\hline 0,050 & 0,049 & 98 & & & \\
\hline 0,050 & 0,037 & 74 & & & \\
\hline 0,050 & 0,040 & 80 & & & \\
\hline 0,050 & 0,038 & 76 & & & \\
\hline 0,10 & 0,071 & 71 & \multirow{6}{*}{74} & \multirow{6}{*}{6} & \multirow{6}{*}{8} \\
\hline 0,10 & 0,070 & 70 & & & \\
\hline 0,10 & 0,085 & 85 & & & \\
\hline 0,10 & 0,072 & 72 & & & \\
\hline 0,10 & 0,073 & 73 & & & \\
\hline- & - & - & & & \\
\hline
\end{tabular}

Tabela XVIII: Recuperação Média das fortificações com aletrina, desvio padrão e coeficiente de variação

\begin{tabular}{|c|c|c|c|c|c|}
\hline $\begin{array}{l}\text { Nível de } \\
\text { Fortificação } \\
\text { mg/kg }\end{array}$ & $\begin{array}{c}\text { Valor } \\
\text { encontrado } \\
\mathrm{mg} / \mathrm{kg}\end{array}$ & $\begin{array}{c}\text { Recuperação } \\
\%\end{array}$ & $\begin{array}{c}\text { Recuperação } \\
\text { Média } \\
\%\end{array}$ & $\begin{array}{l}\text { Desvio } \\
\text { Padrão }\end{array}$ & CV \\
\hline 0,050 & 0,050 & 100 & \multirow{6}{*}{102} & \multirow{6}{*}{9} & \multirow{6}{*}{9} \\
\hline 0,050 & 0,060 & 120 & & & \\
\hline 0,050 & 0,046 & 92 & & & \\
\hline 0,050 & 0,050 & 100 & & & \\
\hline 0,050 & 0,051 & 102 & & & \\
\hline 0,050 & 0,050 & 100 & & & \\
\hline
\end{tabular}


Tabela XIX: Recuperação Média das fortificações com procimidona, desvio padrão e coeficiente de variação.

\begin{tabular}{|c|c|c|c|c|c|}
\hline $\begin{array}{c}\text { Nível de } \\
\text { Fortificação } \\
\text { mg/kg }\end{array}$ & $\begin{array}{c}\text { Valor } \\
\text { encontrado } \\
\mathrm{mg} / \mathbf{k g}\end{array}$ & $\begin{array}{c}\text { Recuperação } \\
\%\end{array}$ & $\begin{array}{c}\text { Recuperação } \\
\text { Média } \\
\%\end{array}$ & $\begin{array}{l}\text { Desvio } \\
\text { Padrão }\end{array}$ & $\mathrm{CV}$ \\
\hline 0,010 & 0,0078 & 78 & \multirow{6}{*}{89} & \multirow{6}{*}{8} & \multirow{6}{*}{9} \\
\hline 0,010 & 0,0086 & 86 & & & \\
\hline 0,010 & 0,0086 & 86 & & & \\
\hline 0,010 & 0,0097 & 97 & & & \\
\hline 0,010 & 0,0087 & 87 & & & \\
\hline 0,010 & 0,010 & 100 & & & \\
\hline 0,10 & 0,85 & 85 & \multirow{6}{*}{89} & \multirow{6}{*}{7} & \multirow{6}{*}{8} \\
\hline 0,10 & 0,87 & 87 & & & \\
\hline 0,10 & 0,80 & 80 & & & \\
\hline 0,10 & 0,88 & 88 & & & \\
\hline 0,10 & 0,92 & 92 & & & \\
\hline 0,10 & 0,10 & 100 & & & \\
\hline
\end{tabular}

Tabela XX: Recuperação Média das fortificações com alfa endosulfam, desvio padrão e coeficiente de variação.

\begin{tabular}{|c|c|c|c|c|c|}
\hline $\begin{array}{c}\text { Nivel de } \\
\text { Fortificação } \\
\text { mg/kg }\end{array}$ & $\begin{array}{c}\text { Valor } \\
\text { encontrado } \\
\mathrm{mg} / \mathrm{kg}\end{array}$ & $\begin{array}{c}\text { Recuperação } \\
\%\end{array}$ & $\begin{array}{c}\text { Recuperação } \\
\text { Média } \\
\%\end{array}$ & \begin{tabular}{|l|} 
Desvioo \\
Padrão
\end{tabular} & CV \\
\hline 0,010 & 0,010 & 100 & \multirow{6}{*}{97} & \multirow{6}{*}{5} & \multirow{6}{*}{5} \\
\hline 0,010 & 0,010 & 100 & & & \\
\hline 0,010 & 0,010 & 100 & & & \\
\hline 0,010 & 0,0090 & 90 & & & \\
\hline 0,010 & 0,010 & 100 & & & \\
\hline 0,010 & 0,0090 & 90 & & & \\
\hline 0,10 & 0,094 & 94 & \multirow{6}{*}{96} & \multirow{6}{*}{3} & \multirow{6}{*}{3} \\
\hline 0,10 & 0,094 & 94 & & & \\
\hline 0,10 & 0,093 & 93 & & & \\
\hline 0,10 & 0,096 & 96 & & & \\
\hline 0,10 & 0,10 & 100 & & & \\
\hline 0,10 & 0,097 & 97 & & & \\
\hline
\end{tabular}


Tabela XXI: Recuperação Média das fortificações com

beta endosulfam, desvio padrão e coeficiente de variação

\begin{tabular}{|c|c|c|c|c|c|}
\hline $\begin{array}{c}\text { Nivel de } \\
\text { Fortificação } \\
\text { mg/kg }\end{array}$ & $\begin{array}{c}\text { Valor } \\
\text { encontrado } \\
\mathrm{mg} / \mathrm{kg}\end{array}$ & $\begin{array}{c}\text { Recuperação } \\
\%\end{array}$ & $\begin{array}{c}\text { Recuperação } \\
\text { Média } \\
\%\end{array}$ & \begin{tabular}{|l|} 
Desvio \\
Padrão
\end{tabular} & $\mathrm{CV}$ \\
\hline 0,010 & 0,0095 & 95 & \multirow{6}{*}{103} & \multirow{6}{*}{10} & \multirow{6}{*}{10} \\
\hline 0,010 & 0,0099 & 99 & & & \\
\hline 0,010 & 0,0095 & 95 & & & \\
\hline 0,010 & 0,011 & 110 & & & \\
\hline 0,010 & 0,010 & 100 & & & \\
\hline 0,010 & 0,012 & 120 & & & \\
\hline 0,10 & 0,12 & 120 & \multirow{5}{*}{103} & \multirow{5}{*}{16} & \multirow{5}{*}{15} \\
\hline 0,10 & 0,088 & 88 & & & \\
\hline 0,10 & 0,12 & 120 & & & \\
\hline 0,10 & 0,099 & 99 & & & \\
\hline 0,10 & 0,089 & 89 & & & \\
\hline
\end{tabular}

Tabela XXII: Recuperação Média das fortificações com sulfato endosulfam, desvio padrão e coeficiente de variação

\begin{tabular}{|c|c|c|c|c|c|}
\hline $\begin{array}{c}\text { Nível de } \\
\text { Fortificação } \\
\mathrm{mg} / \mathrm{kg}\end{array}$ & $\begin{array}{c}\text { Valor } \\
\text { encontrado } \\
\mathrm{mg} / \mathrm{kg}\end{array}$ & $\begin{array}{c}\text { Recuperação } \\
\%\end{array}$ & $\begin{array}{c}\text { Recuperação } \\
\text { Média } \\
\%\end{array}$ & \begin{tabular}{|l|} 
Desvio \\
Padrão
\end{tabular} & $\mathrm{CV}$ \\
\hline 0,050 & 0,040 & 80 & \multirow{5}{*}{96} & \multirow{5}{*}{9} & \multirow{5}{*}{9} \\
\hline 0,050 & 0,050 & 100 & & & \\
\hline 0,050 & 0,050 & 100 & & & \\
\hline 0,050 & 0,050 & 100 & & & \\
\hline 0,050 & 0,050 & 100 & & & \\
\hline 0,50 & 0,45 & 90 & \multirow{6}{*}{86} & \multirow{6}{*}{5} & \multirow{6}{*}{6} \\
\hline 0,50 & 0,41 & 82 & & & \\
\hline 0,50 & 0,44 & 88 & & & \\
\hline 0,50 & 0,41 & 82 & & & \\
\hline 0,50 & 0,41 & 82 & & & \\
\hline 0,50 & 0,46 & 92 & & & \\
\hline
\end{tabular}


Tabela XXIII: Recuperação Média das fortificações com bifentrina, desvio padrão e coeficiente de variação

\begin{tabular}{|c|c|c|c|c|c|}
\hline $\begin{array}{c}\text { Nivel de } \\
\text { Fortificação } \\
\text { mg/kg }\end{array}$ & $\begin{array}{c}\text { Valor } \\
\text { encontrado } \\
\mathrm{mg} / \mathrm{kg}\end{array}$ & $\begin{array}{c}\text { Recuperação } \\
\%\end{array}$ & $\begin{array}{c}\text { Recuperação } \\
\text { Média } \\
\%\end{array}$ & \begin{tabular}{|l|} 
Desvio \\
Padrão
\end{tabular} & CV \\
\hline 0,050 & 0,059 & 118 & \multirow{6}{*}{108} & \multirow{6}{*}{8} & \multirow{6}{*}{7} \\
\hline 0,050 & 0,052 & 104 & & & \\
\hline 0,050 & 0,051 & 102 & & & \\
\hline 0,050 & 0,057 & 114 & & & \\
\hline 0,050 & 0,050 & 100 & & & \\
\hline- & - & & & & \\
\hline 0,10 & 0,084 & 84 & \multirow{6}{*}{86} & \multirow{6}{*}{14} & \multirow{6}{*}{16} \\
\hline 0,10 & 0,082 & 82 & & & \\
\hline 0,10 & 0,076 & 76 & & & \\
\hline 0,10 & 0,11 & 110 & & & \\
\hline 0,10 & 0,077 & 77 & & & \\
\hline- & - & & & & \\
\hline
\end{tabular}

Tabela XXIV: Recuperação Média das fortificações com fempropatrina, desvio padrão e coeficiente de variação

\begin{tabular}{|c|c|c|c|c|c|}
\hline $\begin{array}{c}\text { Nível de } \\
\text { Fortificação } \\
\text { mg/kg }\end{array}$ & $\begin{array}{c}\text { Valor } \\
\text { encontrado } \\
\mathrm{mg} / \mathrm{kg}\end{array}$ & $\begin{array}{c}\text { Recuperação } \\
\%\end{array}$ & $\begin{array}{c}\text { Recuperação } \\
\text { Média } \\
\%\end{array}$ & $\begin{array}{l}\text { Desvio } \\
\text { Padrão }\end{array}$ & $\mathrm{CV}$ \\
\hline 0,10 & 0,090 & 90 & \multirow{5}{*}{92} & \multirow{5}{*}{4} & \multirow{5}{*}{4} \\
\hline 0,10 & 0,10 & 100 & & & \\
\hline 0,10 & 0,090 & 90 & & & \\
\hline 0,10 & 0,090 & 90 & & & \\
\hline 0,10 & 0,090 & 90 & & & \\
\hline 100 & 081 & 81 & \multirow{6}{*}{77} & \multirow{6}{*}{3} & \multirow{6}{*}{4} \\
\hline 1,00 & 0,74 & 74 & & & \\
\hline 1,00 & 0,77 & 77 & & & \\
\hline 1,00 & 0,75 & 75 & & & \\
\hline 1,00 & 0,73 & 73 & & & \\
\hline 1.00 & 0.81 & 81 & & & \\
\hline
\end{tabular}


Tabela XXV: Recuperação Média das fortificações com tetradifona, desvio padrão e coeficiente

\begin{tabular}{|c|c|c|c|c|c|}
\hline $\begin{array}{c}\text { Nível de } \\
\text { Fortificação } \\
\text { mg/kg }\end{array}$ & $\begin{array}{c}\text { Valor } \\
\text { encontrado } \\
\mathrm{mg} / \mathrm{kg}\end{array}$ & $\begin{array}{c}\text { Recuperação } \\
\%\end{array}$ & $\begin{array}{c}\text { Recuperação } \\
\text { Média } \\
\%\end{array}$ & $\begin{array}{l}\text { Desvio } \\
\text { Padrão }\end{array}$ & CV \\
\hline 0,010 & 0,0074 & 74 & \multirow{6}{*}{91} & \multirow{6}{*}{13} & \multirow{6}{*}{14} \\
\hline 0,010 & 0,0089 & 89 & & & \\
\hline 0,010 & 0,0084 & 84 & & & \\
\hline 0,010 & 0,010 & 100 & & & \\
\hline 0,010 & 0,0090 & 90 & & & \\
\hline 0,010 & 0,011 & 110 & & & \\
\hline 0,10 & 0,094 & 94 & \multirow{6}{*}{97} & \multirow{6}{*}{2} & \multirow{6}{*}{2} \\
\hline 0,10 & 0,096 & 96 & & & \\
\hline 0,10 & 0,096 & 96 & & & \\
\hline 0,10 & 0,099 & 99 & & & \\
\hline 0,10 & 0,10 & 100 & & & \\
\hline 0,10 & 0,098 & 98 & & & \\
\hline
\end{tabular}

Tabela XXVI: Recuperação Média das fortificações com procloraz, desvio padrão e coeficiente de variação

\begin{tabular}{|c|c|c|c|c|c|}
\hline $\begin{array}{c}\text { Nível de } \\
\text { Fortificação } \\
\text { mg/kg }\end{array}$ & $\begin{array}{c}\begin{array}{c}\text { Valor } \\
\text { encontrado } \\
\mathrm{mg} / \mathrm{kg}\end{array} \\
\end{array}$ & $\begin{array}{c}\text { Recuperação } \\
\%\end{array}$ & $\begin{array}{c}\text { Recuperação } \\
\text { Média } \\
\%\end{array}$ & $\begin{array}{l}\text { Desvio } \\
\text { Padrão }\end{array}$ & $\mathrm{CV}$ \\
\hline 0,20 & 0,17 & 85 & \multirow{6}{*}{83} & \multirow{6}{*}{5} & \multirow{6}{*}{6} \\
\hline 0,20 & 0,17 & 85 & & & \\
\hline 0,20 & 0,15 & 75 & & & \\
\hline 0,20 & 0,17 & 85 & & & \\
\hline 0,20 & 0,18 & 90 & & & \\
\hline 0,20 & 0,16 & 80 & & & \\
\hline 1,00 & 0,96 & 96 & \multirow{6}{*}{102} & \multirow{6}{*}{6} & \multirow{6}{*}{6} \\
\hline 1,00 & 1,04 & 104 & & & \\
\hline 1,00 & 1,08 & 108 & & & \\
\hline 1,00 & 0,93 & 94 & & & \\
\hline 1,00 & 0,99 & 99 & & & \\
\hline 1,00 & 1,09 & 109 & & & \\
\hline
\end{tabular}


Tabela XXVII: Recuperação Média das fortificações com difenoconazol, desvio padrão e coeficiente de variação

\begin{tabular}{|c|c|c|c|c|c|}
\hline $\begin{array}{c}\text { Nivel de } \\
\text { Fortificação } \\
\text { mg/kg }\end{array}$ & $\begin{array}{c}\text { Valor } \\
\text { encontrado } \\
\text { mg/kg }\end{array}$ & $\begin{array}{c}\text { Recuperação } \\
\%\end{array}$ & $\begin{array}{c}\text { Recuperação } \\
\text { Média } \\
\%\end{array}$ & $\begin{array}{l}\text { Desvio } \\
\text { Padrão }\end{array}$ & $\mathrm{CV}$ \\
\hline 0,20 & 0,18 & 90 & \multirow{6}{*}{95} & \multirow{6}{*}{8} & \multirow{6}{*}{8} \\
\hline 0,20 & 0,17 & 85 & & & \\
\hline 0,20 & 0,19 & 95 & & & \\
\hline 0,20 & 0,20 & 98 & & & \\
\hline 0,20 & 0,22 & 108 & & & \\
\hline 0,20 & 0,19 & 93 & & & \\
\hline 2,00 & 1,62 & 81 & \multirow{6}{*}{92} & \multirow{6}{*}{6} & \multirow{6}{*}{7} \\
\hline 2,00 & 1,88 & 94 & & & \\
\hline 2,00 & 1,89 & 95 & & & \\
\hline 2,00 & 1,85 & 93 & & & \\
\hline 2,00 & 1,89 & 95 & & & \\
\hline 2,00 & 1,92 & 96 & & & \\
\hline
\end{tabular}

Tabela XXVIII: Recuperação Média das fortificações com azoxistrobina, desvio padrão e coeficiente de variação

\begin{tabular}{|c|c|c|c|c|c|}
\hline $\begin{array}{c}\text { Nível de } \\
\text { Fortificação } \\
\text { mg/kg }\end{array}$ & $\begin{array}{c}\text { Valor } \\
\text { encontrado } \\
\mathrm{mg} / \mathrm{kg}\end{array}$ & $\begin{array}{c}\text { Recuperação } \\
\%\end{array}$ & $\begin{array}{c}\text { Recuperação } \\
\text { Média } \\
\%\end{array}$ & $\begin{array}{l}\text { Desvio } \\
\text { Padrão }\end{array}$ & CV \\
\hline 0,40 & 0,37 & 93 & \multirow{5}{*}{105} & \multirow{5}{*}{7} & \multirow{5}{*}{7} \\
\hline 0,40 & 0,44 & 110 & & & \\
\hline 0,40 & 0,44 & 110 & & & \\
\hline 0,40 & 0,41 & 103 & & & \\
\hline 0,40 & 0,43 & 108 & & & \\
\hline 4,00 & 3,47 & 87 & \multirow{6}{*}{82} & \multirow{6}{*}{7} & \multirow{6}{*}{9} \\
\hline 4,00 & 3,03 & 76 & & & \\
\hline 4,00 & 3,53 & 88 & & & \\
\hline 4,00 & 3,06 & 77 & & & \\
\hline 4,00 & 2,99 & 75 & & & \\
\hline 4,00 & 3,56 & 89 & & & \\
\hline
\end{tabular}


Tabela XXIX: Recuperação Média das fortificações com diclorvós, desvio padrão e coeficiente de variação

\begin{tabular}{|c|c|c|c|c|c|}
\hline $\begin{array}{l}\text { Nível de } \\
\text { Fortificação } \\
\mathrm{mg} / \mathrm{kg}\end{array}$ & $\begin{array}{c}\text { Valor } \\
\text { encontrado } \\
\mathrm{mg} / \mathbf{k g}\end{array}$ & $\begin{array}{c}\text { Recuperação } \\
\%\end{array}$ & $\begin{array}{c}\text { Recuperação } \\
\text { Média } \\
\%\end{array}$ & $\begin{array}{l}\text { Desvio } \\
\text { Padrão }\end{array}$ & CV \\
\hline 0,052 & 0,045 & 87 & \multirow{6}{*}{96} & \multirow{6}{*}{7} & \multirow{6}{*}{7} \\
\hline 0,052 & 0,049 & 94 & & & \\
\hline 0,052 & 0,055 & 106 & & & \\
\hline 0,052 & 0,050 & 96 & & & \\
\hline 0,052 & 0,052 & 100 & & & \\
\hline 0,052 & 0,048 & 92 & & & \\
\hline 0,52 & 0,39 & 75 & \multirow{6}{*}{83} & \multirow{6}{*}{5} & \multirow{6}{*}{6} \\
\hline 0,52 & 0,44 & 85 & & & \\
\hline 0,52 & 0,45 & 87 & & & \\
\hline 0,52 & 0,43 & 83 & & & \\
\hline 0,52 & 0,41 & 79 & & & \\
\hline 0,52 & 0,45 & 87 & & & \\
\hline
\end{tabular}

Tabela XXX: Recuperação Média das fortificações com forato, desvio padrão e coeficiente de variação

\begin{tabular}{|c|c|c|c|c|c|}
\hline $\begin{array}{l}\text { Nível de } \\
\text { Fortificação } \\
\text { mg/kg }\end{array}$ & $\begin{array}{c}\text { Valor } \\
\text { encontrado } \\
\mathrm{mg} / \mathrm{kg}\end{array}$ & $\begin{array}{c}\text { Recuperação } \\
\%\end{array}$ & $\begin{array}{c}\text { Recuperação } \\
\text { Média } \\
\%\end{array}$ & $\begin{array}{l}\text { Desvioo } \\
\text { Padrão }\end{array}$ & $\overline{C V}$ \\
\hline 0,050 & 0,042 & 84 & \multirow{6}{*}{88} & \multirow{6}{*}{6} & \multirow{6}{*}{7} \\
\hline 0,050 & 0,041 & 82 & & & \\
\hline 0,050 & 0,042 & 83 & & & \\
\hline 0,050 & 0,045 & 90 & & & \\
\hline 0,050 & 0,049 & 98 & & & \\
\hline 0,050 & 0,044 & 88 & & & \\
\hline 0,50 & 0,43 & 86 & \multirow{6}{*}{89} & \multirow{6}{*}{9} & \multirow{6}{*}{10} \\
\hline 0,50 & 0,47 & 94 & & & \\
\hline 0,50 & 0,48 & 96 & & & \\
\hline 0,50 & 0,46 & 92 & & & \\
\hline 0,50 & 0,36 & 72 & & & \\
\hline 0,50 & 0,48 & 96 & & & \\
\hline
\end{tabular}


Tabela XXXI: Recuperação Média das fortificações com diazinom, desvio padrão e coeficiente de variação.

\begin{tabular}{|c|c|c|c|c|c|}
\hline $\begin{array}{c}\text { Nivel de } \\
\text { Fortificação } \\
\text { mg/kg }\end{array}$ & $\begin{array}{c}\text { Valor } \\
\text { encontrado } \\
\mathrm{mg} / \mathrm{kg}\end{array}$ & $\begin{array}{c}\text { Recuperação } \\
\%\end{array}$ & $\begin{array}{c}\text { Recuperação } \\
\text { Média } \\
\%\end{array}$ & \begin{tabular}{|l|} 
Desvio \\
Padrão
\end{tabular} & CV \\
\hline 0,045 & 0,047 & 104 & \multirow{6}{*}{101} & \multirow{6}{*}{7} & \multirow{6}{*}{7} \\
\hline 0,045 & 0,049 & 109 & & & \\
\hline 0,045 & 0,046 & 102 & & & \\
\hline 0,045 & 0,046 & 102 & & & \\
\hline 0,045 & 0,041 & 91 & & & \\
\hline 0,045 & 0,045 & 100 & & & \\
\hline 0,46 & 0,43 & 93 & \multirow{6}{*}{94} & \multirow{6}{*}{11} & \multirow{6}{*}{12} \\
\hline 0,46 & 0,45 & 98 & & & \\
\hline 0,46 & 0,41 & 89 & & & \\
\hline 0,46 & 0,46 & 100 & & & \\
\hline 0,46 & 0,35 & 76 & & & \\
\hline 0,46 & 0,50 & 109 & & & \\
\hline
\end{tabular}

Tabela XXXIl: Recuperação Média das fortificações com clorpirifós, desvio padrão e coeficiente de variação.

\begin{tabular}{|c|c|c|c|c|c|}
\hline $\begin{array}{l}\text { Nivel de } \\
\text { Fortificação } \\
\text { mg/kg }\end{array}$ & $\begin{array}{c}\text { Valor } \\
\text { encontrado } \\
\mathrm{mg} / \mathrm{kg}\end{array}$ & $\begin{array}{c}\text { Recuperação } \\
\%\end{array}$ & $\begin{array}{c}\text { Recuperação } \\
\text { Média } \\
\%\end{array}$ & \begin{tabular}{|l|} 
Desvioo \\
Padrão
\end{tabular} & $\mathrm{CV}$ \\
\hline 0,050 & 0,047 & 94 & \multirow{6}{*}{90} & \multirow{6}{*}{9} & \multirow{6}{*}{11} \\
\hline 0,050 & 0,049 & 98 & & & \\
\hline 0,050 & 0,038 & 76 & & & \\
\hline 0,050 & 0,046 & 92 & & & \\
\hline 0,050 & 0,049 & 98 & & & \\
\hline 0,050 & 0,040 & 80 & & & \\
\hline 0,50 & 0,43 & 86 & \multirow{6}{*}{85} & \multirow{6}{*}{9} & \multirow{6}{*}{11} \\
\hline 0,50 & 0,46 & 92 & & & \\
\hline 0,50 & 0,45 & 90 & & & \\
\hline 0,50 & 0,46 & 92 & & & \\
\hline 0,50 & 0,35 & 70 & & & \\
\hline 0,50 & 0,40 & 80 & & & \\
\hline
\end{tabular}


Tabela XXXIII: Recuperação Média das fortificações com malationa, desvio padrão e coeficiente de variação.

\begin{tabular}{|c|c|c|c|c|c|}
\hline $\begin{array}{c}\text { Nível de } \\
\text { Fortificação } \\
\text { mg/kg }\end{array}$ & $\begin{array}{c}\text { Valor } \\
\text { encontrado } \\
\text { mg/kg }\end{array}$ & $\begin{array}{c}\text { Recuperação } \\
\%\end{array}$ & $\begin{array}{c}\text { Recuperação } \\
\text { Média } \\
\%\end{array}$ & $\begin{array}{l}\text { Desvio } \\
\text { Padrão }\end{array}$ & CV \\
\hline 0,052 & 0,043 & 83 & \multirow{5}{*}{80} & \multirow{5}{*}{8} & \multirow{5}{*}{10} \\
\hline 0,052 & 0,037 & 71 & & & \\
\hline 0,052 & 0,037 & 71 & & & \\
\hline 0,052 & 0,047 & 90 & & & \\
\hline 0,052 & 0,043 & 83 & & & \\
\hline 0,51 & 0,46 & 90 & \multirow{6}{*}{93} & \multirow{6}{*}{7} & \multirow{6}{*}{8} \\
\hline 0,51 & 0,50 & 98 & & & \\
\hline 0,51 & 0,51 & 100 & & & \\
\hline 0,51 & 0,49 & 96 & & & \\
\hline 0,51 & 0,42 & 82 & & & \\
\hline 0,51 & 0,48 & 94 & & & \\
\hline
\end{tabular}

Tabela XXXIV: Recuperação Média das fortificações com fentiona, desvio padrão e coeficiente de variação

\begin{tabular}{|c|c|c|c|c|c|}
\hline $\begin{array}{c}\text { Nivel de } \\
\text { Fortificação } \\
\mathbf{m g} / \mathbf{k g}\end{array}$ & $\begin{array}{c}\text { Valor } \\
\text { encontrado } \\
\mathrm{mg} / \mathrm{kg}\end{array}$ & $\begin{array}{c}\text { Recuperação } \\
\%\end{array}$ & $\begin{array}{l}\text { Recuperação } \\
\text { Média } \\
\%\end{array}$ & $\begin{array}{l}\text { Desvio } \\
\text { Padrão }\end{array}$ & CV \\
\hline 0,050 & 0,043 & 86 & \multirow{5}{*}{82} & \multirow{5}{*}{7} & \multirow{5}{*}{9} \\
\hline 0,050 & 0,046 & 92 & & & \\
\hline 0,050 & 0,040 & 80 & & & \\
\hline 0,050 & 0,041 & 82 & & & \\
\hline 0,050 & 0,036 & 72 & & & \\
\hline 0,50 & 0,44 & 88 & \multirow{5}{*}{92} & \multirow{5}{*}{5} & \multirow{5}{*}{5} \\
\hline 0,50 & 0,48 & 96 & & & \\
\hline 0,50 & 0,49 & 98 & & & \\
\hline 0,50 & 0,47 & 94 & & & \\
\hline 0,50 & 0,43 & 86 & & & \\
\hline
\end{tabular}


Tabela XXXV: Recuperação Média das fortificações com fentoato, desvio padrão e coeficiente de variação

\begin{tabular}{|c|c|c|c|c|c|}
\hline $\begin{array}{c}\text { Nível de } \\
\text { Fortificação } \\
\text { mg/kg }\end{array}$ & $\begin{array}{c}\text { Valor } \\
\text { encontrado } \\
\mathrm{mg} / \mathrm{kg}\end{array}$ & $\begin{array}{c}\text { Recuperação } \\
\%\end{array}$ & $\begin{array}{c}\text { Recuperação } \\
\text { Média } \\
\%\end{array}$ & $\begin{array}{l}\text { Desvio } \\
\text { Padrão }\end{array}$ & $C V$ \\
\hline 0,050 & 0,055 & 110 & \multirow{6}{*}{102} & \multirow{6}{*}{7} & \multirow{6}{*}{7} \\
\hline 0,050 & 0,054 & 108 & & & \\
\hline 0,050 & 0,046 & 92 & & & \\
\hline 0,050 & 0,051 & 102 & & & \\
\hline 0,050 & 0,052 & 104 & & & \\
\hline 0,050 & 0,047 & 94 & & & \\
\hline 0,50 & 0,45 & 90 & \multirow{6}{*}{95} & \multirow{6}{*}{5} & \multirow{6}{*}{5} \\
\hline 0,50 & 0,49 & 98 & & & \\
\hline 0,50 & 0,51 & 102 & & & \\
\hline 0,50 & 0,47 & 94 & & & \\
\hline 0,50 & 0,44 & 88 & & & \\
\hline 0,50 & 0,48 & 96 & & & \\
\hline
\end{tabular}

Tabela XXXVI: Recuperação Média das fortificações com etiona, desvio padrão e coeficiente

\begin{tabular}{|c|c|c|c|c|c|}
\hline $\begin{array}{c}\text { Nivel de } \\
\text { Fortificação } \\
\mathrm{mg} / \mathrm{kg}\end{array}$ & $\begin{array}{c}\text { Valor } \\
\text { encontrado } \\
\mathrm{mg} / \mathrm{kg}\end{array}$ & $\begin{array}{c}\text { Recuperação } \\
\%\end{array}$ & $\begin{array}{c}\text { Recuperação } \\
\text { Média } \\
\%\end{array}$ & \begin{tabular}{|l|} 
Desvio \\
Padrão
\end{tabular} & CV \\
\hline 0,050 & 0,048 & 96 & \multirow{6}{*}{92} & \multirow{6}{*}{6} & \multirow{6}{*}{7} \\
\hline 0,050 & 0,048 & 96 & & & \\
\hline 0,050 & 0,046 & 92 & & & \\
\hline 0,050 & 0,040 & 80 & & & \\
\hline 0,050 & 0,046 & 92 & & & \\
\hline 0,050 & 0,048 & 96 & & & \\
\hline 0,50 & 0,45 & 90 & \multirow{6}{*}{87} & \multirow{6}{*}{9} & \multirow{6}{*}{10} \\
\hline 0,50 & 0,47 & 94 & & & \\
\hline 0,50 & 0,47 & 94 & & & \\
\hline 0,50 & 0,46 & 92 & & & \\
\hline $.0,50$ & 0,35 & 70 & & & \\
\hline 0,50 & 0,41 & 82 & & & \\
\hline
\end{tabular}


Tabela XXXVII: Recuperação Média das fortificações com fosmete, desvio padrão e coeficiente de variação.

\begin{tabular}{|c|c|c|c|c|c|}
\hline $\begin{array}{c}\text { Nivel de } \\
\text { Fortificação } \\
\text { mg/kg }\end{array}$ & $\begin{array}{c}\text { Valor } \\
\text { encontrado } \\
\mathrm{mg} / \mathrm{kg}\end{array}$ & $\begin{array}{c}\text { Recuperação } \\
\%\end{array}$ & $\begin{array}{c}\text { Recuperação } \\
\text { Média } \\
\%\end{array}$ & $\begin{array}{l}\text { Desvio } \\
\text { Padrão }\end{array}$ & CV \\
\hline 0,050 & 0,054 & 108 & \multirow{6}{*}{98} & \multirow{6}{*}{7} & \multirow{6}{*}{7} \\
\hline 0,050 & 0,046 & 92 & & & \\
\hline 0,050 & 0,047 & 94 & & & \\
\hline 0,050 & 0,051 & 102 & & & \\
\hline 0,050 & 0,046 & 92 & & & \\
\hline 0,050 & 0,051 & 102 & & & \\
\hline 0,50 & 0,43 & 86 & \multirow{6}{*}{84} & \multirow{6}{*}{9} & \multirow{6}{*}{11} \\
\hline 0,50 & 0,45 & 90 & & & \\
\hline 0,50 & 0,48 & 96 & & & \\
\hline 0,50 & 0,31 & 72 & & & \\
\hline 0,50 & 0,39 & 78 & & & \\
\hline 0,50 & 0,40 & 80 & & & \\
\hline
\end{tabular}

\subsection{Repetibilidade}

As variáveis envolvidas na determinação de resíduos de pesticidas são muitas. $O$ nível determinado nas injeções é da ordem de picograma ou nanograma/ $\mu \mathrm{L}$. Desta forma a repetibilidade na análise de resíduos de pesticidas nem sempre é igual à técnicas que determinam concentrações mais altas.

Para avaliar a repetibilidade das áreas do picos dos pesticidas uma amostra foi fortificada com propanil $0,05 \mathrm{mg} / \mathrm{kg}$, alacloro $0,01 \mathrm{mg} / \mathrm{kg}$, dicofol $0,05 \mathrm{mg} / \mathrm{kg}$, aletrina $0,05 \mathrm{mg} / \mathrm{kg}$, procimidona $0,01 \mathrm{mg} / \mathrm{kg}$, alfa endosulfam $0,01 \mathrm{mg} / \mathrm{kg}$, beta endosulfam 0,01 mg/kg, , sulfato endosulfam $0,05 \mathrm{mg} / \mathrm{kg}$, bifentrina $0,05 \mathrm{mg} / \mathrm{kg}$, fempropatrina $0,10 \mathrm{mg} / \mathrm{kg}$, tetradifona $0,01 \mathrm{mg} / \mathrm{kg}$, procloraz $0,20 \mathrm{mg} / \mathrm{kg}$, difenoconazol 0,20 mg/kg, azoxistrobina $0,40 \mathrm{mg} / \mathrm{kg}$, diclorvos $0,052 \mathrm{mg} / \mathrm{kg}$, forato $0,05 \mathrm{mg} / \mathrm{kg}$, diazinom $0,045 \mathrm{mg} / \mathrm{kg}$, clorpirifós $0,05 \mathrm{mg} / \mathrm{kg}$, malationa $0,052 \mathrm{mg} / \mathrm{kg}$, fentiona $0,05 \mathrm{mg} / \mathrm{kg}$, fentoato $0,05 \mathrm{mg} / \mathrm{kg}$, etiona $0,05 \mathrm{mg} / \mathrm{kg}$ e fosmete $0,05 \mathrm{mg} / \mathrm{kg}$ foi injetada 10 vezes nos dia 15, 16 e 18 de fevereiro de 2003 (pesticidas analisados pelo detector de captura de elétrons) e 17, 18 e 19 de fevereiro (pesticidas analisados pelo detector fotométrico de chama). 
O documento SANCO $825 / 00$ da European Comission (Guidance document on residual analytical methods, 2000) e o CODEX ALIMENTARIUS (2000) diz que a repetibilidade deve ser expressa através do coeficiente de variação que deve ser menor ou igual a 20 . Todos os princípios ativos analisados satisfizeram está condição.

Tabela XXXVIII: Repetibilidade do sinal de propanil em amostra de manga fortificada com $0,05 \mathrm{mg} / \mathrm{kg}$ no mesmo dia e em dias diferentes.

\begin{tabular}{lccc}
\hline Injeção $n^{\circ}$ & $\begin{array}{c}\text { Recuperação } \\
\text { dia15/02/2003 }\end{array}$ & $\begin{array}{c}\text { Recuperação } \\
\text { dia16/02/2003 }\end{array}$ & $\begin{array}{c}\text { Recuperação } \\
\text { dia 18/02/2003 }\end{array}$ \\
\hline 1 & 103 & 95 & 94 \\
2 & 101 & 96 & 96 \\
3 & 97 & 104 & 100 \\
4 & 105 & 95 & 103 \\
5 & 98 & 108 & 103 \\
6 & 92 & 99 & 94 \\
7 & 101 & 98 & 105 \\
8 & 103 & 98 & 99 \\
9 & 103 & 100 & 105 \\
10 & 96 & 98 & 101 \\
\hline
\end{tabular}

\begin{tabular}{lccc}
\hline Intervalo de confiança & $100 \pm 2,9$ & $99 \pm 2,9$ & $100 \pm 3,0$ \\
\hline Coeficiente de variação & 4,0 & 4,1 & 4,2 \\
\hline
\end{tabular}


Tabela XXXIX: Repetibilidade do sinal de alacloro em amostra de manga fortificada com $0,01 \mathrm{mg} / \mathrm{kg}$ no mesmo dia e em dias diferentes.

\begin{tabular}{lccc}
\hline Injeção $^{\circ}$ & $\begin{array}{c}\text { Recuperação } \\
\text { dia15/02/2003 }\end{array}$ & $\begin{array}{c}\text { Recuperação } \\
\text { dia16/02/2003 }\end{array}$ & $\begin{array}{c}\text { Recuperação } \\
\text { dia 18/02/2003 }\end{array}$ \\
\hline 1 & 100 & 96 & 95 \\
2 & 103 & 97 & 101 \\
3 & 99 & 95 & 104 \\
4 & 102 & 96 & 108 \\
5 & 98 & 105 & 101 \\
6 & 97 & 97 & 98 \\
7 & 102 & 104 & 96 \\
8 & 101 & 104 & 104 \\
9 & 104 & 101 & 98 \\
10 & 94 & 105 & 96 \\
\hline
\end{tabular}

\begin{tabular}{lccc}
\hline Intervalo de confiança & $100 \pm 2,2$ & $100 \pm 3,0$ & $100 \pm 3,0$ \\
\hline Coeficiente de variação & 3,1 & 4,2 & 4,3 \\
\hline
\end{tabular}

Tabela XL: Repetibilidade do sinal de dicofol em amostra de manga fortificada com $0,05 \mathrm{mg} / \mathrm{kg}$ no mesmo dia e em dias diferentes.

\begin{tabular}{lccc}
\hline Injeção $n^{\circ}$ & $\begin{array}{c}\text { Recuperação } \\
\text { dia15/02/2003 }\end{array}$ & $\begin{array}{c}\text { Recuperação } \\
\text { dia16/02/2003 }\end{array}$ & dia 18/02/2003 \\
\hline 1 & & 88 & 99 \\
2 & 107 & 95 & 102 \\
3 & 108 & 87 & 104 \\
4 & 97 & 86 & 107 \\
5 & 98 & 105 & 102 \\
6 & 96 & 92 & 91 \\
7 & 92 & 99 & 103 \\
8 & 106 & 98 & 98 \\
9 & 96 & 100 & 99 \\
10 & 104 & 96 & 94 \\
\hline
\end{tabular}

\begin{tabular}{lccc}
\hline Intervalo de confiança & $100 \pm 4,0$ & $95 \pm 4,5$ & $100 \pm 3,4$ \\
\hline Coeficiente de variação & 5,6 & 6,6 & 4,8 \\
\hline
\end{tabular}


Tabela XLI : Repetibilidade do sinal de aletrina em amostra de manga fortificada com $0,05 \mathrm{mg} / \mathrm{kg}$ no mesmo dia e em dias diferentes.

\begin{tabular}{lccc}
\hline Injeção $n^{\circ}$ & $\begin{array}{c}\text { Recuperação } \\
\text { dia15/02/2003 }\end{array}$ & $\begin{array}{c}\text { Recuperação } \\
\text { dia16/02/2003 }\end{array}$ & Recuperação \\
& & & dia \\
\hline 1 & 97 & $1002 / 2003$ \\
2 & 99 & 97 & 95 \\
3 & 98 & 97 & 100 \\
4 & 99 & 100 & 103 \\
5 & 100 & 103 & 103 \\
6 & 98 & 99 & 99 \\
7 & 99 & 101 & 99 \\
8 & 101 & 102 & 102 \\
9 & 103 & 104 & 100 \\
10 & 105 & 97 & 101 \\
\hline
\end{tabular}

\begin{tabular}{lccc}
\hline Intervalo de confiança & $100 \pm 1,8$ & $100 \pm 1,8$ & $100 \pm 1,8$ \\
\hline Coeficiente de variação & 2,5 & 2,6 & 2,4 \\
\hline
\end{tabular}

Tabela XLII: Repetibilidade do sinal de procimidona em amostra de manga fortificada com $0,01 \mathrm{mg} / \mathrm{kg}$ no mesmo dia e em dias diferentes.

\begin{tabular}{lccc}
\hline Injeção $^{\circ}$ & $\begin{array}{c}\text { Recuperação } \\
\text { dia15/02/2003 }\end{array}$ & $\begin{array}{c}\text { Recuperação } \\
\text { dia16/02/2003 }\end{array}$ & $\begin{array}{c}\text { Recuperação } \\
\text { dia 18/02/2003 }\end{array}$ \\
\hline 1 & 93 & 87 & 101 \\
2 & 96 & 93 & 92 \\
3 & 108 & 111 & 92 \\
4 & 93 & 93 & 92 \\
5 & 109 & 123 & 95 \\
6 & 95 & 90 & 93 \\
7 & 105 & 102 & 130 \\
8 & 98 & 108 & 114 \\
9 & 96 & 99 & 105 \\
10 & 107 & 93 & $100 \pm 9,7$ \\
\hline & & $100 \pm 8,0$ & 13,6 \\
\hline Intervalo de confiança & $100 \pm 4,6$ & 11,2 & \\
\hline Coeficiente de variação & 6,5 & & 95 \\
\hline
\end{tabular}


Tabela XLIII: Repetibilidade do sinal de alfa endosulfam em amostra de manga fortificada com $0,01 \mathrm{mg} / \mathrm{kg}$ no mesmo dia e em dias diferentes.

\begin{tabular}{lccc}
\hline Injeção $\mathbf{n}^{\circ}$ & $\begin{array}{c}\text { Recuperação } \\
\text { dia15/02/2003 }\end{array}$ & $\begin{array}{c}\text { Recuperação } \\
\text { dia 16/02/2003 }\end{array}$ & $\begin{array}{c}\text { Recuperação } \\
\text { dia 18/02/2003 }\end{array}$ \\
\hline 1 & 97 & 104 & 94 \\
2 & 99 & 101 & 100 \\
3 & 99 & 91 & 105 \\
4 & 99 & 97 & 101 \\
5 & 100 & 102 & 99 \\
6 & 104 & 95 & 98 \\
7 & 101 & 99 & 100 \\
8 & 103 & 110 & 107 \\
9 & 103 & 99 & 101 \\
10 & 98 & 104 & $100 \pm 2,7$ \\
\hline Intervalo de confiança & $100 \pm 0,6$ & & 3,8 \\
\hline Coeficiente de variação & 2,4 & $100 \pm 3,8$ & 5,3 \\
\hline
\end{tabular}

Tabela XLIV: Repetibilidade do sinal de beta endosulfam em amostra de manga fortificada com $0,01 \mathrm{mg} / \mathrm{kg}$ no mesmo dia e em dias diferentes.

\begin{tabular}{lccc}
\hline Injeção $n^{\circ}$ & $\begin{array}{c}\text { Recuperação } \\
\text { dia15/02/2003 }\end{array}$ & $\begin{array}{c}\text { Recuperação } \\
\text { dia16/02/2003 }\end{array}$ & $\begin{array}{c}\text { Recuperação } \\
\text { dia 18/02/2003 }\end{array}$ \\
\hline 1 & 93 & 95 & 96 \\
2 & 99 & 97 & 94 \\
3 & 99 & 95 & 98 \\
4 & 96 & 98 & 99 \\
5 & 114 & 118 & 99 \\
6 & 100 & 92 & 98 \\
7 & 107 & 102 & 102 \\
8 & 99 & 103 & 107 \\
9 & 97 & 107 & 107 \\
10 & 97 & 93 & 101 \\
\hline \multicolumn{4}{l}{} \\
\hline Intervalo de confiança & $100 \pm 4,36$ & $100 \pm 5,6$ & $100 \pm 3,1$ \\
\hline Coeficiente de variação & 6,1 & 7,9 & 4,3 \\
\hline
\end{tabular}


Tabela XLV: Repetibilidade do sinal de sulfato endosulfam em amostra de manga fortificada com $0,05 \mathrm{mg} / \mathrm{kg}$ no mesmo dia e em dias diferentes.

\begin{tabular}{lccc}
\hline Injeção $n^{\circ}$ & $\begin{array}{c}\text { Recuperação } \\
\text { dia15/02/2003 }\end{array}$ & $\begin{array}{c}\text { Recuperação } \\
\text { dia16/02/2003 }\end{array}$ & $\begin{array}{c}\text { Recuperação } \\
\text { dia 18/02/2003 }\end{array}$ \\
\hline 1 & 91 & 124 & 92 \\
2 & 95 & 88 & 97 \\
3 & 106 & 92 & 98 \\
4 & 109 & 103 & 97 \\
5 & 112 & 127 & 94 \\
6 & 97 & 84 & 98 \\
7 & 98 & 93 & 118 \\
8 & 86 & 90 & 108 \\
9 & 112 & 99 & 101 \\
10 & 94 & 99 & 96 \\
\hline & & & $100 \pm 5,5$ \\
\hline Intervalo de confiança & $100 \pm 6,6$ & $100 \pm 10,5$ & 7,7 \\
\hline Coeficiente de variação & 9,2 & 14,7 & \\
\hline
\end{tabular}

Tabela XLVI: Repetibilidade do sinal de bifentrina em amostra de manga fortificada com $0,05 \mathrm{mg} / \mathrm{kg}$ no mesmo dia e em dias diferentes.

\begin{tabular}{lccc}
\hline Injeção $n^{\circ}$ & $\begin{array}{c}\text { Recuperação } \\
\text { dia15/02/2003 }\end{array}$ & $\begin{array}{c}\text { Recuperação } \\
\text { dia16/02/2003 }\end{array}$ & $\begin{array}{c}\text { Recuperação } \\
\text { dia 18/02/2003 }\end{array}$ \\
\hline 1 & 94 & 99 & 93 \\
2 & 99 & 98 & 99 \\
3 & 98 & 95 & 100 \\
4 & 101 & 95 & 105 \\
5 & 100 & 106 & 102 \\
6 & 100 & 100 & 100 \\
7 & 103 & 105 & 97 \\
8 & 104 & 104 & 102 \\
9 & 104 & 101 & 101 \\
10 & 98 & 97 & 101 \\
\hline & & & $100 \pm 2,36$ \\
\hline Intervalo de confiança & $100 \pm 2,26$ & $100 \pm 2,86$ & 3,2 \\
\hline Coeficiente de variação & 3,1 & 4,0 & \\
\hline
\end{tabular}


Tabela XLVII: Repetibilidade do sinal de fempropatrina em amostra de manga fortificada com $0,10 \mathrm{mg} / \mathrm{kg}$ no mesmo dia e em dias diferentes.

\begin{tabular}{lccc}
\hline Injeção $\mathrm{n}^{\circ}$ & $\begin{array}{c}\text { Recuperação } \\
\text { dia15/02/2003 }\end{array}$ & $\begin{array}{c}\text { Recuperação } \\
\text { dia16/02/2003 }\end{array}$ & $\begin{array}{c}\text { Recuperação } \\
\text { dia 18/02/2003 }\end{array}$ \\
\hline 1 & 95 & 98 & 100 \\
2 & 97 & 93 & 95 \\
3 & 99 & 92 & 98 \\
4 & 100 & 108 & 100 \\
5 & 99 & 102 & 104 \\
6 & 101 & 96 & 102 \\
7 & 102 & 101 & 100 \\
8 & 102 & 101 & 99 \\
9 & 105 & 117 & 102 \\
10 & 99 & 104 & 100 \\
\hline
\end{tabular}

\begin{tabular}{cccc}
\hline Intervalo de confiança & $100 \pm 2,0$ & $101 \pm 5,3$ & $100 \pm 1,8$ \\
\hline Coeficiente de variação & 2,8 & 7,3 & 2,4 \\
\hline
\end{tabular}

Tabela XLVIII: Repetibilidade do sinal de tetradifona em amostra de manga fortificada com $0,01 \mathrm{mg} / \mathrm{kg}$ no mesmo dia e em dias diferentes.

\begin{tabular}{lccc}
\hline Injeção $n^{\circ}$ & $\begin{array}{c}\text { Recuperação } \\
\text { dia15/02/2003 }\end{array}$ & $\begin{array}{c}\text { Recuperação } \\
16 / 02 / 2003\end{array}$ & $\begin{array}{c}\text { Recuperação } \\
\text { dia 20/02/2003 }\end{array}$ \\
\hline 1 & 103 & 85 & 104 \\
2 & 105 & 96 & 93 \\
3 & 105 & 96 & 94 \\
4 & 103 & 113 & 104 \\
5 & 106 & 108 & 107 \\
6 & 98 & 96 & 113 \\
7 & 94 & 111 & 71 \\
8 & 91 & 94 & 103 \\
9 & 97 & 105 & 98 \\
10 & 97 & 96 & 115 \\
\hline
\end{tabular}

\begin{tabular}{lccc}
\hline Intervalo de confiança & $100 \pm 3,7$ & $100 \pm 6,3$ & $100 \pm 8,6$ \\
\hline Coeficiente de variação & 5,2 & 8,8 & 12,5 \\
\hline
\end{tabular}


Tabela XLIX: Repetibilidade do sinal de procloraz em amostra de manga fortificada com $0,20 \mathrm{mg} / \mathrm{kg}$ no mesmo dia e em dias diferentes.

\begin{tabular}{lccc}
\hline Injeção $n^{\circ}$ & $\begin{array}{c}\text { Recuperação } \\
\text { dia15/02/2003 }\end{array}$ & $\begin{array}{c}\text { Recuperação } \\
\text { dia16/02/2003 }\end{array}$ & $\begin{array}{c}\text { Recuperação } \\
\text { dia 18/02/2003 }\end{array}$ \\
\hline 1 & 93 & 97 & 99 \\
2 & 100 & 95 & 94 \\
3 & 96 & 96 & 99 \\
4 & 106 & 96 & 108 \\
5 & 97 & 116 & 102 \\
6 & 93 & 94 & 96 \\
7 & 108 & 103 & 105 \\
8 & 108 & 106 & 105 \\
9 & 98 & 97 & 105 \\
10 & 101 & 100 & $100 \pm 4,6$ \\
\hline Intervalo de confiança & $100 \pm 4,1$ & 5,7 & 6,4 \\
\hline Coeficiente de variação & 5,7 & $100 \pm 4,8$ & 8,8 \\
\hline
\end{tabular}

Tabela $L$ : Repetibilidade do sinal de difenoconazol em amostra de manga fortificada com $0,20 \mathrm{mg} / \mathrm{kg}$ no mesmo dia e em dias diferentes.

\begin{tabular}{|c|c|c|c|}
\hline Injeção $n^{\circ}$ & $\begin{array}{l}\text { Recuperação } \\
\text { dia15/02/2003 }\end{array}$ & $\begin{array}{c}\text { Recuperação } \\
\text { dia16/02/2003 }\end{array}$ & $\begin{array}{c}\text { Recuperação } \\
\text { dia } 18 / 02 / 2003\end{array}$ \\
\hline 1 & 94 & 102 & 103 \\
\hline 2 & 98 & 102 & 86 \\
\hline 3 & 94 & 104 & 91 \\
\hline 4 & 103 & 93 & 94 \\
\hline 5 & 96 & 115 & 105 \\
\hline 6 & 93 & 94 & 104 \\
\hline 7 & 107 & 97 & 95 \\
\hline 8 & 104 & 95 & 112 \\
\hline 9 & 107 & 100 & 105 \\
\hline 10 & 104 & 99 & 108 \\
\hline Intervalo de confiança & $100 \pm 4,0$ & $100 \pm 4,6$ & $100 \pm 5,9$ \\
\hline Coeficiente de variação & 5,6 & 6,4 & 8,3 \\
\hline
\end{tabular}


Tabela LI : Repetibilidade do sinal de azoxistrobina em amostra de manga fortificada com $0,05 \mathrm{mg} / \mathrm{kg}$ no mesmo dia e em dias diferentes.

\begin{tabular}{lccc}
\hline Injeção $n^{\circ}$ & $\begin{array}{c}\text { Recuperação } \\
\text { dia15/02/2003 }\end{array}$ & $\begin{array}{c}\text { Recuperação } \\
\text { dia16/02/2003 }\end{array}$ & $\begin{array}{c}\text { Recuperação } \\
\text { dia 18/02/2003 }\end{array}$ \\
\hline 1 & 95 & 102 & 103 \\
2 & 99 & 101 & 88 \\
3 & 97 & 105 & 92 \\
4 & 104 & 95 & 96 \\
5 & 97 & 113 & 100 \\
6 & 95 & 94 & 103 \\
7 & 107 & 98 & 95 \\
8 & 104 & 93 & 113 \\
9 & 107 & 101 & 103 \\
10 & 96 & 98 & 106 \\
\hline & & & $100 \pm 5,2$ \\
\hline Intervalo de confiança & $100 \pm 3,5$ & $100 \pm 4,2$ & 7,3 \\
\hline Coeficiente de variação & 4,9 & 5,9 & \\
\hline
\end{tabular}

Tabela LII: Repetibilidade do sinal de diclorvós em amostra de manga fortificada com $0,05 \mathrm{mg} / \mathrm{kg}$ no mesmo dia e em dias diferentes.

\begin{tabular}{lccc}
\hline Injeção $n^{\circ}$ & $\begin{array}{c}\text { Recuperação } \\
\text { dia17/02/2003 }\end{array}$ & $\begin{array}{c}\text { Recuperação } \\
\text { dia18/02/2003 }\end{array}$ & $\begin{array}{c}\text { Recuperação } \\
\text { dia 19/02/2003 }\end{array}$ \\
\hline 1 & 97 & 102 & 98 \\
2 & 95 & 109 & 101 \\
3 & 101 & 96 & 101 \\
4 & 105 & 94 & 109 \\
5 & 87 & 106 & 99 \\
6 & 101 & 97 & 92 \\
7 & 101 & 97 & 100 \\
8 & 101 & 105 & 97 \\
9 & 103 & 97 & 98 \\
10 & 107 & 98 & 105 \\
\hline & & & $100 \pm 3,3$ \\
\hline Intervalo de confiança & $100 \pm 4,1$ & $100 \pm 3,6$ & 4,6 \\
\hline Coeficiente de variação & 5,7 & 5,0 & \\
\hline
\end{tabular}


Tabela LIII: Repetibilidade do sinal de forato em amostra de manga fortificada com $0,05 \mathrm{mg} / \mathrm{kg}$ no mesmo dia e em dias diferentes.

\begin{tabular}{lccc}
\hline Injeção $n^{\circ}$ & $\begin{array}{c}\text { Recuperaçăo } \\
\text { dia17/02/2003 }\end{array}$ & $\begin{array}{c}\text { Recuperação } \\
\text { dia18/02/2003 }\end{array}$ & $\begin{array}{c}\text { Recuperaçăo } \\
\text { dia 19/02/2003 }\end{array}$ \\
\hline 1 & 100 & 105 & 106 \\
2 & 98 & 104 & 105 \\
3 & 92 & 103 & 104 \\
4 & 98 & 98 & 98 \\
5 & 98 & 97 & 88 \\
6 & 100 & 96 & 101 \\
7 & 103 & 96 & 100 \\
8 & 102 & 98 & 98 \\
9 & 106 & 100 & 97 \\
10 & 102 & 104 & 103 \\
\hline \multicolumn{4}{l}{} \\
\hline Intervalo de confiança & $100 \pm 2,7$ & $100 \pm 2,6$ & $100 \pm 3,8$ \\
\hline Coeficiente de variação & 3,8 & 3,6 & 5,2 \\
\hline
\end{tabular}

Tabela LIV : Repetibilidade do sinal de diazinom em amostra de manga fortificada com 0,05 mg/kg no mesmo dia e em dias diferentes.

\begin{tabular}{lccc}
\hline Injeção $n^{\circ}$ & $\begin{array}{c}\text { Recuperação } \\
\text { dia17/02/2003 }\end{array}$ & $\begin{array}{c}\text { Recuperaçăo } \\
\text { dia18/02/2003 }\end{array}$ & $\begin{array}{c}\text { Recuperação } \\
\text { dia 19/02/2003 }\end{array}$ \\
\hline 1 & 98 & 92 & 96 \\
2 & 100 & 87 & 97 \\
3 & 98 & 95 & 99 \\
4 & 98 & 103 & 98 \\
5 & 97 & 108 & 104 \\
6 & 98 & 105 & 101 \\
7 & 102 & 103 & 103 \\
8 & 101 & 103 & 102 \\
9 & 103 & 103 & 98 \\
10 & 106 & 107 & 101 \\
\hline & & & $100 \pm 1,9$ \\
\hline Intervalo de confiança & $100 \pm 2,1$ & $101 \pm 4,9$ & 2,7 \\
\hline Coeficiente de variação & 2,9 & 6,9 & \\
\hline
\end{tabular}


Tabela LV: Repetibilidade do sinal de clorpirifós em amostra de manga fortificada com $0,05 \mathrm{mg} / \mathrm{kg}$ no mesmo dia e em dias diferentes.

\begin{tabular}{lccc}
\hline Injeção $\mathrm{n}^{\circ}$ & $\begin{array}{c}\text { Recuperação } \\
\text { dia17/02/2003 }\end{array}$ & $\begin{array}{c}\text { Recuperação } \\
\text { dia18/02/2003 }\end{array}$ & $\begin{array}{c}\text { Recuperação } \\
\text { dia } 19 / 02 / 2003\end{array}$ \\
\hline 1 & 76 & 91 & 109 \\
2 & 98 & 113 & 108 \\
3 & 109 & 95 & 103 \\
4 & 124 & 91 & 87 \\
5 & 96 & 92 & 93 \\
6 & 102 & 92 & 95 \\
7 & 102 & 103 & 103 \\
8 & 99 & 105 & 109 \\
9 & 84 & 108 & 86 \\
10 & 109 & 109 & 106 \\
\hline
\end{tabular}

\begin{tabular}{lccc}
\hline Intervalo de confiança & $100 \pm 9,5$ & $100 \pm 6,1$ & $100 \pm 6,4$ \\
\hline Coeficiente de variação & 13,3 & 8,6 & 8,9 \\
\hline
\end{tabular}

Tabela LVI: Repetibilidade do sinal de malationa em amostra de manga fortificada com $0,05 \mathrm{mg} / \mathrm{kg}$ no mesmo dia e em dias diferentes.

\begin{tabular}{lccc}
\hline Injeção $n^{\circ}$ & $\begin{array}{c}\text { Recuperação } \\
\text { dia17/02/2003 }\end{array}$ & $\begin{array}{c}\text { Recuperação } \\
\text { dia18/02/2003 }\end{array}$ & $\begin{array}{c}\text { Recuperação } \\
\text { dia 19/02/2003 }\end{array}$ \\
\hline 1 & 107 & 91 & 100 \\
2 & 100 & 97 & 103 \\
3 & 100 & 98 & 99 \\
4 & 96 & 101 & 105 \\
5 & 97 & 96 & 94 \\
6 & 97 & 102 & 97 \\
7 & 97 & 105 & 99 \\
8 & 101 & 99 & 98 \\
9 & 103 & 104 & 99 \\
10 & 102 & 106 & 106 \\
\hline
\end{tabular}

\begin{tabular}{lccc}
\hline Intervalo de confiança & $100 \pm 2,5$ & $100 \pm 3,3$ & $100 \pm 2,6$ \\
\hline Coeficiente de variação & 3,4 & 4,6 & 3,7 \\
\hline
\end{tabular}


Tabela LVII: Repetibilidade do sinal de fentiona em amostra de manga fortificada com $0,05 \mathrm{mg} / \mathrm{kg}$ no mesmo dia e em dias diferentes.

\begin{tabular}{lccc}
\hline Injeção $n^{\circ}$ & $\begin{array}{c}\text { Recuperação } \\
\text { dia17/02/2003 }\end{array}$ & $\begin{array}{c}\text { Recuperação } \\
\text { dia18/02/2003 }\end{array}$ & $\begin{array}{c}\text { Recuperação } \\
\text { dia 19/02/2003 }\end{array}$ \\
\hline 1 & 101 & 97 & 96 \\
2 & 103 & 99 & 104 \\
3 & 102 & 95 & 96 \\
4 & 97 & 99 & 104 \\
5 & 98 & 104 & 102 \\
6 & 95 & 104 & 99 \\
7 & 99 & 102 & 98 \\
8 & 102 & 97 & 99 \\
9 & 103 & 104 & 99 \\
10 & 100 & 100 & $100 \pm 2,1$ \\
\hline & & & 3,0 \\
\hline Intervalo de confiança & $100 \pm 1,9$ & $100 \pm 2,3$ & 3,3 \\
\hline Coeficiente de variação & 2,7 & & 99 \\
\hline
\end{tabular}

Tabela LVIII: Repetibilidade do sinal de fentoato em amostra de manga fortificada com $0,05 \mathrm{mg} / \mathrm{kg}$ no mesmo dia e em dias diferentes.

\begin{tabular}{lccc}
\hline Injeção $n^{\circ}$ & $\begin{array}{c}\text { Recuperação } \\
\text { dia17/02/2003 }\end{array}$ & $\begin{array}{c}\text { Recuperação } \\
\text { dia18/02/2003 }\end{array}$ & $\begin{array}{c}\text { Recuperação } \\
\text { dia 19/02/2003 }\end{array}$ \\
\hline 1 & 108 & 87 & 105 \\
2 & 102 & 95 & 101 \\
3 & 83 & 106 & 99 \\
4 & 101 & 103 & 99 \\
5 & 92 & 100 & 99 \\
6 & 113 & 100 & 97 \\
7 & 107 & 98 & 102 \\
8 & 76 & 100 & 106 \\
9 & 106 & 106 & 95 \\
10 & 111 & 105 & 97 \\
\hline & & & $100 \pm 2,5$ \\
\hline Intervalo de confiança & $100 \pm 8,8$ & $100 \pm 4,2$ & 3,5 \\
\hline Coeficiente de variação & 12,4 & 5,8 & \\
\hline
\end{tabular}


Tabela LIX: Repetibilidade do sinal de etiona em amostra de manga fortificada com $0,05 \mathrm{mg} / \mathrm{kg}$ no mesmo dia e em dias diferentes.

\begin{tabular}{lccc}
\hline Injeção $^{\circ}$ & $\begin{array}{c}\text { Recuperação } \\
\text { dia17/02/2003 }\end{array}$ & $\begin{array}{c}\text { Recuperação } \\
\text { dia18/02/2003 }\end{array}$ & $\begin{array}{c}\text { Recuperação } \\
\text { dia 19/02/2003 }\end{array}$ \\
\hline 1 & 102 & 100 & 97 \\
2 & 99 & 99 & 98 \\
3 & 90 & 98 & 104 \\
4 & 98 & 100 & 99 \\
5 & 100 & 100 & 102 \\
6 & 99 & 97 & 97 \\
7 & 101 & 98 & 93 \\
8 & 100 & 101 & 103 \\
9 & 102 & 104 & 103 \\
10 & 110 & 102 & 103 \\
\hline
\end{tabular}

\begin{tabular}{lccc}
\hline Intervalo de confiança & $100 \pm 3,5$ & $100 \pm 1,5$ & $100 \pm 2,6$ \\
\hline Coeficiente de variação & 4,9 & 2,1 & 3,6 \\
\hline
\end{tabular}

Tabela LX: Repetibilidade do sinal de fosmete em amostra de manga fortificada com $0,05 \mathrm{mg} / \mathrm{kg}$ no mesmo dia e em dias diferentes.

\begin{tabular}{lccc}
\hline Injeção $^{\circ}$ & $\begin{array}{c}\text { Recuperação } \\
\text { dia17/02/2003 }\end{array}$ & $\begin{array}{c}\text { Recuperação } \\
\text { dia18/02/2003 }\end{array}$ & $\begin{array}{c}\text { Recuperação } \\
\text { dia 19/02/2003 }\end{array}$ \\
\hline 1 & 106 & 103 & 94 \\
2 & 99 & 100 & 101 \\
3 & 98 & 102 & 100 \\
4 & 102 & 107 & 101 \\
5 & 102 & 97 & 103 \\
6 & 96 & 98 & 106 \\
7 & 91 & 105 & 96 \\
8 & 88 & 104 & 96 \\
9 & 110 & 96 & 101 \\
10 & 103 & 96 & 101 \\
\hline
\end{tabular}

\begin{tabular}{lccc}
\hline Intervalo de confiança & $100 \pm 4,7$ & $101 \pm 2,8$ & $100 \pm 2,6$ \\
\hline Coeficiente de variação & 6,7 & 3,9 & 3,6 \\
\hline
\end{tabular}




\subsection{Limite de Detecção e Limite de Quantificação}

Em análise de resíduos de pesticidas o LQ pode ser estimado em função do Limite máximo de resíduos permitidos pela Legislação, por esta razão quando se valida uma metodologia é necessário conhecer estes valores.

O documento SANCO 825/00 da European Commission (Guidance document on residue analytical methods) diz que o LD e LQ podem ser determinados a partir dos estudos de recuperação do LQ proposto.

Neste trabalho foi utilizado o Limite de detecção e Limite de quantificação calculado a partir dos resultados de recuperação do menor nível adicionado.

Exemplo: Propanil LOQ proposto $=0,05 \mathrm{mg} / \mathrm{kg}$

Recuperações:

$\begin{array}{lcc}\text { Identificação } & \begin{array}{c}\text { Adicionado } \\ \mathrm{mg} / \mathrm{kg}\end{array} & \begin{array}{c}\text { Recuperado } \\ \mathrm{mg} / \mathrm{kg}\end{array} \\ & 0,050 & 0,060 \\ \text { Fortificação 1 } & 0,050 & 0,059 \\ \text { Fortificação 2 } & 0,050 & 0,060 \\ \text { Fortificação 3 } & 0,050 & 0,058 \\ \text { Fortificação 4 } & 0,050 & 0,058 \\ \text { Fortificação 5 } & 0,050 & 0,060 \\ \text { Fortificação 6 } & \text { média }= & 0,059 \\ & \text { desvio padrão }= & 0,001 \\ & \text { LQ }=10 \times S=0,01 \mathrm{mg} / \mathrm{kg} \\ & \mathrm{LD}=3 \times \mathrm{S}=0,003 \mathrm{mg} / \mathrm{kg}\end{array}$

Caso o LQ estatistico seja superior ao LOQ proposto novos ensaios de recuperação deverão ser efetuados.

Os valores de $L D$ e $L Q$ encontrados se encontram na tabela $L X I$. 
Tabela LXI: Limite de Detecção e Limite de Quantificação dos Pesticidas

\begin{tabular}{|c|c|c|c|}
\hline Principo Ativo & Detecção & $\begin{array}{l}\text { Limite de } \\
\text { Detecção } \\
\text { LD } \mathrm{mg} / \mathrm{kg}\end{array}$ & $\begin{array}{c}\text { Limite de } \\
\text { Quantificação } \\
\text { LQ mg/kg }\end{array}$ \\
\hline Propanil & ECD & 0,003 & 0,01 \\
\hline Alacloro & ECD & 0,003 & 0,01 \\
\hline Dicofol & ECD & 0,01 & 0,04 \\
\hline Aletrina & ECD & 0,01 & 0,05 \\
\hline Procimidona & ECD & 0,002 & 0,01 \\
\hline Alfa Endosulfam & ECD & 0,002 & 0,005 \\
\hline Beta Endosulfam & ECD & 0,003 & 0,01 \\
\hline Sulfato Endosulfam & ECD & 0,01 & 0,04 \\
\hline Bifentrina & ECD & 0,01 & 0,04 \\
\hline Fempropatrina & ECD & 0,01 & 0,04 \\
\hline Tetradifona & ECD & 0,003 & 0,009 \\
\hline Procloraz & ECD & 0,03 & 0,10 \\
\hline Difenoconazol & ECD & 0,05 & 0,17 \\
\hline Axoxistrobina & ECD & 0,09 & 0,29 \\
\hline Diclorvós & FPD & 0,01 & 0,03 \\
\hline Forato & FPD & 0,009 & 0,03 \\
\hline Diazinom & FPD & 0,008 & 0,03 \\
\hline Clorpirifós & FPD & 0,01 & 0,05 \\
\hline Malationa & FPD & 0,01 & 0,04 \\
\hline Fentiona & FPD & 0,01 & 0,04 \\
\hline Fentoato & FPD & 0,01 & 0,04 \\
\hline Etiona & FPD & 0,009 & 0,03 \\
\hline Fosmete & FPD & 0,01 & 0,03 \\
\hline
\end{tabular}


10.6 RESULTADOS DAS AMOSTRAS DE MANGA COMPRADAS NO VAREJO

\section{DE SÃO PAULO}

Foram compradas 37 amostras de manga no varejo de São Paulo, em uma destas uma foi encontrado o Procloraz na concentração de $0,20 \mathrm{mg} / \mathrm{kg}$, em outras duas o Procloraz foi detectado, porém em níveis abaixo do Limite de quantificação; nenhum dos outros pesticidas analisados foram encontrados.

A figura 34 mostra o cromatograma da amostra onde foi encontrado o procloraz.

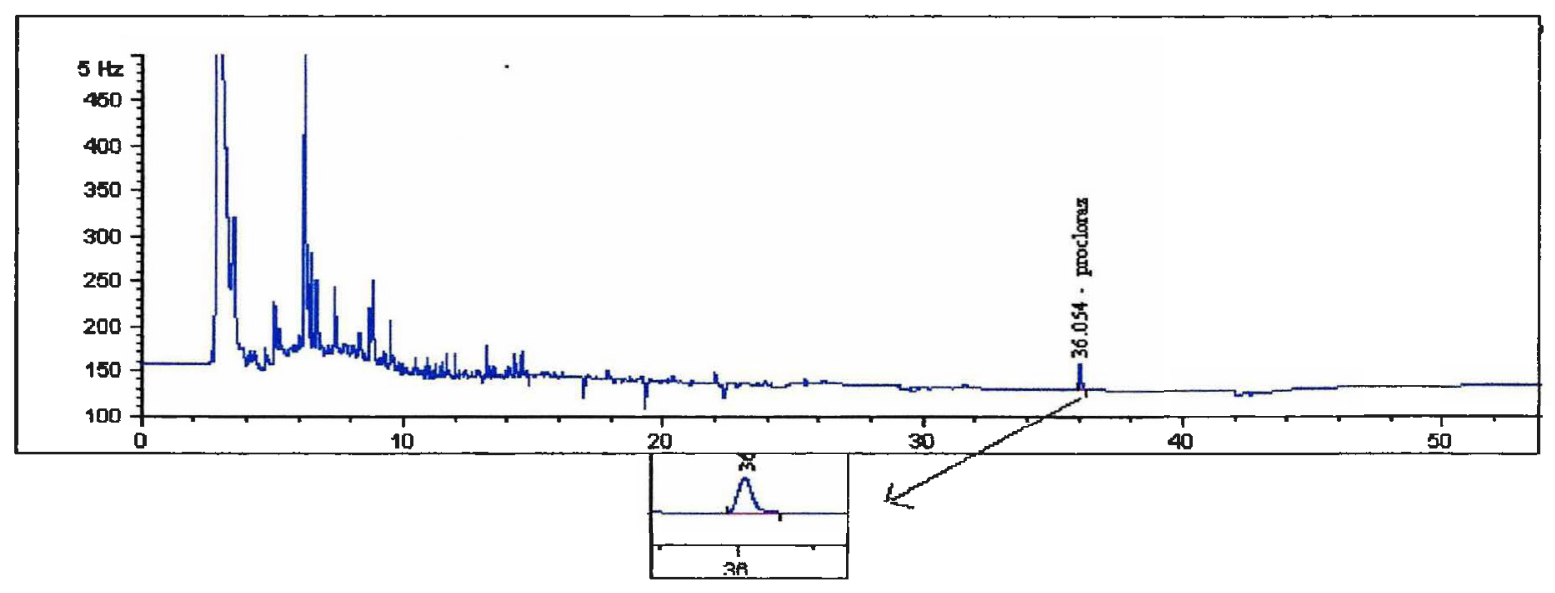

Figura 34: Amostra de manga comprada no varejo de São Paulo que apresentou o procloraz a 0,2 mg/kg. 


\section{DISCUSSÃO}

- Efeito Matriz:

O fosmete foi o único organofosforado que apresentou problemas de efeito matriz, isto está da acordo com a literatura (Schenck et. al, 2000) que atribui o efeito ao fato do fosmete possuir 2 ligações $P=0$.

O sulfato endosulfam e a azoxistrobina só apresentaram problemas de efeito matriz no menor nível de recuperação $(0,05$ e 0,40 $\mathrm{mg} / \mathrm{kg}$ respectivamete) nos níveis maiores os resultados de recuperação apresenteram-se dentro da faixa aceitável. A literatura (Jimenez et. al, 1998 e Hajslová et. al, 1998) mostra que, quanto menor a concentração do pesticida maior a probabilidade de ocorrer o efeito matriz. O procloraz e o difenoconazol apresentaram problemas de efeito matriz nos dois niveis de fortificação. O sulfato endosulfam, azoxistrobina, procloraz e difenoconazol foram analisados pelo detector de captura de elétrons.

A literatura sugere que os liners são os responsáveis pelos problemas de efeito matriz, porém o uso de liners sinalizados não minimizou nem ao menos na primeira injeção o problema, o que nos leva a pensar que maiores estudos são necessários para elucidação do efeito matriz.

- Validação

O uso de uma determinada metodologia analítica deve ser sempre precedida da verificação de sua aplicabilidade. A utilização de métodos validados, deve ser precedida por uma avaliação da conformidade ou validação desse método.

A validação é um processo contínuo e não deve ser feita apenas no início do trabalho. A performance da metodologia deve ser checada periodicamente dentro do laboratório. 
Os estudos de recuperação realizados no presente trabalho, foram feitos a fim de se avaliar a recuperação do método empregado. Os resultados obtidos mostraram recuperação adequada às normas nacionais e internacionais.

O coeficiente de variação da repetibilidade das injeções não ultrapassou os $20 \%$. Em análise de resíduos de pesticidas as quantidades injetadas são da ordem de pg/uL, o que explica o fato do EPA e do CODEX Aimentarius aceitarem um coeficiente de variação neste valor. Quando trabalha-se com quantidades maiores, é mais fácil conseguir uma variação menor.

Os parâmetros de linearidade e especificidade foram checados e apresentaram-se aplicáveis ao estudo.

\section{- Resíduos Permitidos em Manga}

Dentre os princípios ativos estudados é permitido o uso do procloraz, difenoconazol e fentiona nos valores de 0,$2 ; 0,2 ;$ e $0,05 \mathrm{mg} / \mathrm{kg}$ respectivamente, no cultivo da manga pela Legislação Brasileira. O CODEX Alimentarius permite dentre os pesticidas estudados apenas o procloraz na concentração de $2,0 \mathrm{mg} / \mathrm{kg}$.

O procloraz é o resíduo de pesticida mais encontrado pelos países importadores da manga brasileira e por isso merece uma certa atenção.

O monitoramento de resíduos de pesticidas deve ser feito rotineiramente nas mais variadas matrizes. $O$ ideal seria que todo alimento consumido fosse monitorado, porém esta é uma realidade que ainda está longe de ser atingida. O Estado de São Paulo possuí apenas 2 laboratórios que fazem este tipo de trabalho o Instituto Biológico e o Instituto Adolfo Lutz que não tem capacidade para atender a todo o Estado. 


\section{CONCLUSÕES}

Com base nos resultados obtidos no presente trabalho, pode-se estabelecer as seguintes conclusões:

O efeito matriz é uma característica que existe para determinados princípios ativos na matriz manga e precisa ser levado em consideração na análise de resíduos de pesticidas. Este efeito precisa ser melhor estudado para completo esclarecimento de sua existência.

As causas propostas para este fenômeno são os sítios ativos, principalmente do liner do injetor que contribuem para recuperações aparentemente mais altas que as esperadas. Durante o nosso trabalho procurou-se utilizar liners silanizados e os resultados não se alteraram já que, teoricamente, um liner silanizado não apresenta sítios ativos livres, o fenômeno não deveria ocorrer, principalmente nas primeiras injeções.

O efeito matriz foi contornado com o preparo das soluções padrões no extrato da amostra testemunha. Quando se trabalha com uma única amostra como no presente trabalho este fenômeno é facilmente contornado desta forma; já quando se trabalha em um laboratório que analisa as mais diversas matrizes, 0 uso de amostras testemunhas de cada cultura pode ser um procedimento laborioso e por isso tentar elucidar este problema ainda é um desafio.

A validação da metodologia é essencial na análise de resíduos de pesticidas, pois só a partir dela podemos verificar se os pesticidas apresentam problemas durante a análise.

Buscar novas metodologias que minimizem o uso de solventes ainda é uma tarefa importante, pois estes além de gerarem resíduos tóxicos encarecem a análise. Durante o trabalho o consumo de solvente foi de aproximadamente $100 \mathrm{~mL}$ por amostra (sem levar em consideração a lavagem dos materiais), apesar da quantidade ser bem menor do que métodos mais antigos que se utilizam de purificação em colunas de sílica ou florisil e o consumo neste caso pode chegar a $400 \mathrm{~mL}$ por amostra, ainda devemos buscar metodologias que 
gerem menos resíduos tóxicos e também baratear a análise já que todos os solventes utilizados são de qualidade grau resíduo.

Das amostras de manga comercializadas em São Paulo apenas 1 amostra estava contaminada com o fungicida procloraz, porém em niveis permitidos pela Legislação Brasileira; nenhum dos outros princípios ativos estudados foram detectados, o que nos leva à conclusão que a manga apresenta-se em condições adequadas para o consumo.

É importante o controle de resíduos de pesticidas não só na manga como em qualquer alimento, pois o Brasil é um grande consumidor de pesticidas e algumas culturas apresentam-se mais susceptiveis ao ataque de agentes externos .

\section{PROPOSTAS FUTURAS}

- Analisar os carbamatos e benzimidazóles através da mesma extração, para assim gerar menos resíduos tóxicos.

- Aumentar o número de pesticidas analisados por cromatografia à gás para assim verificar a existência do efeito matriz para estes princípios ativos

- Validar o método em diferentes matrizes 


\section{4- REFERÊNCIAS BIBLIOGRÁFICAS}

1- AGROFIT disponivel em URL: www.ministerioagricultura.gov.br pesquisa feita em dezembro de 2001

2- AMARAL, C.M.; CARMO, H.C.E.; MAURY, P.M., Estudos sobre o Mercado de Frutas/coordenado por Eduardo Marcondes Filinto da Silva.São Paulo: FIPE, 1999. 373 p.

3- Analytical Methods for Pesticide Residues in Foodstuffs, 6 th Edition, General Inspectore for Health Protection. Ministery of Public Health, Welfare and Spot The Netherlands, 1996

4- ANVISA Agência Nacional de Vigilância Sanitária disponível em URL: unw.anvisa.gov.br, pesquisa feita em dezembro de 2001.

\section{5- AZEVEDO, L.A.S. Proteção Integrada de Plantas com Fungicidas:}

Teoria, Prática e Manejo. Luís Antonio Siqueira de Azevedo, São Paulo, 2001.230p.

6- BRASIL-Leis Decretos, etc. Lei 7802, de 11/07/1989. Legislação Federal de Agrotóxicos e afins, Brasília, Ministério da Agricultura, Departamento de Defesa e Inspeção Vegetal, 1998.

7- BRASIL-Leis Decretos, etc. Portaria 3, de 16/01/1992. Legislação Federal de Agrotóxicos e afins, Brasília, Ministério da Agricultura, Departamento de Defesa e Inspeção Vegetal, 1998.

8- BRASIL-Leis Decretos, etc. Portaria 160, de 31/12/1996. Legislação Federal de Agrotóxicos e afins, Brasília, Ministério da Agricultura, Departamento de Defesa e Inspeção Vegetal, 1998. 
9- BRASIL-Leis Decretos, etc. Resolução 44, de 10/05/2000. Legislação

Federal de Agrotóxicos e afins, Brasília, Ministério da Agricultura, Departamento de Defesa e Inspeção Vegetal, 2000.

10- BARCELÓ D., LAWRENCE J.F., Emergeing Strategies for Pesticide Analysis. CRC Press, United States of America, 1992. 589 p.

11- BARCELÓ D., HENNION M.C., Trace Determination of Pesticides and their Degradation Products in water. Elsevier, Amsterdam, 1997. $542 \mathrm{p}$.

12- CATI, disponivel em URL: http://www.cati.sp.gov.br/, pesquisa feita em dezembro de 2002.

13- CABRAS, P.;ANGIONI,A.;MELIS,M.; MINELLI,E.; PIRISI, F.M., Simplified multiresidue method for the determination of organophosphorus insecticides in olive oil. J. Chromatog A. v.761, p. 327-331,1997.

14- CHEN Z.M. ; WANG, Y.H., Chromatographic methods for the determination of pyrethrin and pyrethroid pesticide residues in crops, foods and environmental samples. J. Chromatog A. v.754 p. 367-395, 1996.

15- CODEX ALIMENTARIUS Pesticide Residues in Food - Methods of analysis and sampling volume 2 A Part 1, 2 ed., 2000. p. $39-47$

16- CONCEIÇÃO, M.A. ,Resíduos de pesticidas em tomates: metodologia analítica e avaliação da exposição humana. Brasília, 2002. Tese de Doutorado, Universidade de Brasília. 
17-CoreseSabores, disponivel em URL:

http://www.coresesaborestropicais.com.br, pesquisa feita em janeiro de 2003.

18- COSTA M.A. E OLIVEIRA, J.J.V. Níveis de Resíduos de Prochloraz em Maçãs. Braz. J. Food Technol. v. 5, p. 61-65, 2001.

19- EPA- Environmental Protection Agency. Residue Chemistry Test Guidelines. Office of Prevention, Pesticides and Toxic Substances OPPTS 860.1340. Residue Analytical Method, Washington:EPA, 1996.12p.

20- ETO, M., Organophosphorus Pesticides: Organic and Biological Chemistry, CRC PRESS, Ohio, 1974. p.235-291

21- European Comission. Directorate General Health and Consumer Protection. Guidance document on Residue Analytical Methods:SANCO/825/00 rev.6 s.n.t.2000 16p.

22- European Comission. Gidelines for Residues Monitoring in the European Union. Quality Control Procedures for Pesticide Residue Analysis: SANCO/3103/2000 2 ed. s.n.t. 1999/2000. 30 p..

23- FAO Food and Agriculture Organization of the United Nations. Guidelines for The Registration and Control of Pesticides, Rome, 1985. 45p.

24- FONSECA, M. O. ,Efeito de fungicidas e cera na conservação pós colheita de manga (Mangífera indica L.) "Haden”. Viçosa, 1998. Dissertação de Mestrado,Universidade Federal de Viçosa. 
25- GELSOMINO, A.;PETROVICOVÁ, B.; TIBURTINI, S.; MAGNANI, E.;

FELICI, M.. Multiresidue analysis of pesticides in fruits and vegetables by gel permeation chromatography followed by gas chromatography with electron-capture and mass spectrometric detection.

J. Chromatog A. v. 782, p.105-122, 1997.

26- HAJSLOVÁ,J.;HOLADOVÁ,K.;POUSTKA, J.;GODULA, M.;CUHRA P.,KEMPNY, M., Matrix-induced effects: a critical point in the gas chromatographic analysis of pesticide residues.J. Chromatog A. v. 800, p. $283-295,1998$.

27- HASSAL, K.A., The chemistry of pesticides: their metabolism, mode of action and uses in crop protections, McMillan,Ltd., New York, 1983

28- JIMÉNEZ, J.J.; BERNAL, J.L.; NOZAL,D.; TORIBIO,L.; MARTÍN, M.T.. Gas chromatography with electron-capture and nitrogen-phosphorus detection in the analysis of pesticides in honey after elution from florisil column Influence of the honey matrix on the quantitative results.

J. Chromatog A. v. 823, p. 381-387, 1998.

29- JOHNSON, P.D.; RIMMER, D.A.; BROWN, R.H..Adaptation and application of a multi-residue method for the determination of a range of pesticides, including phenoxy acid herbicides en vegetation, ased on high-resolution gel permeation chromatographic clean up and gas chromatographic analysis with mass-selective detection.

J. Chromatog A. v. 765, p. 3-11, 1997.

30- LEMES, V.R.R., INOMATA, O.N.K., BARRETO, H.H.C., Resíduos de Endosulfam em Tubérculos e Frutos. Rev.Inst.Adolfo Lutz. v. 53(1/2), p. $49-54,1993$. 
31- LUCKE, M. ${ }^{\text {a; }}$ FROBERG, J.E.; MASUMOTO, H.T., Extration and Clean up of organochlorine, organophosphate, organoni and hidrocarbon pesticide produce for determination by gas-liquid chromatographic, J.Assoc.Off. Anal. Chem. v..,58, p. 1020-1039, 1975

32- MANLEY, J.D. Prochloraz Residues, Schering Report Residues R62, Germany, 1989. 52p.

33- MATOLCSY,G., NÁDASY M., ANDRISKA V., Pesticide Chemistry, Elsevier, Amsterdã,1988. p.117-255

34- MINISTÉRIO DA AGRICULTURA, disponível em URL: http://www.ministerioagricultura.gov.br/, pesquisa feita em março de 2001.

35- NIESSER G.; BUCHBERGER W.; BONN G.K. Rapid multiresidue screening method for the determination of pesticides in plant materials. J. Chromatog A. v. 737 , p. 215-222,1996.

36- NISHIGUCHI, ILKA. Estudo da degradação de resíduos de endosulfam em palha de café. Botucatu,SP,1999.Dissertação de Mestrado. Universidade Estadual Paulista.

37- NUNES, G.S. Análise de inseticidas n-metilcarbamatos em amostras vegetais,empregando técnicas cromatográficas , imunoensaio elisa e biosensores amperométricos. Araraquara, 1999. Tese de Doutorado.Universidade Estadual Paulista .

38- OLIVEIRA, J.J.V.; TOLEDO M.C.F.; Yotsuyanagi, K. Estudo da Degradação de Thiabendazole e Imazalil em Laranja Pêra Tratada em Pós Colheita . Braz. J. Food Technol. v..4, p. 33-41, 2001. 
39- Pesquisa de Orçamentos Familiares 1995-1996:Consumo Alimentar Domiciliar Per Capta . v.2, IBGE. Rio de Janeiro, 1998.

40- RICHARDSON M., Pesticides-Friend or Foe?. Wat.Sci.Tech. v. 37 n.8, p.19-25, 1998.

41- RIZOS, C.L., AVRAMIDES, E.J., CHERASCO, F.. Low-temperature clean-up method for the determination of organophosphorus insecticides in olive oil. J. Chromatog A. v.912, p.135-142, 2001.

42- SCHENCK,F.; LEHOTAY, S.J. Does further clean-up reduce the matrix enhancement effect in gas chromatographic analysis of pesticide residues in food?. J. Chromatog A. v.868, p. 51-61, 2000.

43- SIMPLÍCIO A. L.; BOAS L.V.Validation of a solid microextraction method for the determination of organophosphorus pesticides in fruits and fruit juice.J. Chromatog A . v. 833, p. 35-42,1999.

44- SINDAG Sindicato Nacional da Indústria de Produtos para Defesa Agrícola disponível em URL: http://umw.sindag.com.br/, pesquisa feita em janeiro de 2001.

45- SOLIMAN, K.M. Changes in concentration of pesticide residues in potatoes during washing and home preparation. Food and Chemical Toxicology, v. 39, p. 887-991, 2001.

46- The American Chemical Society. Principles of Environmental Analysis.

Committee on Environmental Improvement. United States, $198310 \mathrm{p}$. 
47- TORRES, C.M.; PICO Y.; MAÑES J.. Determination of pesticide residues in fruit and vegetables. J. Chromatog A. v. 754, p. 301-331,1996.

48- TOTAL DIET SURVEY NEW ZEALAND 1997/98, Ministry of Health New Zealand, Wellington, 2000.93p.

49- TERRA RURAL disponível em URL: http:// www.terrarural.com.br, pesquisa feita em 10 de janeiro de 2003.

50- WU, Y.S.; LEE, H.K; LI, S.F.Y.High-perfomance chiral separation of fourteen triazole fungicides by sulfated $\beta$-cyclodextrin-mediated capillary electrophoresis J. Chromatog A. v. 912, p. 171-179,2001. 


\section{LISTA DE TABELAS}

Tabela I

Tabela II

Tabela III

Tabela IV

Tabela V

Tabela VI

Tabela VII

Tabela VIII

Tabela IX

Tabela $\mathrm{X}$

Tabela XI

Tabela XII

Tabela XIII

Tabela XIV

Tabela XV

Tabela XVI

Tabela XVII

Tabela XVIII

Tabela XIX

Tabela XX

Tabela XXI

Principais países exportadores de produtos agrícolas. 2

Principais pragas que atacam a mangueira: sintomas e controle. 12

Principais doenças que atacam a mangueira: sintomas e controle. 15

Formulações de Alacloro comercializadas no Brasil com classificação toxicológica e classificação ambiental.

Defensivos Agrícolas em linha de comercialização no Brasil por classes toxicológicas.

Pesticidas Organoclorados, e classificação toxicológica.

Pesticidas Organoclorados, piretróides e estrobirulina: função, classe e fórmula estrutural.

Pesticidas Organofosforados, e classificação toxicológica.

Pesticidas Organofosforados função, classe e fórmula estrutural. 32

Diferentes metodologias empregadas em análises de multiresíduos. 40

Recuperaçăo do sulfato endosulfam e azoxistrobina em 6 amostras de manga comparando-se com o padrão preparado em hexano.

Recuperaçăo do sulfato endosulfam e azoxistrobina em 6 amostras de manga comparando-se com o padrão preparado no extrato da amostra testemunha

Recuperação do difenoconazol, procloraz e fosmete em 6 amostras de manga comparando-se com o padrão preparado em hexano

Recuperação do difenoconazol, procloraz e fosmete em 6 amostras de manga comparando-se com o padrāo preparado no extrato da amostra testemunha......

Recuperação Média das fortificações com propanil, desvio padrão e coeficiente de variação.

Recuperaçăo Média das fortificações com Alacloro, desvio padrăo e coeficiente de variação.

Recuperação Média das fortificações com dicofol, desvio padrão e coeficiente de variação.

Recuperação Média das fortificações com aletrina, desvio padrão e coeficiente de variação.

Recuperaçăo Média das fortificações com procimidona, desvio padrão e coeficiente de variação

Recuperação Média das fortificações com alfa endosulfam, desvio padrắo e coeficiente de variação

Recuperação Média das fortificações com beta endosulfam, desvio padrăo e coeficiente de variaçăo. 
Tabela XXII

Tabela XXIII

Tabela XXIV

Tabela XXV

Tabela XXVI

Tabela XXVII

Tabela XXVIII

Tabela XXIX

Tabela XXX

Tabela XXXI

Tabela XXXII

Tabela XXXIII

Tabela XXXIV

Tabela XXXV

Tabela XXXVI

Tabela XXXVII

Tabela XXXVIII

Tabela $X X X \mid X$

Tabela XL

Tabela XLI
Recuperação Média das fortificaçőes com sulfato endosulfam, desvio padrăo e coeficiente de variação.

Recuperação Média das fortificaçōes com bifentrina, desvio padrão e coeficiente de variação.

Recuperação Média das fortificações com fenpropatrina, desvio padrão e coeficiente de variação.

Recuperação Média das fortificaçōes com tetradifona, desvio padrão e coeficiente de variação.

Recuperação Média das fortificaçōes com procloraz, desvio padrão e coeficiente de variação.

Recuperação Média das fortificações com difenoconazol, desvio padrão e coeficiente de variação.

Recuperação Média das fortificações com azoxistrobina, desvio padrão e coeficiente de variação.

Recuperação Média das fortificações com diclorvós, desvio padrão e coeficiente de variação.

Recuperação Média das fortificações com forato, desvio padrão e coeficiente de variação.

Recuperação Média das fortificaçōes com diazinom, desvio padrăo e coeficiente de variação.

Recuperação Média das fortificações com clorpirifós, desvio padrão e coeficiente de variação.

Recuperação Média das fortificações com malationa, desvio padrão e coeficiente de variação.

Recuperação Média das fortificações com fentiona, desvio padrão e coeficiente de variação.

Recuperação Média das fortificações com fentoato, desvio padrão e coeficiente de variação.

Recuperação Média das fortificaçōes com etiona, desvio padrāo e coeficiente de variação.

Recuperação Média das fortificações com fosmete, desvio padrão e coeficiente de variação.

Repetibilidade do sinal de propanil em amostra de manga fortificada com 0,05 mg/kg no mesmo dia em dias diferentes.

Repetibilidade do sinal de alacloro em amostra de manga fortificada com $0,01 \mathrm{mg} / \mathrm{kg}$ no mesmo dia e em dias diferentes.

Repetibilidade do sinal de dicofol em amostra de manga fortificada com $0,05 \mathrm{mg} / \mathrm{kg}$ no mesmo dia e em dias diferentes...

Repetibilidade do sinal de aletrina em amostra de manga fortificada com $0,05 \mathrm{mg} / \mathrm{kg}$ no memso dia e em dias diferentes. 
Tabela XLII

Tabela XLIII

Tabela XLIV

Tabela XLV

Tabela XLVI

Tabela XLVII

Tabela XLVIII

Tabela XLIX

Tabela L

Tabela LI

Tabela LII

Tabela LIII

Tabela LIV

Tabela LV

Tabela LVI

Tabela LVII

Tabela LVIII

Tabela LIX

Tabela LX

Tabela LXI

Repetibilidade do sinal de procimidona em amostra de manga fortificada com $0,01 \mathrm{mg} / \mathrm{kg}$ no mesmo dia e em dias diferentes.

Repetibilidade do sinal de alfa endosulfam em amostra de manga fortificada com $0,01 \mathrm{mg} / \mathrm{kg}$ no mesmo dia e em dias diferentes.

Repetibilidade do sinal de beta endosulfam em amostra de manga fortificada com $0,01 \mathrm{mg} / \mathrm{kg}$ no mesmo dia e em dias diferentes.

Repetibilidade do sinal de sulfato endosulfam em amostra de manga fortificada com $0,05 \mathrm{mg} / \mathrm{kg}$ no mesmdia e em dias diferentes.

Repetibilidade do sinal de bifentrina em amostra de manga fortificada com $0,05 \mathrm{mg} / \mathrm{kg}$ no mesmo dia e em dias diferentes.

Repetibilidade do sinal de fempropatrina em amostra de manga fortificada com $0,10 \mathrm{mg} / \mathrm{kg}$ no mesmo dia e em dias diferentes.

Repetibilidade do sinal de tetradifona em amostra de manga fortificada com $0,01 \mathrm{mg} / \mathrm{kg}$ no mesmo dia e em dias diferentes.

Repetibilidade do sinal de procloraz em amostra de manga fortificada com 0,20 mg/kg no mesmo dia e em dias diferentes.

Repetibilidade do sinal de difenoconazol em amostra de manga fortificada com $0,20 \mathrm{mg} / \mathrm{kg}$ no mesmo dia e em dias diferentes.

Repetibilidade do sinal de azoxistrobina em amostra de manga fortificada com $0,05 \mathrm{mg} / \mathrm{kg}$ no mesmo dia e em dias diferentes.

Repetibilidade do sinal de diclorvós em amostra de manga fortificada com $0,05 \mathrm{mg} / \mathrm{kg}$ no mesmo dia e em dias diferentes.

Repetibilidade do sinal de forato em amostra de manga fortificada com $0,05 \mathrm{mg} / \mathrm{kg}$ no mesmo dia e em dias diferentes

Repetibilidade do sinal de dizinom em amostra de manga fortificada com $0,05 \mathrm{mg} / \mathrm{kg}$ no mesmo dia e em dias diferentes.

Repetibilidade do sinal de clorpirifós em amostra de manga fortificada com $0,05 \mathrm{mg} / \mathrm{kg}$ no mesmo dia e em dias diferentes.

Repetibilidade do sinal de malationa em amostra de manga fortificada com $0,05 \mathrm{mg} / \mathrm{kg}$ no mesmo dia e em dias diferentes

Repetibilidade do sinal de fentiona em amostra de manga fortificada com $0,05 \mathrm{mg} / \mathrm{kg}$ no mesmo dia e em dias diferentes.

Repetibilidade do sinal de fentoato em amostra de manga fortificada com $0,05 \mathrm{mg} / \mathrm{kg}$ no mesmo dia e em dias diferentes.

Repetibilidade do sinal de etiona em amostra de manga fortificada com $0,05 \mathrm{mg} / \mathrm{kg}$ no mesmo dia e em dias diferentes. 


\section{ÍNDICE DE FIGURAS}

Figura 1 Principais países consumidores de Defensivos Agricolas

Figura 2 Padrão procloraz (Área $=87,24$ ) e difenoconazol $($ Área $=152,94) 75$ pg/uL em hexano.

Figura 3 Padrão procloraz (Área $=147,24$ ) e difenoconazol (Área $=221,49) 75$ pg/uL no extrato da matnz.

Figura 4 Recuperação: Amostra fortificada com procloraz 1,0 $\mathrm{mg} / \mathrm{kg}$ e difenoconazol 2,0 $\mathrm{mg} / \mathrm{kg}$ que corresponde ao padrão de procloraz e difenoconazol $75 \mathrm{pg} / \mathrm{uL} \ldots \ldots \ldots . .51$

Figura 5 Curva Analítica Propanil........................................................................... 52

Figura 6 Curva Analítica Alacloro.......................................................................... 52

Figura 7 Curva Analítica Dicofol............................................................................... 53

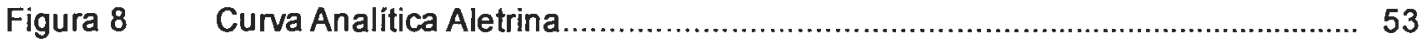

Figura 9 Curva Analitica Procimidona.................................................................... 53

Figura 10 Curva Analítica Alfa Endosulfam................................................................... 54

Figura 11 Curva Analitica Beta Endosulfam ............................................................ 54

Figura 12 Curva Analítica Sulfato Endosulfam .......................................................... 54

Figura 13 Curva Analítica Bifentrina.................................................................... 55

Figura 14 Curva Analítica Fempropatrina ....................................................................... 55

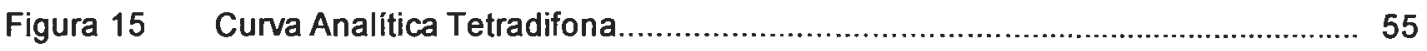

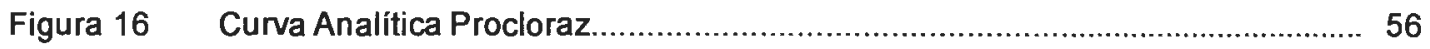

Figura 17 Curva Analítica Difenoconazol............................................................... 56

Figura 18 Curva Analítica Azoxistrobina................................................................ 56

Figura 19 Curva Analitica Diclorvós............................................................................ 57

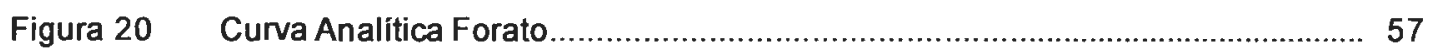

Figura 21 Curva Analitica Diazinom ……............................................................ 57

Figura 22 Curva Analítica Clorpirifós..................................................................... 58

Figura 23 Curva Analitica Malationa ............................................................................. 58

Figura 24 Curva Analítica Fentiona.......................................................................... 58

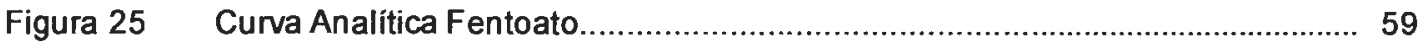

Figura 26 Curva Analítica Etiona.......................................................................... 59 
Figura 27 Curva Analítica Fosmete......

Figura 28 Cromatograma do branco dos reagentes analisado por cromatografia a gás com detector de captura de elétrons

Figura 29 Cromatograma da amostra testemunha analisada por cromatografia a gás com detector de capturas de elétrons.

Figura 30 Cromatograma dos pesticidas organoclorados, piretróides e azoxistrobina analisados por cromatografia a gás com detector de captura de elétrons..

Figura 31 Cromatograma do branco dos reagentes analisados por cromatografia a gás com detector fotométrico de chama.

Figura 32 Cromatograma da amostra testemunha analisada por cromatografia a gás com detector fotométrico de chama.

Figura 33 Cromatogranma dos pesticidas organofosforados analisados por cromatografia a gás com detector fotométrico de chama. 


\section{ANEXOS}

\section{Anexo 1}

Resolução RDC n॰ 44, de 10 de maio de 2000 


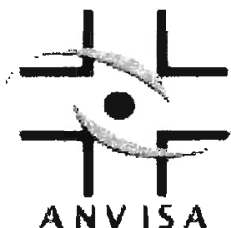

1

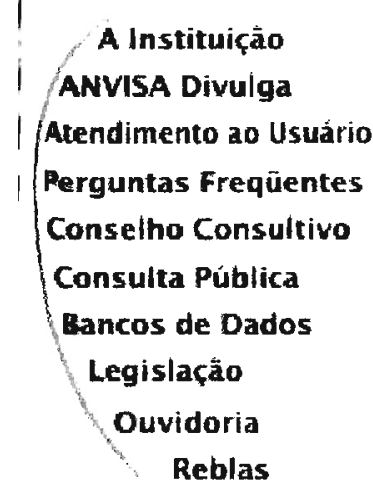

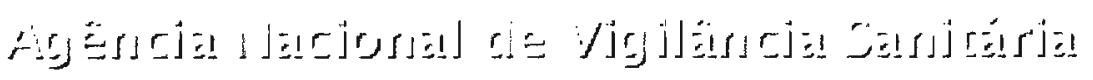

Areas de Atwaçäo-

\section{Resoluçōes}

\section{Resolução - RDC n 44, de 10 de maio de 2000 (*)}

A Diretoria Colegiada da Agência Nacional de Vigilância Sanitária, no uso da atribuição que the confere 0 art. 11, inciso IV, do Regulamento da ANVS aprovado pelo Decreto 3.029, de 16 de abril de 1999, em reunião realizada em 3 de maio de 2000 , adota a seguinte Resolução de Diretoria Colegiada e eu, Diretor-Presidente, determino a sua publicação:

considerando a necessidade de aprimorar as ações de controle de registro dos produtos agrotóxicos no que diz respeito a Vigilância Sanitária;

considerando a necessidade de atualizar à apresentação dos relatórios de estudos de resíduos de agrotóxicos de acordo com as normas Codex I FAO,

adota a seguinte Resolução de Diretoria Colegiada e eu, DiretorPresidente, determino a sua publicação:

Art. $1^{\circ}$ Alterar as Diretrizes e Exigências Referentes a Autorização de Registro de Produtos Agrotóxicos e Afins, $n^{\circ} 1$, de 09 de dezembro de 1991, ratificada pela Portaria $n^{\circ} 3$ de 16 de Janeiro de 1992 (título de acordo com Decreto 991/93), substituindo o texto do item 1.2, sub-item 1.2.2, letra " $\mathrm{m}$ " por: "Proposições quanto ao Limite Máximo de Residuos (LMR) baseadas nas tabelas individuais apresentadas, referentes aos três ensaios de campo ou a dois ensaios pós-colheita, nos casos de Limites de Resíduos Estranhos (LME) estes deverão também ser propostos.

Art. $2^{\circ}$ Alterar as Diretrizes e Exigências Referentes a Autorização de Registro de Produtos Agrotóxicos e Afins $n^{\circ} 1$ de 09 de dezembro de 1991, ratificada pela Portaria $n^{\circ} 3$ de 16 de Janeiro de 1992 (título de acordo com Decreto 991/93), substituindo o texto dos itens 1Delineamento experimental (sub-item 1.1) e 5- Informações de campo e Laudo Analítico do Anexo IV e constantes desta Portaria pelo texto a seguir: 1.1- Locais: os ensaios destinados a pesquisa de resíduos deverão ser conduzidos, no mínimo, em 3 (três) áreas distintas representativas do cultivo na mesma safra ou em duas safras consecutivas no mesmo local e outro, em local diferente. Para póscolheita, deverão ser conduzidos, no mínimo, 2 (dois) ensaios de pesquisa de resíduos, em local representativo da operação de tratamento; 5- Dados que deverão constar no relatório de estudo de resíduos e 6- Dados que deverão constar do Relatório de estudo de resíduos - tratamento pós-colheita.

Art. $3^{\circ}$ O ANEXO IV DAS DIRETRIZES E EXIGÊNCIAS REFERENTES À AUTORIZAÇÃO DE REGISTROS DE PRODUTOS AGROTÓXICOS E AFINS - $N^{\circ} 1$, DE 09 DE DEZEMBRO DE 1991, aprovadas pela Portaria $\mathrm{n}^{\circ} 3$, de 16 de janeiro de 1992, do Diretor do Departamento Técnico Normativo, da Secretaria Nacional de Vigilância Sanitária, passa a vigorar com a seguinte redação: 
5- DADOS QUE DEVERÃO CONSTAR NO RELATÓRIO DE ESTUDO DE RESÍDUOS

CAPA (única contemplando o laudo analítico e o relatório de campo)

Título: Relatório de estudo de resíduo de em ........................... (discriminar a parte do vegetal que foi analisada, exemplo: polpa, casca, fruto inteiro, etc)

Número do protocolo do estudo

Nome, endereço, telefone, fax, endereço eletrônico da empresa contratante

Nome, endereço, telefone, fax, endereço eletrônico do laboratório contratado

Autor(es) do relatório

Data do início do estudo

Data do término do estudo

ASSINATURAS (em página separada)

(data) (Responsável pelo laboratório)

(data) (Responsável pela empresa contratante)

Observação: Numerar e rubricar todas as páginas do relatório DECLARAÇÃO DE CONFORMIDADE ANALITICA (em página separada) Texto

(data) (Responsável pela análise)

(data) (Responsável pelo laboratório)

\subsection{RELATÓRIO DE CAMPO}

Capa

Título: Relatório de estudo de em

Número do protocolo do estudo

Número de Relatório de Campo 
Nome do responsável pelo ensaio

Nome, endereço, telefone, fax, endereço eletrônico da empresa executora

Data de início do estudo

Data do término do estudo

Declaração de conformidade de Boas Práticas Agricolas (em página separada)

(data) (Responsável pela parte de campo)

(data) (Responsável pelo ensaio de campo)

\subsubsection{IDENTIFICAÇÃO DO PRODUTO TESTADO}

a) Substância teste (marca comercial / código)

b) Nome químico do(s) ingrediente(s) ativo(s)

c) Nome comum do(s) ingrediente(s) ativo(s)

d) Classe (se sistêmico, informar)

e) Tipo de Formulação

f) Concentração do(s) ingrediente(s) ativo(s) (por litro ou kg de formulação)

g) Certificado de análise para confirmação do teor do(s) ingrediente(s) ativo(s) na formulação

\subsubsection{IDENTIFICAÇÃO DO CAMPO EXPERIMENTAL}

a) Local do ensaio (Município / Estado)

b) Nome e endereço da propriedade

c) Cultura

d) Cultivar

e) Espaçamento

f) Tamanho de cada parcela

g) Número de parcelas

h) Data do plantio ou idade da planta 
i) Data de emergência da planta (quando aplicável)

j) Data da colheita

\subsubsection{DOSES TESTADAS E FORMA DE APLICAÇÃO}

a) Dose(s) testada(s) do produto formulado

b) Dose(s) do(s) ingrediente(s) ativo(s)

c) Data(s) de aplicação

d) Estágio da cultura em cada aplicação

e) Forma de aplicação

f) Equipamento

g) Volume de calda aplicada em L/ha (quando aplicável)

h) Temperatura no momento da aplicação

i) Outros produtos aplicados no decorrer do ensaio

\subsubsection{INFORMAÇÕES EDAFOLÓGICAS}

a) Tipo de solo (textura)

b) $\mathrm{pH}$

c) Porcentagem de matéria orgânica

d) Topografia do terreno

\subsubsection{TRATOS CULTURAIS REALIZADOS NA PARCELA}

Descrever

\subsubsection{INFORMAÇÕES METEOROLÓGICAS}

a) Última chuva antes da(s) aplicação(ões)

b) Primeira chuva após a(s) aplicação(ões)

c) Precipitação no período do ensaio

d) Temperatura média no período do ensaio

\subsubsection{AMOSTRAGEM}

a) Data(s) da(s) coleta(s) da(s) amostra(s)

b) Métodos de amostragem dentro da parcela e forma de retirada do material 
c) Parte da cultura amostrada

d) Estágio da cultura no momento da coleta

e) Quantidade amostrada

f) Tipo de embalagem da amostra

g) Tamanho da área amostrada

h) Condições de armazenamento até o envio ao laboratório

\subsubsection{BENEFICIAMENTO DA AMOSTRA}

a) Tipo de beneficiamento (ex.: secagem)

b) Data do início e final do processo de beneficiamento

c) Condições em que a amostra foi mantida durante o beneficiamento

\subsubsection{ENVIO DA AMOSTRA PARA O LABORATÓRIO}

a) Data do envio

b) Forma de transporte

c) Tipo de embalagem

d) Condições de armazenamento e conservação durante o transporte

e) Quantidade de cada amostra enviada

f) Número de amostras enviadas

\subsection{RELATÓRIO ANALÍTICO}

\subsubsection{OBJETIVO}

\subsubsection{RESUMO}

\subsubsection{DADOS DA(S) SUBSTÂNCIA(S) DE REFERÊNCIA}

a) Nome químico

b) Nome comum

c) Peso molecular

d) Fórmula estrutural

e) Solubilidade (água e solventes orgânicos)

f) Pressão de vapor

g) Outros dados relevantes (pureza, origem, validade, etc.) 


\subsubsection{AMOSTRAS}

a) Descrição da(s) amostra(s) incluindo o número do relatório de campo

b) Data de recebimento das amostras

c) Condições de armazenamento no laboratório

\subsubsection{RESUMO DO MÉTODO}

\subsubsection{MÉTODO DE ANÁLISE}

Descrição dos procedimentos efetivamente realizados na condução das análises (vide Apêndice)

\subsubsection{IDENTIFICAÇÃO}

(vide Apêndice )

\subsubsection{QUANTIFICAÇÃO}

(vide Apêndice)

\subsubsection{CURVA DE CALIBRAÇÃO}

(vide Apêndice)

\subsubsection{RECUPERAÇÃO}

Dados finais segundo o exemplo da Tabela I

Tabela I : Recuperação média das fortificações e desvio padrão

\begin{tabular}{|l|l|l|l|}
\hline $\begin{array}{l}\text { Nivel de } \\
\text { fortificação } \\
\text { (mg/kg) }\end{array}$ & Recuperação (\%) & $\begin{array}{l}\text { Recuperação } \\
\text { Média }\end{array}$ & Desvio Padrão \\
\hline F1 & & & \\
\hline F1 & & & \\
\hline \hline F1 & & & \\
\hline F2 & & & \\
\hline F2 & & & \\
\hline F2 & & & \\
\hline
\end{tabular}

F1 = limite mínimo de fortificação = limite de quantificação

F2 = limite máximo de fortificação

Obs: Serão no mínimo dois niveis de fortificação com pelo menos três repetições cada um quando da avaliação do método. A porcentagem de recuperação não deve ser utilizada para correção dos resultados. Apenas valores no intervalo de $70 \%$ a $120 \%$ de recuperação deverão ser aceitos. Quando da condução das análises (amostras testemunha e tratadas), pelo menos um nível de fortificação deverá ser conduzida, e os demais poderão ser provenientes da verificação do método.

\subsubsection{LIMITE DE QUANTIFICAÇÃO}


(vide Apêndice)

5.2.12. RESULTADOS (dados finais do estudo, segundo o exemplo da Tabela II)

Tabela II Resíduos de em

\begin{tabular}{|l|l|l|l|}
\hline \hline Amostra & Dose (unidade) & DAT * & Analito $(\mathrm{mg} / \mathrm{Kg})$ \\
\hline \hline Testemunha & - & - & 1 \\
\hline \hline Cultura & Máxima & & $\mathrm{y}_{1}$ \\
\hline \hline Cultura & Dobro & & $\mathrm{y}_{2}$ \\
\hline \hline
\end{tabular}

* Dias após o tratamento

x1 Limite de quantificação

y1 Concentração na dose máxima

y2 Concentração na dose dobro

\subsubsection{BIBLIOGRAFIA}

\section{DADOS QUE DEVERÃO CONSTAR NO RELATÓRIO DE ESTUDO DE RESÍDUOS - TRATAMENTO PÓS-COLHEITA}

CAPA (única contemplando o laudo analítico e o relatório de tratamento pós-colheita)

Título: Relatório de estudo de residuo de em ......................(discriminar a parte do vegetal analisada, exemplo: polpa, casca, fruto inteiro, etc)

Número do protocolo do estudo

Nome, endereço, telefone, fax, endereço eletrônico da empresa contratante

Nome, endereço, telefone, fax, endereço eletrônico do laboratório contratado

Autor(es) do relatório

Data do início do estudo

Data do término do estudo

ASSINATURAS (em página separada)

(data) (Responsável pelo laboratório) 
(data) (Responsável pela empresa contratante)

Observação: numerar e rubricar todas as páginas do relatório.

DECLARAÇÃO DE CONFORMIDADE ANALÍ'TICA (em uma página separada)

(data) (Responsável pela análise)

(data) (Responsável pelo laboratório)

\subsection{RELATÓRIO DE TRATAMENTO PÓS-COLHEITA}

CAPA

Título: Relatório de estudo de em tratamento pós-colheita

Número do protocolo do estudo

Número do Relatório de Tratamento Pós-colheita

Nome do responsável pelo ensaio

Nome, endereço, telefone, fax, endereço eletrônico da empresa executora

Data do início da estudo

Data do término do estudo

Declaração de Conformidade de Boas Práticas Agrícolas (em uma página separada)

(data) (Responsável pela parte de tratamento pós-colheita)

(data) (Responsável pelo ensaio de tratamento pós-colheita)

\subsubsection{IDENTIFICAÇÃO DO PRODUTO TESTADO}

a) Substância teste (marca comercial / código)

b) Nome químico do(s) ingrediente(s) ativo(s)

c) Nome comum do(s) ingrediente(s) ativo(s)

d) Classe (se sistêmico, informar) 
e) Tipo de Formulação

f) Concentração do(s) ingrediente(s) ativo(s) (por litro ou kg de formulação)

g) Certificado de análise para confirmação do teor do(s) ingrediente(s) ativo(s) na formulação

\subsubsection{IDENTIFICAÇÃO DA UNIDADE DE TRATAMENTO PÓS-} COLHEITA
a) Local do ensaio(Município / Estado)
b) Nome da propriedade
c) Cultura
d) Cultivar
e) Data do tratamento pós-colheita

\subsubsection{DOSES TESTADAS E FORMA DE APLICAÇÃO}

a) Dose(s) do produto comercial

b) Dose(s) do(s) ingrediente(s) ativo(s)

c) Data de aplicação

d) Forma de aplicação

e) Quantidade tratada

f) Equipamento

g) Temperatura no momento da aplicação

h) Outros produtos aplicados no decorrer do ensaio

\subsubsection{AMOSTRAGEM}

a) Data(s) da(s) coleta(s) de amostra(s)

b) Método de amostragem

c) Quantidade amostrada

d) Tipo de embalagem das amostras

e) Condições de armazenamento até o envio ao laboratório

\subsubsection{ENVIO DA AMOSTRA PARA O LABORATÓRIO}

a) Data do envio

b) Forma de transporte 
c) Tipo de embalagem

d) Condições de armazenamento e conservação durante o transporte

e) Quantidade de cada amostra enviada

f) Número de amostras enviadas

\subsection{RELATÓRIO ANALÍTICO}

Conforme item 5.2 a 5.2 .13

APÊNDICE (em página separada do relatório)

I) MÉTODO ANALIITIICO PARA DETERMINAÇÃO DE EM

a) Equipamentos, reagentes, vidrarias e/ou outros materiais

b) Preparação de soluções padrão, de calibração e de fortificação

c) Preparação da amostra

d) Procedimento analítico (descrição detalhada)

e) Análise instrumental (condições de operação)

f) Modificação do método (se houver)

II ) IDENTIFICAÇÃO

Identificar os analitos e padrão interno (se houver) por tempo de retenção e massas dos íons de fragmentação (se for o caso) e outros (especificar), anexando:

a) um cromatograma ou espectros do padrão;

b) um cromatograma ou espectro do branco;

c) cromatograma(s) ou espectro(s) da testemunha(s);

d) cromatogramas das fortificações nos diferentes níveis, realizados em triplicata;

e) cromatogramas das amostras.

III ) QUANTIFICAÇÃO / CÁLCULOS

a) apresentar a(s) fórmula(s) utilizada(s) para os cálculos;

b) apresentar o gráfico da curva de calibração obtido com a equação de regressão da curva e o coeficiente de correlação;

c) anexar um cromatograma de cada ponto do gráfico obtido no item " $b$ ".

Art. $4^{\circ}$ Permanecem válidos os Relatórios que já tiverem sido elaborados 
conforme as normas anteriores à data da vigência desta Resolução.

$\S 1^{\circ}$ Os ensaios de campo instalados com datas anteriores à vigência desta Resolução, bem como as amostras e estudos analíticos deles decorrentes, serão considerados válidos.

$\S 2^{\circ}$ As empresas notificarão à Agência Nacional de Vigilância Sanitária sobre os estudos que se enquadrem no parágrafo anterior, no prazo de até 30 (trinta) dias, a partir da data de publicação desta Resolução.

$\S 3^{\circ}$ A elaboração do terceiro ensaio de resíduo, previsto nesta Resolução, terá o prazo de 18 (dezoito) meses para sua apresentação, a partir da data de publicação desta Resolução, sem prejuízo da avaliação dos processos em andamento ou a serem protocolados neste período.

Art. $5^{\circ}$ Esta Resolução de Diretoria Colegiada entra em vigor na data de sua publicação.

GONZALO VECINA NETO

(")Republicada por ter saido com incorreção, do original, no DO no 90-E, de 11/5/2000, Seção 1-E pág 14 